\title{
EXAMINING THE IMPACT OF DESIGN VARIABLES AND MEDIA RICHNESS ON RESPONSES TO PRODUCT DESIGN
}

\author{
A Dissertation \\ presented to \\ the Faculty of the Graduate School \\ at the University of Missouri-Columbia \\ In Partial Fulfillment \\ of the Requirements for the Degree \\ Doctor of Philosophy \\ by \\ EHSAN NADERI \\ Dr. Bimal Balakrishnan, Dissertation Supervisor \\ December 2017
}


The undersigned, appointed by the dean of the Graduate School, have examined the dissertation entitled

\section{EXAMINING THE IMPACT OF DESIGN VARIABLES AND MEDIA RICHNESS ON RESPONSES TO PRODUCT DESIGN}

presented by Ehsan Naderi,

a candidate for the degree of doctor of philosophy,

and hereby certify that, in their opinion, it is worthy of acceptance.

Bimal Balakrishnan, Ph.D.

Ruth Tofle, Ph.D.

Peter Bloch, Ph.D.

Laura Cole, Ph.D. 


\section{ACKNOWLEDGEMENTS}

First and foremost, I would like to thank Professor Bimal Balakrishnan for all his advices and support throughout my doctoral studies at the University of Missouri. I truly appreciate his continuous guidance that shaped my research agenda and improved my understanding of working in an academic environment in the United States.

I would also like to express my sincere gratitude to members of my doctoral committee, Dr. Ruth Tofle, Dr. Peter Bloch, and Dr. Laura Cole for their insightful comments that enriched my research and doctoral education.

I would like to thank my fellow colleague, James Hopfenblatt, for his help, support, and valuable input on my research. Finally, I would like to thank my endlessly supportive wife, Zhaleh Khosravi, my beloved parents and my brother, Dr. Iman Naderi for their encouragement and support. 


\section{TABLE OF CONTENTS}

ACKNOWLEDGEMENTS...............................................................ii

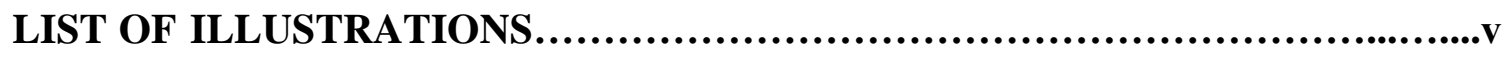

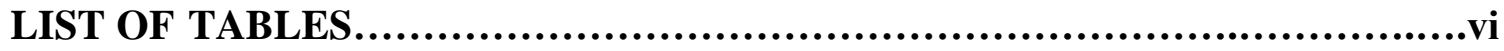

LIST OF ABBREVIATIONS..................................................vii

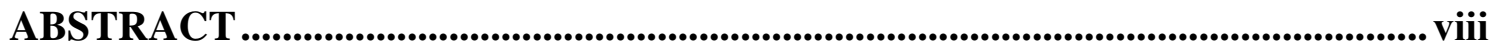

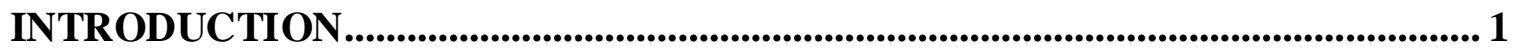

CHAPTER 1: REVIEW OF THE LITERATURE......................................................8

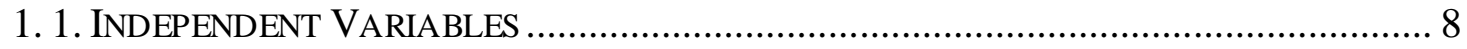

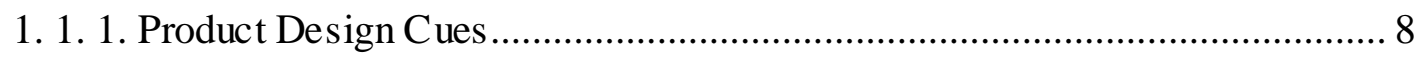

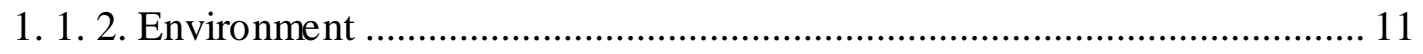

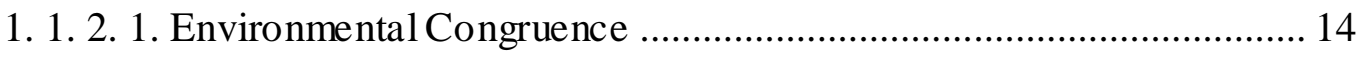

1. 1. 2. 2. Product Display as a Promotional Environment .............................. 16

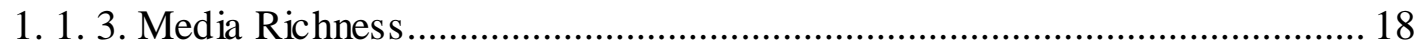

1. 1. 3. 1. Media Richness and Modality: Breadth and Depth .......................... 20

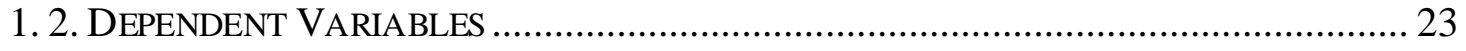

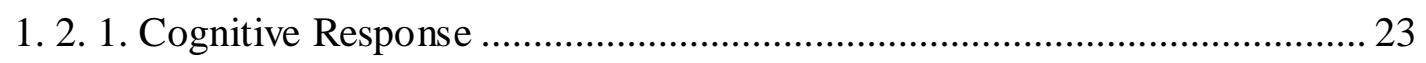

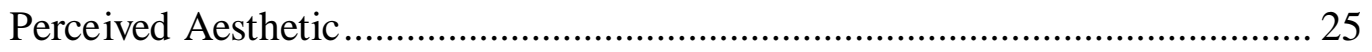

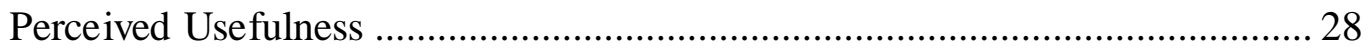


Perceived Ease-of-use

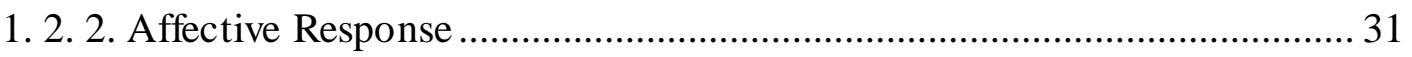

1. 3. THE RELATIONSHIP BETWEEN INDEPENDENT AND DEPENDENT VARIABLES ......... 34

1. 3. 1. The Influence of Product Design Cues on Users' Cognitive Responses ..... 36

1. 3. 2. The Influence of Product Design Cues on Users' Affective Responses ..... 39

1. 3. 3. The Influence of Environment Congruence on Users' Cognitive Response 40

1. 3. 4. The Influence of Environment Congruence on Users' Affective Responses

1. 3. 5. The Influence of Media Richness on Users' Cognitive Response 43

1. 3. 6. The Influence of Media Richness on Users' Affective Response 45

CHAPTER 2: RESEARCH METHODOLOGY 48

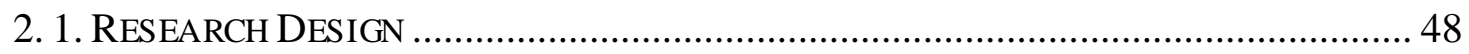

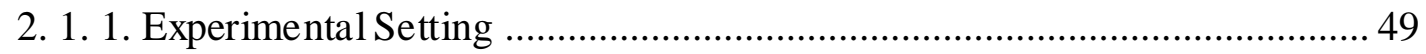

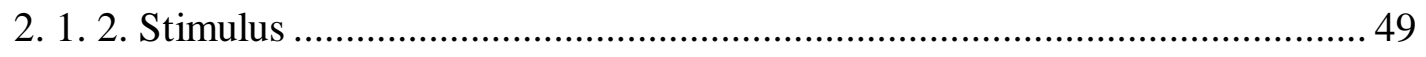

2. 2. OPERATIONALIZATION OF INDEPENDENT VARIABLES .................................... 55

2. 2. 1. Operationalizing Product Design Cues .................................................. 55

2. 2. 2. Operationalizing Environment Congruence .......................................56

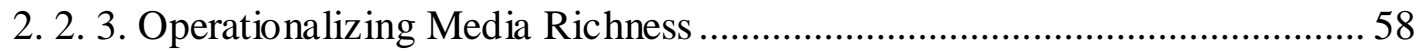

2. 3. MEASUREMENT OF DEPENDENT VARIABLES ................................................. 59

2. 3. 1. Measures of Cognitive Response ..............................................................5

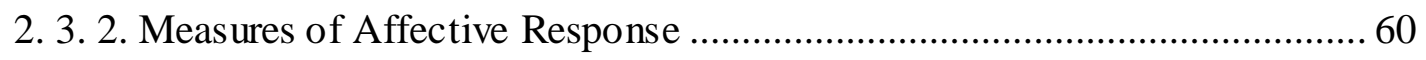

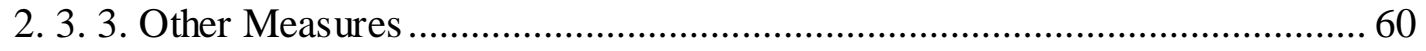

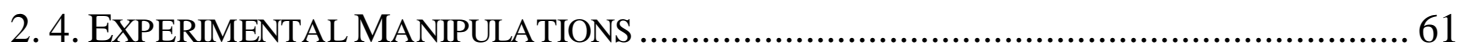




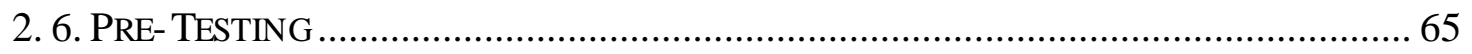

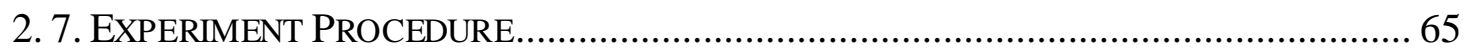

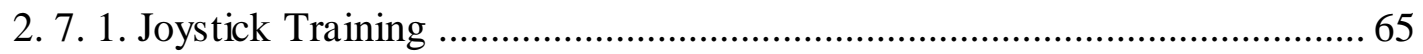

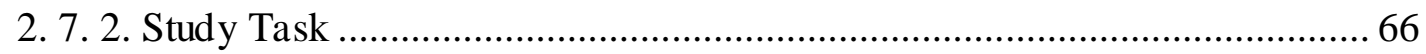

CHAPTER 3: ANALYSIS \& RESULTS ........................................................................... 68

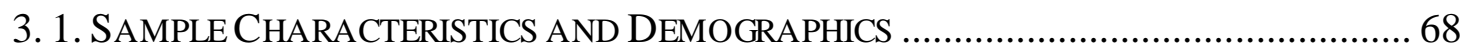

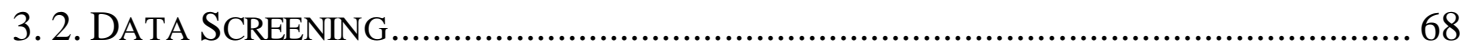

3. 3. RELIABILITY ANALYSIS FOR DEPENDENT VARIABLES AND COVARIATES............. 70

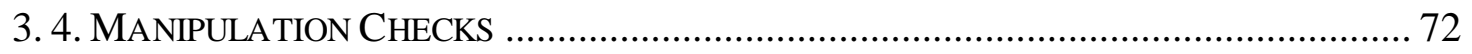

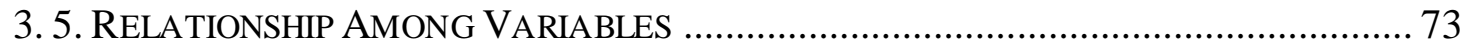

3. 6. HYPOTHESIS TESTING.............................................................................. 74

3. 6. 1. Hypotheses set I: Impact of design cues on users' cognitive and affective

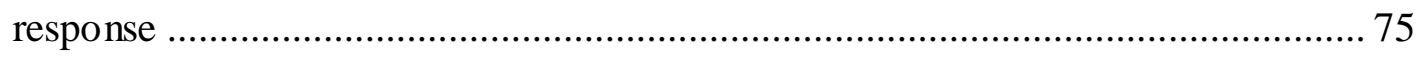

3. 6. 2. Hypotheses set II: Impact of environment congruence on users' cognitive

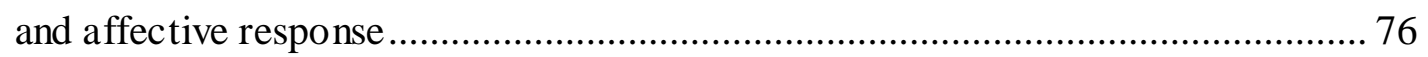

3. 6. 3. Hypotheses set III: Impact of media richness on users' cognitive and

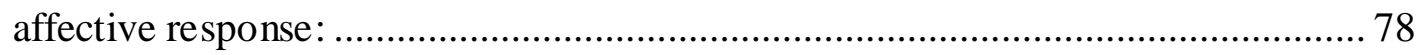

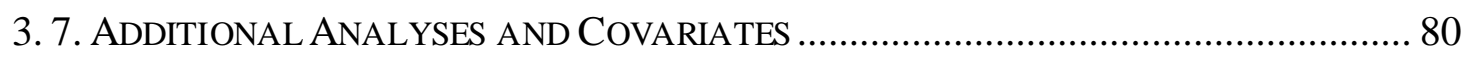

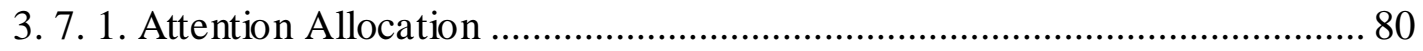

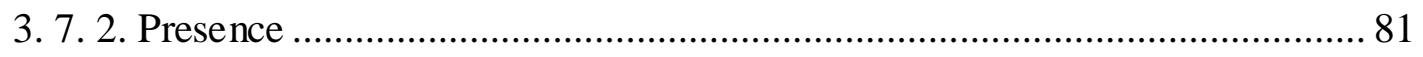

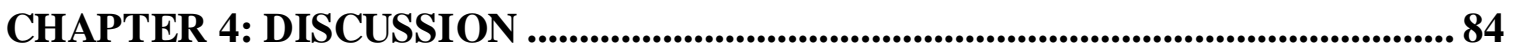

4. 1. SUMMARY OF RESULTS AND THEORETICAL IMPLICATIONS ................................. 84 


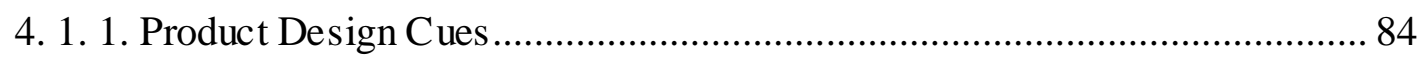

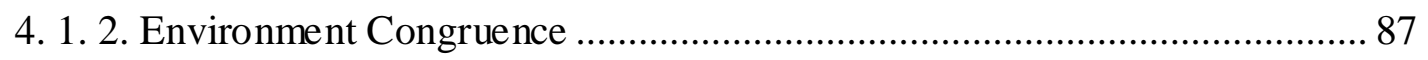

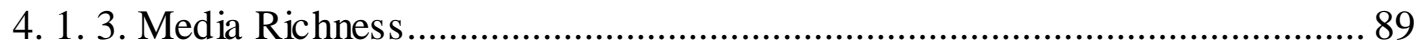

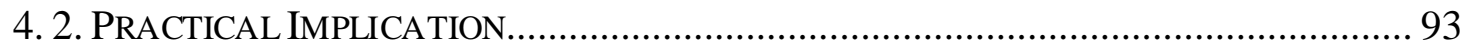

4. 2. 1. Implications for Product Design and Development..................................... 93

4. 2. 2. Implications for Marketing, Consumer Behavior, and Retail Merchandising

4. 2. 3. Implications for Communication and Media ……...................................... 96

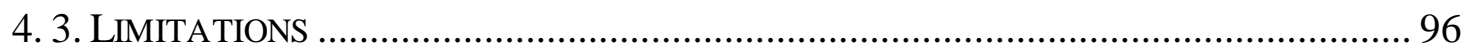

4. 4. CONCLUSION AND FUTURE DIRECTIONS ……………..................................... 98

REFERENCES ..................................................................................................................... 102

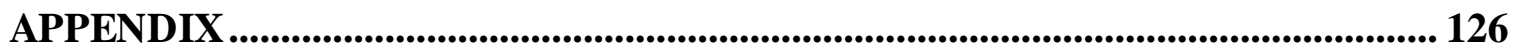

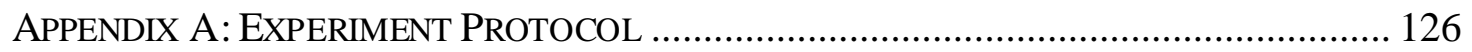

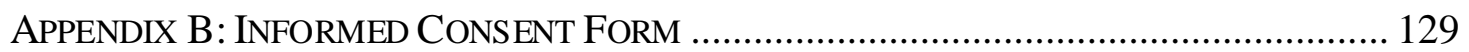

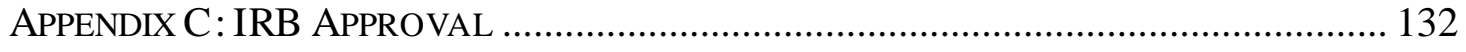

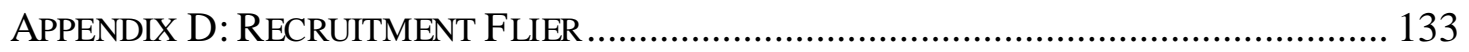

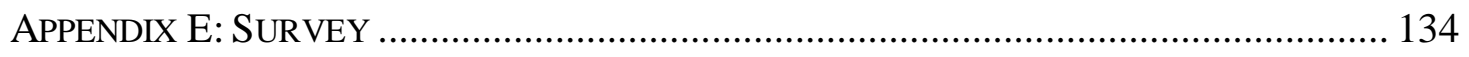

APPENDIX F: RELIABILITY ANALYSIS OF MEASURES ................................................ 144

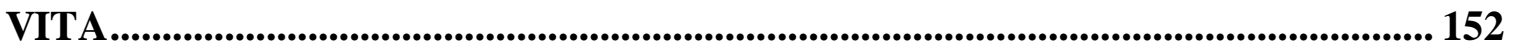




\section{LIST OF ILLUSTRATIONS}

Figure

Page

Figure 1: Independent and dependent variables 35

Figure 2: Summary of hypotheses

Figure 3: Stimuli for product design cues: higher-quality design (left) vs. Lower-quality design (right) 50

Figure 4: Product design cues: higher-quality design condition (perspective view) ........ 51

Figure 5: Product design cues: lower-quality design condition (perspective view) .........51

Figure 6: Non-congruent (generic) environment | low and high quality product design .. 52

Figure 7: Congruent environment with lower-quality product design 52

Figure 8: Congruent environment with higher-quality product design 53

Figure 9: Non-congruent (generic) product display 53

Figure 10: Product display: congruent with lower-quality prod uct design....................... 54

Figure 11: Product display: congruent with higher-quality product design 54

Figure 12: Oculus Rift CV1 head-mounted display is used for higher-level of media richness condition

Figure 13: A 70 inch UHD TV is used for low level of media richness condition 64

Figure 14: Significant interaction between Environment-Congruence*Product Design

Cues on Perceived Aesthetic 78

Figure 15: Summary of results for hypothesis testing ( $\mathrm{S}$ - significant, $\mathrm{P}$ - partially

significant, $\mathrm{N}$ - no significance) 82 


\section{LIST OF TABLES}

Table

Page

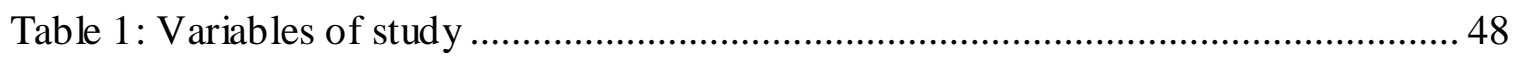

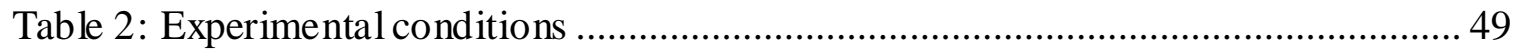

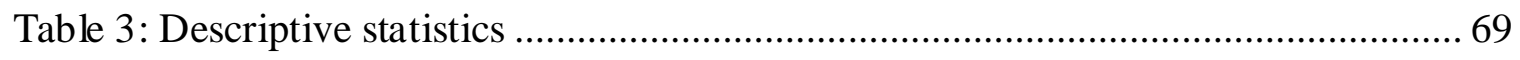

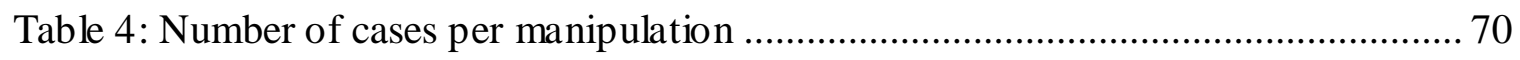

Table 5: Reliability for dependent variables and covariates ................................... 71

Table 6: Bivariate correlations among cognitive and affective response scales.............. 71

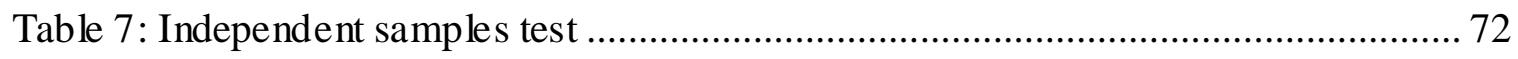

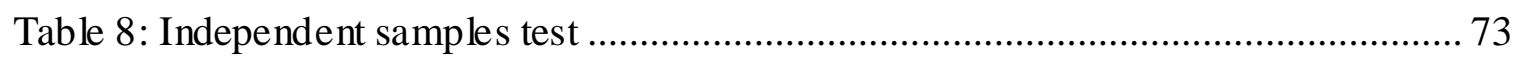

Table 9: Correlations between dependent variables and covariates .............................. 73 


\section{LIST OF ABBREVIATIONS}

$\alpha \quad$ Cronbach's index of internal consistency

$d f \quad$ Degrees of freedom

$F \quad$ F distributions: Fisher's $F$ ratio of two variances

M Sample Mean: the sum of a set of measurements divided by the number of measurements in the set

$p \quad$ Probability of success in a binary trial

$r \quad$ Estimate of the Pearson product-moment correlation coefficient

SE Standard error

SD Standard deviation

$<\quad$ Less than

$>\quad$ Greater than

$=\quad$ Equal to

$\lambda \quad$ Wilk's Lambda: test to see differences between the means of identified groups of subjects on a combination of dependent variables

$\eta \quad$ Partial eta squared: The proportion of variance associated with or accounted for by each of the main effects, interactions, and error

$\beta \quad$ Beta coefficient: estimates resulting from an analysis carried out on independent variables that have been standardized so that their variances are 1 


\begin{abstract}
This study makes examines the influence of product design cues, environment congruence, and media richness on users' cognitive and affective responses to product design. These three factors were systematically manipulated in a $2 \times 2 \times 2$ full-factorial experiment. A sample of 181 participants was used to test the study hypotheses. This study employed a between-subject design, and participants were randomly assigned to one of the eight experimental conditions. The results from statistical analysis of covariance (ANCOVA) revealed the influence of product design cues, environment congruence, and media richness on cognitive and affective responses.
\end{abstract}

The results of this study revealed that higher quality of product design and environment congruence did lead to a more positive aesthetic and affective response. In addition, the results showed a significant two-way interaction between environmental congruence and design cues for perceived aesthetic. Results however, didn't show a significant influence of design cues and environment congruence on perceived usefulness and perceived easeof-use. Moreover, it was confirmed that media richness significantly predicted the perceived ease-of-use, although no statistical significance was found for perceived aesthetic and perceived usefulness. This study has practical implications across various domains including product design, marketing and retail merchandising, and communication and media studies. 


\section{INTRODUCTION}

Three-dimensional (3D) presentation is increasingly employed in online shopping to attract, entertain, and inform users about features and specifications of new products. Virtual reality technology is starting to empower retailers to deliver product presentation content through richer media because, conventional media may not always provide sufficient information about the product features and usage in the context. Therefore, Amazon has recently announced its plan for creating a virtual reality shopping mall (Ryan, 2017). This strategy can help online retailers to bridge the gap between user experience in a physical retail store and the virtual online store. This dissertation investigates the users' cognitive and affective response to products while they are shopping in the virtual reality store.

As an illustration, imagine a scenario in which Jane visits an online store on her mobile phone to purchase an activity tracker wristband. She searches the online store and finds a certain brand activity tracker. Jane looks for some direct and indirect information to build a product knowledge about that activity tracker to make her purchase decision. First, she looks at the images of the product to see if she likes or dislikes the design of that product. Jane found the bright color and the rounded shape of the activity tracker appealing. But at the same time, the plastic rubber strap in a baby blue color made her uncertain about the usefulness and durability of the activity tracker.

Jane wants to get a better sense of the texture and size of this activity tracker. The mobile phone doesn't allow her to easily evaluate the shape, size, and texture of product. Therefore, she wears a compatible head-mounted display (HMD) to explore the product 
further in virtual reality environment. Her stereoscopic 3D HMD enables Jane to move around the activity tracker and see it from different angles and various distances. She feels better about the product because of moving around the product and seeing the shadows and light on the product gives her a better understanding of texture and size.

Taking another look at product presentation display, Jane found inconsistency between the product and background. While the activity tracker has rounded shapes in a bright color, the virtual presentation environment has sharp angle corners in black and red. She thought: 'Ha! It seems that the product might be more appropriate for professionals, but I need something for my daily activities. Is this product suitable for me?" The inconsistency between product and its presentation environment gives her a feeling of uncertainty about the functionality and appropriateness of this activity tracker.

In this scenario, Jane's understanding and feelings about the activity tracker have been shaped or changed because of the product design, the presentation environment in which the product is displayed, and the type of presentation medium. This understanding and feelings determines her buying behavior. The goal of this study is to investigate the interplay of design cues, presentation environment, and presentation medium on user's cognitive understanding and affective responses to a product. How different elements of design influence users' perception and affective responses? What happens if a welldesigned high-end product is shown in a poorly-designed background or virtual environment? What happens if the product information is communicated through a lowquality medium? How do potential users evaluate the product and how do they feel about it? 
A recent business analysis has revealed that design-driven companies such as Apple, Ford, Herman Miller, IBM, Nike, Steelcase, and Whirlpool, outperformed the S\&P 500 a stock market index of 500 large publicly traded companies - by $228 \%$ over the past ten years (Westcott, 2014). Businesses try to gain a competitive advantage in the crowded market by distinguishing themselves from others by product design. The increase of global information communication and the internet has enabled enterprises in developing countries to produce the products with similar functions and attributes of leading products market in the market (Huffman \& Kahn, 1998). Also, well-known brands, which share the market of a specific product, produce products with comparable features in an almost similar product lifecycle. Therefore, these brands should offer a competitive price for the specific product class. In such a complex competitive atmosphere, design plays a major role in differentiating the product -in particular, and the brand in general - in the market. But, it is still unclear how product design and its visual cues affect user cognitive judgment and feelings in a given context. The question is: how do visual cues of a product influence user understanding and how do they elicit affective responses to a product? This dissertation attempts to answer this research question first.

Even a well-designed product with promising functions, performance, and ergonomics can be a commercially unsuccessful product in the market due to poor presentation and promotion strategies. That's why well-known brands carefully manage the whole process of the product lifecycle from user's insight to design and development to product launch in the market. In addition to intrinsic aspects of product -such as design cues and functions - that evoke emotions, extrinsic aspects - such as presentation environment or country of origin - and also supporting information may create a positive or negative 
impact on perception of brand message and purchase decision. Taking this into consideration, the present study attempts to address the question of whether or not the product presentation environment influences user's cognitive and affective response to product. According to the PricewaterhouseCoopers (2015) consumer report, due to the convenience of online shopping, almost $27 \%$ of people shop on the internet every week. On the other hand, however, $60 \%$ of those users who shop at the physical store, expressed their concern for trying out the product before buying it. Research also has proven the importance of using extrinsic cues, which enable users to build a comprehensive understanding of the product that may lead to a product purchase decision (Bearden \& Shimp, 1982). So, it seems reasonable that extrinsic cues of the product such as the design of the promotional environment must be aligned and consistent with the brand image as well as the product image. In fact, a poorly designed environment, or even a well-designed but the non-congruent environment can cause confusion which may lead to avoidance. The congruity of environmental design with product design is a determinant factor which influences user perception and affective response and needs further investigation. But, to what extent and how does the congruency of environment design influence cognitive and affective responses of users to the product? This is the second research question that the present study tries to address.

Nowadays, products are not alone in communicating their features and capabilities to potential users. Products are presented with digital technologies that help potential users to engage with the product and improve their product knowledge via provided information. Emerging technologies, ultra-HD monitors, and immersive displays are becoming mainstream in the market, and online retailers may employ these powerful 
media to provide an in-depth presentation of the product. In fact, in the online shopping context, it is critical to communicate the utilitarian and hedonic aspects of product through a medium.

In online shopping context, the major role of the medium is a presentation of the product features as well as engaging users with the product or product advertisement. Although it is expected that users receive more information through a richer medium, important questions still exist: Does the media richness help users to perceive the product cues better? Does the richness of presentation medium improve user's perception and affective responses to product? These are the third research questions that are investigated in the current study.

The purpose of this dissertation is to investigate the influence of product cues, presentation environment, and media richness on user's responses. The main goal is to improve our understanding of how environment, product, and media enhances user's cognitive perception and affective response. So this dissertation attempts to address three main research questions: (a) How do product design cues influence user's cognitive perception and affective reaction to the product? (b) How do the similarities between product and promotional environment influence user's cognitive perception and affective responses? (c) How does media richness influence user's cognitive perception and affective response to the product? Based on the findings, this dissertation outlines theoretical and practical implications.

Chapter one further reviews the literature and explicates the concepts of product design cues, environment congruence, and media richness which are crucial to the research 
questions. Based on the literature review, hypotheses are proposed regarding cognitive and affective responses as the functions of design cues, environment congruence, and media richness. Chapter two details research methodology. It also provides details of the controlled experiment carried out to address the research questions and hypotheses. Then, it goes further to the operationalization of independent variables in the context of research and their measures. Chapter three details the data analysis procedure and results pertaining to specific hypothesis and their interpretations. Chapter four concludes the study with a discussion of the findings and the theoretical and practical implications, in addition to limitations of the study and directions for future research. 


\section{CHAPTER 1: REVIEW OF THE LITERATURE}

This chapter discusses the key concepts related to the user responses to a product. The focus here is to enhance our theoretical understanding of how product design, the promotional environment of the product, and media richness affect users' cognitive and affective responses. Therefore, each section of this chapter starts with identifying and explicating key concepts mapping out the relationship between them to pose the overall research question and generate specific hypotheses for conducting the study.

\section{1. Independent Variables}

This study examines the impact of product design cues, environment congruence, and media richness on user's response. The following section introduces these three concepts which are the independent variables of the study in greater depth.

\section{1. 1. Product Design Cues}

Along with price, promotion, and place, the product is one of the four P's of marketing mix (Bloch, 1995; Kotler \& Armstrong, 2010). Product design is a process in which, designers, business strategists, product analysts, marketing managers, and engineers work to gather to create a product that addresses hedonic and functional needs of end users, business profit and revenue, and environmental factors. In fact, product design is a multifaceted activity which involves different aspects of engineering, marketing, and design aesthetic (Bloch, 1995; Bloch, Brunel, \& Arnold, 2003). 
Product design is employed as a strategic tool for businesses to distinguish their products in the crowded market and to communicate meanings with their users (Kotler \& Rath, 1984). If a product design fails to communicate certain meanings clearly, users will encounter difficulties to evaluate product values. Therefore the chance of product failure in the market will be increased (Blijlevens, Creusen, \& Schoormans, 2009). If that happens, brands must spend too much on expensive product campaigns to communicate those intended meanings to their potential users (Krippendorff, 1989). For example, in the 1950s when Ford motor company heavily invested in a campaign for Edsel (the car of the future), no one expected the product failure because consumers started to compare the design of front grill to a toilet seat.

Product design also plays a major role in drawing users' attention to the product at the beginning of user-product interaction (Berkowitz, 1987; Blijlevens et al., 2009; Bloch, 1995; Bloch et al., 2003; Crilly, Moultrie, \& Clarkson, 2004). Moreover, design can transfer information about product quality and values to the consumer which leads to user satisfaction. It is important that a product draws the users' attention at first glance and then creates and maintains a meaningful communication with them during the rest of the product lifecycle. In the context of the technology-related products, product cues influence user's perception of product performance, product categorization, and selfexpression in the society (S. Lee, Ha, \& Widdows, 2011). Therefore, designers should successfully transform abstract concepts into visual cues of product design (Govers, Hekkert, \& Schoormans, 2003). But, there is a significant difference between designers and users regarding how design cues are perceived (Bahn, Lee, Nam, \& Yun, 2009). 
According to Kotler and Rath (1984), the term "design" is used in different ways. It can be referred to a process; it can be associated with the certain country (e.g., Italian design); or it can be reflected on visual and functional characteristics of product. One of the most important aspects of product design is its ability to give the product a unique and desirable appearance. So there is an agreement among researchers that visual characteristics of the product are among the important factors of product success in the market (Cooper \& Kleinschmidt, 1987; S. Lee et al., 2011).

Users are highly dependent on intrinsic and extrinsic product cues to develop product knowledge and to evaluate the products based on them (Rao \& Monroe, 1988). Product design cues are the most important intrinsic product cues because they are on the top layer of product-user communication. From the beginning of users' search for purchasing a new product, they start acquiring product knowledge about different available choices in the market. Product design cues help them to reach their ultimate goal (Cowley \& Mitchell, 2003). In fact, users seek product information to evaluate and compare products to make the best purchase decision (Bei \& Widdows, 1999). After drawing attention to the product, design cues help users to initiate and complete their knowledge of the product and decide if the product will address their needs. Therefore, design cues are effective sources of product information.

Research has revealed that users with higher product knowledge have a better understanding of product cues during product search (Alba \& Hutchinson, 1987; Blijlevens et al., 2009). These users also have a good understanding of product category, product cues, and whether or not the product enables them to perform their tasks (Bei \& 
Widdows, 1999; Mitchell \& Dacin, 1996; Sujan, 1985). Blijlevens et al. (2009) postulate that novice users can only distinguish a few cues of products while they have no clue about the other cues. But expert users with a higher level of product knowledge can identify a larger number of cues and meanings.

Bei and Widdows (1999) examined how vital the product knowledge is for users. They found complex product information is important for expert users because they already know the simple product information. In contrast, they found information complexity is not a major role player in decision making of novice users. In other words, prior product knowledge facilitates the process of new product information acquisition for expert users (Rao \& Monroe, 1988).

There is agreement among researchers that product information is processed by users, influences on their response and behavior (Cowley \& Mitchell, 2003; Nedungadi, 1990; Wyer Jr \& Srull, 2014). The following sections of this study attempt to clarify how product design cues -as a source of product information influences user's cognitive and affective responses.

\section{1.2. Environment}

Products are not alone in communicating their capabilities and features with potential users. In addition to product intrinsic cues, external factors play an influential role on users' cognitive judgment about the product and their feelings about it. Intrinsic cues refer to embedded cues of the product that determine the product appearance and functions. For instance, John Varvatos Dark Rebel Rider fragrance has leather and woody 
notes and a leather cover which are associated with masculinity. Extrinsic cues however, refer to external elements of environment or concepts that influence the users' understanding of the product. For example, country of origin for Swiss made watches, a celebrity brand ambassador like Nicole Kidman for Coco Chanel No5 perfume, or simple and clean interior design of an Apple store are important extrinsic cue for users that help them to develop a better understanding of product and brand. There are quite a few studies that examined the impact of "extrinsic" product cues on users in consumer research (Blijlevens et al., 2009; Dodds, Monroe, \& Grewal, 1991; Enneking, Neumann, \& Henneberg, 2007; Szybillo \& Jacoby, 1974).

The ultimate goal of extrinsic product cues is to reduce the risk of the purchase decision (Bearden \& Shimp, 1982) and to form an overall judgment about the product (Szybillo \& Jacoby, 1974). Moreover, it is expected that additional extrinsic cues negatively influence users' concern about the product price and positively influence perceived product quality. Extrinsic product cues provide more information about the product particularly when the intrinsic cues cannot communicate product meanings and values. Also, prior product knowledge and congruity of extrinsic cues with product information can influence facilitation role of extrinsic cues (Dodds et al, 1991). We also know that users with higher product knowledge depend more on product intrinsic cues to evaluate the product (Rao \& Monroe, 1988), they employ extrinsic cues to create a bigger picture of the product (C. W. Park \& Lessig, 1981). But, users with lower product knowledge use extrinsic product cues as an index of product significance (C. W. Park \& Lessig, 1981). 
Many researchers have identified several extrinsic cues of products. For example, Henderson, Giese, and Cote (2004) identified typeface and logotype; Orth and Malkewitz (2008) identified product packaging; Szybillo and Jacoby (1974) found price and store image; Milgrom and Roberts (1986) identified advertising; Bearden and Shimp (1982) came up with product warranty and brand reputation; Dodds et al. (1991) showed the brand name and store name, --as some extrinsic cue, influence user responses. Teas and Agarwal (2000) also identified brand name, store name, and country of origin as the key extrinsic cues. But, there is a lack of research about the influence of the promotional environment of product - as an extrinsic cue- on users' cognitive and affective response to product.

The influence of the environment on user response has been studied under the term atmospherics that was coined by Kotler (1973). He argues that a well-designed retail environment influences users' product evaluation process. Atmospherics research has also proved that a poorly-designed environment has a negative effect on shopping experience and user affective responses (Spies, Hesse, \& Loesch, 1997). The concept of atmospherics in marketing has been borrowed from environmental psychology to enable retailers to employ design elements for effective retailing (Bloch, Gopalakrishna, Crecelius, \& Murarollia, 2018). In environment behavior discipline, the most important role of environment is to help users to reach their specific goals (Canter, 1983).

In the context of this study, the product promotion environment helps users to create a more effective product experience when they interact with the product in an online shopping environment. But, for users with specific product buying agenda in mind, the 
influence of environment becomes less important compared to someone who is freely browsing product (Bloch et al., 2018).

\section{1. 2. 1. Environmental Congruence}

A well-designed product may be perceived positively in isolation (Bloch, 1995), although the same product can elicit negative emotions because of the poor fit with other products or the surrounding (Michie \& Forty, 1987). An appealing promotional environment has always been an important factor in product retailing (Bitner, 1992) because product experience is always shaped under the influence of the characteristics of the context where the user-product interaction happens (Desmet \& Hekkert, 2007). Users expect to experience consistency among different elements that shape their overall understanding. Such a congruence among different elements of product presentation helps users to integrate meanings into an overall impression. Meaningful overall impression leads to a deeper level of product perception. In fact, a congruence between perception of promotional environment and a mental image when stored in user minds, increases product and brand familiarity, acceptability, and approach response (Fiore, Yah, \& Yoh, 2000)

Environment congruence has been used to explain how users prefer to shop at certain retail stores (Suryandari \& Paswan, 2014). Fiore et al. (2000) posit that congruity happens between environment and mental representation of the object in the user mind. It refers to a high level of cognitive fit between the perception of environment and the mental information stored about the product or brand in the cognitive schema. Lightfoot and Bullock (1990) demonstrated how users interpret the consistency among different 
channels to evaluate the credibility of a communication pattern (as cited in Van Rompay and Pruyn (2011).

The working mechanism behind congruence can be explained by the theory of cognitive dissonance in psychology. Cognitive dissonance refers to a situation in which users encounter inconsistency and conflict among values and behaviors (Festinger, 1962). In fact, users hold many assumptions about their environment and phenomena. When they encounter inconsistency, they tend to reduce the tension of cognitive dissonance. In marketing, this may result in consumer avoidance behavior. The goal of congruence is to increase fluency and consistency among different elements of product presentation through which the perceived credibility and product value are increased.

To highlight the importance of congruence concept, Bloch et al. (2018) emphasize the positive synergy between the product and environment, and Fiore et al. (2000) argue how this positive synergy effects user response and generates a desire for the presented product. Also, research has proven that congruence of extrinsic cues influences the perceived value of product and credibility which leads to user willingness to pay more for a certain product (Van Rompay \& Pruyn, 2011).

Some researchers have studied the effect of congruence of visual features of the product. For instance, Bottomley and Doyle (2006) identified the congruence of product type and color; and Van Rompay and Pruyn (2011) examined the congruence of shape and typeface. Besides, there are quite a few studies that emphasize the important role of store environment congruence in user purchase behavior. Meyers-Levy and Tybout (1989) showed the positive impact of congruity on cognitive pleasure. Berger and Fitzsimons 
(2008) demonstrated how predictive context of congruent environment facilities users' positive evaluation of the product. But there is still a huge gap in the literature that bridges the gap between the influence of promotional environment congruency and its effect on user cognitive and affective responses.

\section{1. 2. 2. Product Display as a Promotional Environment}

In the information era when the crowded market is packed with different types of product advertisements, users often highly depend on tangible product experience offered in the store. That's why marketers employ product displays with different visual, tactile, and auditory elements to positively stimulate users for an in-store purchase behavior (Wu et al., 2013). But, employing product display is not new. In fact, the important role of product display in retailing was recognized in the second half of the nineteenth century (Wu et al., 2013). Mills, Paul, and Moorman (1995) state that around $25 \%$ of retail sale happens because of the influence of product displays (As cited in (Fiore et al., 2000). The role of product displays becomes even more vivid when users casually search the store environment with an impulse shopping behavior (Ko \& Rhee, 1994). In fact, store environment and product displays are influential marketing program moderators which can enhance or fail the product success. Store managers employ the power of product displays to shape the experience of users while they interact with the product (Bloch, 1995). They also employ environment and display design techniques to facilitate a positive purchase behavior (Fiore et al., 2000). Besides, a well-designed environment for displaying product helps to create a long-term strategic relationship between brand and user. In fact, product displays increase the chance of product purchase by attracting, informing, and entertaining users. 
Product display is also a communication channel which provides important information about product, price, promotions, and brand. In addition to their educating role, product displays can be used to entertain users (Pegler, 2006). Product display also plays an important role in drawing visitors' attention to company in general and product in particular specially in the crowded environment of a trade show (Bloch \& KamranDisfani, 2018).

The influence of product display - as a promotional environment - on user's behavioral response to approach or avoidance has been investigated (Fiore et al., 2000; Wu et al., 2013). In fact, the product display facilitates the positive evaluation of displayed product which evokes cognitive and affective pleasure. When a positive evaluation of an object or environment happens due to the cognitive processing of information -which is sent by sensory receptors, about the qualities of object or environment, users experience cognitive and affective pleasure (Fiore, 2010). Fiore (2010) continues to explain the qualities of an object or environment are the most important determinant of such a positive evaluation. Like product design cues, a product display -which is used as a promotional environment for product, has similar physical cues such as color, shape, size, and geometry, and texture which are perceived through the senses and elicit cognitive and affective responses among the users. Ballantine, Jack, and Parsons (2010) showed the dominant role of product display features among atmospheric cues in a store. Kerfoot, Davies, and Ward (2003) studied the influence of product display on brand communication and purchase intention. The influence of product display and booth design elements on user willingness to visit was examined by Bloch et al. (2018). They also showed how the design of product presentation station influences the user 
willingness to experience the product and to be in touch with corporate. But there is a lack of empirical studies about the effect of product display on user cognitive and affective responses. The present study takes product display as an important element of the environment in store scale and as a promotional environment for the product on a smaller scale. In addition, the pervasiveness of product display in retail environment emphasizes the necessity of further research on it as a component of the environment.

\section{1.3. Media Richness}

Indeed, online shopping has been on rise for last three decades. Online shoppers are usually motivated by goal-oriented aspects compared to in-store shoppers, however online retailers are increasingly invested in experiential aspects online shopping (Wolfinbarger \& Gilly, 2001). They widely employ the power of digital media to attract more users and provide more information about their product. During the 2016 holiday season consumers spend over $\$ 91.7$ billion in online sales (Gustafson, 2017). With an annual growth of $19 \%$, the business of interactive advertising hit $\$ 32.7$ billion in 2016 (PricewaterhouseCoopers, 2016). This growth is partly the result of user searches for more product information. In fact, the important pre-purchase activity is the effort to understand the product (Lightner \& Eastman, 2002). Different channels such as product advertisement, product presentation or window shopping all help improve our understanding of products (Bloch \& Richins, 1983). Human-computer interaction which is a feature of new communication channel enhances the opportunity to gain information about products. Users prefer product presentations that enable them to envision product usage (Kerfoot et al., 2003) and new digital technologies help them to reach this goal. In 
addition, product presentation medium stimulates users' desire for buying and owning the product, because they can obtain different types of information about the appearance and functions of product (S. F. Liu, Cheng, \& Chen, 2015).

It is a challenging activity for marketers to employ specific medium to communicate product functions and its advantages in online shopping. In the context of virtual reality however, users can obtain certain product information through virtual interaction with products (J. Park, Stoel, \& Lennon, 2008). Because in online shopping scenario users cannot evaluate the product using all five senses (Klatzky, Lederman, \& Matula, 1993) online retailers should identify the most appropriate communication medium that illustrates product functions and features effectively. We can assume that if the product is presented through a more effective and vivid medium, understanding of the product and affective response toward it will be improved. An effective product presentation helps users to process the information more efficiently and develop a deeper understanding of product (J. Park et al., 2008). New media and emerging technologies provide a promising opportunity for marketers to use a more effective medium for product presentation and advertising. In online shopping context, researchers suggest employing state-of-the-art visual media to inform users better and to reduce their cognitive effort (H. J. Park \& Stoel, 2002; J. Park et al., 2008).

Interactive media has shifted the one-way marketer-to-user communication model to a two-way interaction that enables users to process, use and respond to information selectively (Stewart \& Pavlou, 2002). In addition to information communication, interactive product presentation draws users attention to the product and engage them in 
the shopping process (Then \& DeLong, 1999). During this interaction, users are engaged with the shopping process and obtain more information about the product to make an informed purchase decision.

In addition to interactivity, product presentation in stereoscopic 3D helps users to virtually experience the shape and product functionalities (J. Park et al., 2008). Besides, 3D technologies provide the opportunity for online businesses to present their product in a more engaging and understandable way (Jin, 2009). In fact, virtual product experiences help users to gain more information about the product and improve their sense of presence for evaluating the product in a context (Li, Daugherty, \& Biocca, 2001). The assumption behind using virtual reality is that it is an accurate replication of product, context and real interactions that enable users to understand both physical and psychological aspects of interaction (Balakrishnan \& Sundar, 2011).

\section{1. 3. Media Richness and Modality: Breadth and Depth}

Each product presentation medium has its capabilities and characteristics which conveys different amounts of information with different levels of quality. It has been well established that employing multimodal product presentations in advertising, catches user attention and improves communication of product information (Jiang \& Benbasat, 2007; Unnava, Burnkrant, \& Erevelles, 1994). The explanation of this process is provided by the media richness theory.

Introduced by Daft and Lengel (1984), the theory of media richness refers to the capability of media to convey and communicate messages with different amounts of 
information. According to Steuer (1992), media richness refers to media vividness and information intensity which is presented to each sense. The richness is an internal property of the communication medium. Also, a rich medium communicates more cues and provides more feedback which facilitates the process of message understanding (Simon \& Peppas, 2004). The importance of media richness in user's understanding of product can be explained by cue-summation (Jiang \& Benbasat, 2007). When the number of cues increases within a channel (modality richness) or across the channels (multimodality), users' understanding of the product is improved (Moore, Burton, \& Myers, 2004). Media richness has two dimensions: breadth, and depth. While breadth refers to some senses which are involved, depth refers to the resolution and information quality of each perceptual channel (Steuer, 1992). Similar to the construct of media richness Ramirez and Burgoon (2004) introduced modality richness which refers to the number of modalities that a communication medium provides. In spite of the power of new media, there are still some limitations for an effective and rich product presentation in online shopping context (Rose, Khoo, \& Straub, 1999).

Several studies have examined the effect of media format on user responses. But, they are operationalized to measure the effect of media type or concept of modality breadth on user responses (Adelaar, Chang, Lancendorfer, Lee, \& Morimoto, 2003; Chaudhuri \& Buck, 1995; Dijkstra, Buijtels, \& Van Raaij, 2005). Jin (2009) determined the positive impact of media richness on users' shopping behavior in 3D virtual store. But, the stimulus of this study is a virtual store which is presented on a regular 2D nonstereoscopic screen. In another study, Jiang and Benbasat (2007) found that presentation of product information in a regular text and image format is not sufficient and effective. 
This was because a product presentation does not communicate the product usage in different contexts clearly and does not illustrate the different functions of product. Griffith, Krampf, and Palmer (2001) found that media richness has a positive impact on user involvement and behavioral responses of online users.

Other studies address the concept of depth in the media richness. For example, Li, Daugherty, and Biocca (2002) found that in an online shopping context, product presentation in 3D increases the amount of perceived product information compared to product presentation in 2D. In a supporting study, Li et al. (2002) found product presentations in 3D enhances users' knowledge of the product. Jeandrain (2001) found that realistic presentation of the product in $3 \mathrm{D}$ evokes positive affective responses in users.

Although some studies have examined the effect of multimodality, media format, or a specific aspect of virtual reality (e.g., 3D rotation) on user responses, research about the effect of different virtual reality technologies on users' cognitive and affective response is rare. In fact, the present study attempts to investigate the impact of the depth media richness on user's response to product design. It is assumed that virtual reality is a rich medium that provides more information to the visual sense. Compared to traditional media, such as TV commercials and printed product ads, virtual reality causes a higher level of sense of pretense (Grigorovici \& Constantin, 2004). This is why threedimensional media have attracted marketers as the rich media for product advertising in immersive environments (Grigorovici \& Constantin, 2004). 


\section{2. Dependent Variables}

The previous section focused on explication of independent variables. In this section, dependent variables in this research, including cognitive and affective response, are explained and explicated, and the sub-components of each of them are discussed. This section also elaborates on the relationship between independent and dependent variables.

\section{2. 1. Cognitive Response}

This section attempts to identify the dimensions of users' cognitive responses that are related to the context of this study. It starts with the definition of cognition then follows with comparing and contrasting different dimensions of cognitive perception as a construct to identify the components of the first independent variable. After a review of differences and commonalities of cognitive perception construct, three components of cognitive perception were identified as (a) perceived aesthetic, (b) perceived usefulness, (c) perceived ease of use.

According to Merriam-Webster (2006), cognition reffers to conscious mental activities including thinking, understanding, learning, and remembering. In the context of this dissertation, cognition is defined as the process of information acquisition, processing, retention, and retrieval in user mind (S. Lee et al., 2011). In fact, users process the information about the product usage to perceive a cognitive pleasure (Fiore et al., 2000).

The model of product experience proposed by Desmet and Hekkert (2007) has three elements of user response. The first two elements are focused on user's cognitive 
perception: a) aesthetic pleasure, b) attribution of meaning (such as interpretation, memory, retrieval, and association); and the third one has focused on user affective responses: c) the emotional response. Aligned with this Crilly et al. (2004) identified three components of cognitive perception: (a) aesthetic, (b) symbolic, and (c) semantics. As Desmet and Hekkert (2007) argue, the attribution of meaning fits into the concept of semantic interpretation and symbolic association of Crilly et al. (2004) model of product design perception. Moreover, aesthetic pleasure is an intangible aspect of cognition which is discussed by Hassenzahl (2001) as the perceived hedonic quality.

In the second approach, Hassenzahl (2001) argues that users combine perceived hedonic qualities with perceived ergonomic qualities into a single evaluation and judgment about the product. The consequences of such a mixed perception are behavioral variables such as (a) user attachment to the product/acceptance/increased usage frequency, (b) better work performance, (c) fewer user errors, (d) milder learning curve/decreased time. While hedonic is defined by non-task-related aspects of user-product interaction, the ergonomic qualities are associated with task-related aspects. So they are independent and can be measured as the different components of user cognition (Hassenzahl, 2001; Robinson, 1993).

Scherer (1984) explain five different stages of user cognition in response to a stimulus. Their theory also fits into the identified user cognitive responses to product design. The first stage involves evaluation and understanding of novelty. In the second stage, users evaluate the product by referring to their prior experiences. In the third stage, the product is examined based on user goals. In fact, a user perceptually evaluates product usefulness. 
Users evaluate the product in the fourth stage to see if they can accomplish a task with the help of product. In this stage, perceived ease-of-use is involved in the cognitive processing of information. In the fifth stage, a user compares the product usage with norms and standards. The perceived aesthetic is elicited from the first and the fifth stage of this theory. Novelty is also considered as a dimension of aesthetic, but users compare product with norms, standards, and their prior experience. This comparison is a cognitive task which is associated with the function of communication of symbolic meanings in aesthetic judgement. This idea is also supported by Bloch (1995) where he argues that a good product should provide users with both aesthetic values and utilitarian values. In addition to aesthetic, the visual aspects of product appearance help users to develop an understanding of product functionality and performance. Also, users decide to use (or not to use) a specific product by assessing the outcome of using the product against the amount of effort that is required for using the product. Therefore, three dimensions of cognitive response to product design -including perceived aesthetic, perceived usefulness, perceived ease of use, are discussed with more details in the next section.

\section{Perceived Aesthetic}

Throughout the long history of humanity, aesthetical objects and the products have always elicited positive responses from people (Bloch et al., 2003). The "aesthetics" origin in Greek refers to a sensory understanding of delightful objects or phenomena, including but not limited to artwork, product, landscape, and environment (Hekkert, 2006). Aesthetic is defined as the sensitivity to beautiful things. Among the other

applications of the aesthetic concept in art, philosophy, and psychology, businesses have 
widely recognized the importance of aesthetic perception in product design and its influence on user behavior (Veryzer, 1993).

There is agreement among researchers that aesthetic perception is a major role player in user understanding of products (Blijlevens et al., 2009; Bloch et al., 2003; Crilly et al,, 2004; S. Lee et al., 2011). Although, little research has been done on perceived product aesthetics (Veryzer, 1993). Desmet and Hekkert (2007) define aesthetics as an important quality of the product which facilitates pleasure through one or more sensory modalities. Overbeeke and Wensveen (2003) define the pleasant experience of interacting with the product as an intangible instrumental aspect of aesthetic perception. Moreover, some researchers divide the aesthetic quality into two categories of formal and symbolic aesthetic which refer to physical cues and communication of intangible meanings (Kopec, 2006; Lang, 1988). Finally, Veryzer (1993) defines aesthetic responses as a users' reaction to products based on their perception of product design cues. This aesthetic perception might be a nonconscious cognitive processing of information about unity and proportions of objects. Users nonconsciously learn the design principles of artifacts and environment during their lifetime. They negatively respond to the product that doesn't exhibit the same principles (Veryzer, 1993). The explanation of aesthetic perception can be completed by the synesthesia design that postulates users employ a variety of perceptual strategies to perceive the aesthetic in a systematic way (Haverkamp, 2013). So, users process the information they receive from each sense at first and then, they make the connection among the senses in the development phase. This approach is different from the genuine synesthesia theory that posits simultaneous multimodal sensation of a phenomenon in the brain leads to aesthetic experience (Cytowic, 2002). 
In addition to general definitions given above, some researchers go further in detail to define the components of aesthetic perception. Fiore (2010) has identified three levels of aesthetic pleasure regarding the experience of product and product display including cognitive pleasure, affective pleasure, and arousal. The first identified level is related to perception and understanding of meanings. Similar to the Fiore (2010) construct, the Hassenzahl (2001) model of user-product interaction consists of three components including (a) objective product quality: designers/brand message which is carried out through the product design, (b) subjective quality perceptions: hedonic and ergonomic (c) affective, and behavioral consequences. However, Hassenzahl (2001) identified different dimensions of product quality (e.g., predictability and controllability in ergonomic quality) and argues that aesthetics are the key factor of user satisfaction because it refers to subjective, non-instrumental needs of users such as beauty, originality, novelty, social acceptance, and innovativeness.

Blijlevens et al. (2009) argue that design cues of the product have often been viewed from the designers' perspective. They identified three important cues from user's perspective when they perceive product appearance: modernity, simplicity, and playfulness. In their study, consumers were asked to identify the product appearance cues that enable them to distinguish durable consumer products. Veryzer (1993) identified "proportion" and "unity" as the determinant elements of the aesthetic response. Similarly, M. Lee and Lou (1995) examined the key element of product design cues. They argue that appearance consists of two components including visual appeal -which refers to the aesthetic perception, and prototypicality that defines the product category. 


\section{Perceived Usefulness}

Indeed, People look for some visual cues in the products to make sure that products addresses their specific needs and enables them to do their job. There is an agreement among researchers that users are motivated to purchase the products based on perceived product functionalities (Blijlevens et al., 2009; Bloch, 1995; Creusen \& Schoormans, 2005). Schultz and Slevin (1973) proposed the effect of perceived usefulness on system usage. Perceived usefulness refers to users judgment about how effectively a system or product would help them to perform their job better and faster (Davis, 1989). Users compare the visual cues of stimulus with visual references in their memory to form a judgment about the product's potential to accomplishing a task. For example, some materials such as stainless steel and chrome are associated with product durability; durable product encasement is usually associated with heavy duty tasks and product performance. Similarly, the repetition of the same visual aspects in a congruent product display facilitates this understanding. During this process, media depict the product usage in the context and its specific features and specifications that may enable user to do the job more efficiently.

S. Lee et al. (2011) also identified usefulness as a component of perceived product

performance which influences user response. Other researchers also recognized the same concept but under the title of perceived product effectiveness (Hassenzahl, 2001; Hauser \& Simmie, 1981).

A similar construct which overlaps with usefulness is the concept of usability. Usability is defined as the objective effectiveness and efficiency of product that helps users to 
achieve their goals in a given context of use (Bevan \& Macleod, 1994; ISO, 1998). In addition, researchers agree that usability is a separate concept from the hedonic aspects such as perceived aesthetic (Hassenzahl, 2001; Igbaria, Schiffman, \& Wieckowski, 1994). Investigation of correlation between hedonic aspects and usability has also revealed that lack of perceived usability has a negative impact on the perceived aesthetic (Hassenzahl, 2001; Kurosu \& Kashimura, 1995; Tractinsky, 1997).

Desmet and Hekkert (2007) operationalize usability based on three elements of effectiveness, efficiency, and ease of use. Then, they state that overlapping components of usability and product experience are similar, which is the outcome of the user-product interaction. Therefore, experience and affective responses are affected by the negative or positive impact of perceived usability. Whether we look at perceived usefulness independently from Davis' (1989) point of view or like Desmet and Hekkert (2007) take it as a sub-component of usability, it has been seen as an important element of users' cognitive perception.

\section{Perceived Ease-of-use}

Users usually search for products that enable them to perform their job more effectively. In addition, they also evaluate the needed effort for learning the product operation -and if the product purchase is worthful. The cost-benefit theory (Marshall, 1892) can be used to explain why users try to make an optimized decision when they chose a product or technology. It explains the relationship between the needed effort for task accomplishment and the quality of decision results (Beach \& Mitchell, 1978; Johnson \& Payne, 1985; Payne, 1982). 
Among the multiple factors that determine user cognition and attitude toward the product, perceived ease-of-use has been identified as an important element of users' cognition (Davis, 1989; Larcker \& Lessig, 1980; Swanson, 1987). Davis (1989) defined ease-of-use as the degree to which a person believes that using a particular system would be free of effort. Ease-of-use has been identified as a dimension of users' perception (Hauser \& Simmie, 1981). Similarly, Bloch (1995) categorizes the ease-of-use as a component of user's cognitive response. Hassenzahl (2001) states that perceived ergonomics is an important component of cognitive response which refers to usability that addresses user needs and goals. S. Lee et al. (2011) put the ease-of-use in the category of perceived product performance.

The concept of ease-of-use is supported by Bandura's (1982) theory of self-efficacy which refers to the users' judgment of their ability to perform certain tasks dealing with a prospective situation. This theory puts more emphasis on self-evaluation when users expect success or failure given the task difficulty. The technology acceptance model (Davis, 1986) also recognizes the importance of the concept of ease-of-use. This theory emphasizes perceived ease-of-use as a determinant of technology adoption (Davis, 1989; S. Lee et al., 2011; Saadé \& Bahli, 2005; Tornatzky \& Klein, 1982). In this case, users prefer products which are perceived as easier to use.

Finally, the construct of usability adds more support to the assumption that ease-of-use enhances adoption of a product. Usability is defined as the product ability to help users to achieve their goals (Norman, 2013). Nielsen (2012) describes the usability the quality attribute that assesses how easy it is to use the product. Nielsen (1994) identified five 
components of usability including learnability, efficiency, memorability, error, and satisfaction. In this viewpoint, learnability, memorability, and error are obviously the dimensions of ease-of-use.

\subsubsection{Affective Response}

The Merriam-Webster dictionary (2006) describes the term "affection" as a moderate feeling or emotion. The construct of affection has been used for decades in different disciplines such as marketing and consumer research (Creusen \& Schoormans, 2005; Schmitt, 1999); design (Jordan, 1999; Norman, 2004); industrial engineering (Bahn et al., 2009); human factors and ergonomics (Helander, 2002); and cognitive sciences (Picard, 1997). Increasingly, marketers are interested in understanding the process of users' affective responses to products and services (Batra \& Ray, 1986; Westbrook, 1987).

Scherer (1984) argue that affection is the consequence of cognitive interpretation of phenomena. Similarly, Davis (1989) states that affective responses of users and their attitudes are usually a consequence of their perception. In support of this perspective Hassenzahl (2001) argue that during the user-product interaction, different cognitive perception qualities elicit different affective responses. In fact, the mechanism of affective responses can be described by the evaluation (appraisal) model. Based on this model, evaluation of an object, environment, or phenomenon causes some beneficial or harmful concerns in users' mind and then the proper emotional reaction to that (Hekkert, 2006; Ortony, Clore, \& Collins, 1990; Scherer, Schorr, \& Johnstone, 2001). When users perceive beneficial qualities - either hedonic or utilitarian - owning or using a product, they unconsciously develop some affective responses to that. For example, a user may 
develop positive affective responses to a Tag Heuer Monaco ${ }^{\odot}$ watch because he thinks that owning this product facilitates self-expression in the society. In addition, dark, sleek product display -with two vertical strips in blue and orange and also the silhouette of convex polygon logo- exhibits congruency with a product which supports the product perception and positive affective responses in consequence. Understanding of product benefits and affective responses are influenced not only by presentation of product performance which is associated with how Lewis Hamilton drives a Formula 1 race car; or the luxury features which are associated with showing Tiger Woods playing golf. Also, this could be happen by showing the micro details of mechanical movement or tourbillon chronograph feature. Media richness is necessary for an effective presentation of hedonic and functional aspects of a product which will eventually influence users' affective responses.

However Bradley and Lang's (1994) perspective in psychology postulate the bipolar aspects of affection as the pleasant and unpleasant emotions. The two most commonly accepted dimensions of affect in psychology are pleasantness and arousal (Schlosberg, 1952). Later, Mehrabian and Russell (1974) added the third component of affective response, namely dominance to previously defined pleasure and arousal. Based on two accepted emotions of pleasure and arousal, Posner, Russell, and Peterson (2005) developed "Circumplex Model of Affect" which includes users' different moods. Similarly, Posner et al. (2005) expanded the model to multi-dimension aspects of affect which combine the physiological arousal with a two-dimensional circular model. In this perspective, pleasure refers to the good feelings, emotions, and satisfaction with the 
product, and arousal as way to capture the user excitement about the product (S. Lee et al., 2011)

Another shift happened in the field of human-product interaction when researchers focused on affect instead of investigating behavior and cognition (Desmet \& Hekkert, 2007; Norman, 2004). According to Hekkert (2006), product experience consists of three interrelated components including (a) aesthetic experience (b) experience of meanings (c) emotional experience which refers to user affects. While the first and the second components refer to cognitive perception -which is investigated in this study - the third component reveals the importance of affective response in user-product interaction.

Desmet, Overbeeke, and Tax (2001) defined three types of user's concerns that shape affective responses to a product design. Those three concerns are: (a) goals which are associated with the user's functional and social expectations from a product, (b) standards and norms either in society, or user's mind, and (c) attitudes which is defined by "liking" and "disliking" of product. Besides, users develop different affective responses to the product design because of differences in their set of concerns (Bloch et al., 2003; Desmet et al., 2001).

The relationship between cognitive response and affective response has always been a keenly debated topic among psychology scholars. Some researchers argue that affective response is a consequence of conscious or unconscious evaluation of phenomena (Arnold, 1960). Others believe that reward or punish motivators determine the affective responses (Rolls, 2005). Particularly, the relationship between affective response and aesthetic perception has been a topic of debate (Silvia, 2005). 
Berlyne (1975) postulates aesthetic response is the consequence of perceiving the objective characteristics of an artistic piece. Appraisal theory supports this approach because it holds that users' affective responses are derived from evaluation and interpretation of objects or phenomena (Lazarus, 2001). This school of thought was founded based on James' (1950) idea that postulates emotional changes are the direct consequence of people's perceptions. Thus, the present study has been shaped around this approach that holds aesthetic perception - as a dimension of cognitive response, contributes to affective response (Schachter \& Singer, 1962).

\section{3. The Relationship Between Independent and Dependent Variables}

The overall framework of the present study is rooted in environmental psychology, consumer behavior, cognitive phycology, and product design. The Stimulus-OrganismResponse framework (Mehrabian \& Russell, 1974), drawn from environmental psychology explains how users develop cognitive and affective responses based on interaction with stimuli and form behavioral responses based on their cognitive and emotional states.

In marketing, Bloch (1995) investigated how consumers respond to visual aspects of product form and how the product appearance stimulates users' psychological and behavioral responses. In cognitive psychology, Hassenzahl (2001) suggests the model of perceived product qualities and user's cognitive judgment of appealing and its emotionalbehavioral consequences. In product design, Crilly et al. (2004) developed their argument about how users respond to product design, around the basic model of communication proposed by Shannon (1948). They explain the product (transmitter) is experienced in an 
environment (channel) by user (receiver) and shapes cognitive responses, as well as affective and behavioral responses. Similarly, in the human-computer interaction area, Norman (2004) explains three levels of information processing where visceral level (judgmental perceptual) causes the affective processing which then turns to behavioral responses.

In addition to models above, other researchers go further into detail to explain the interplay of the components of this process. For instance, on one hand, Desmet and Hekkert (2007) explain the influence of aesthetic and symbolic experience on the overall emotional experience. On the other hand, Blijlevens et al. (2009) and Hekkert (2006) have only focused on user's perception of product appearance. Followed by explicating the dependent and independent variables of study, here the relationship between those variables is discussed and the hypotheses are introduced.

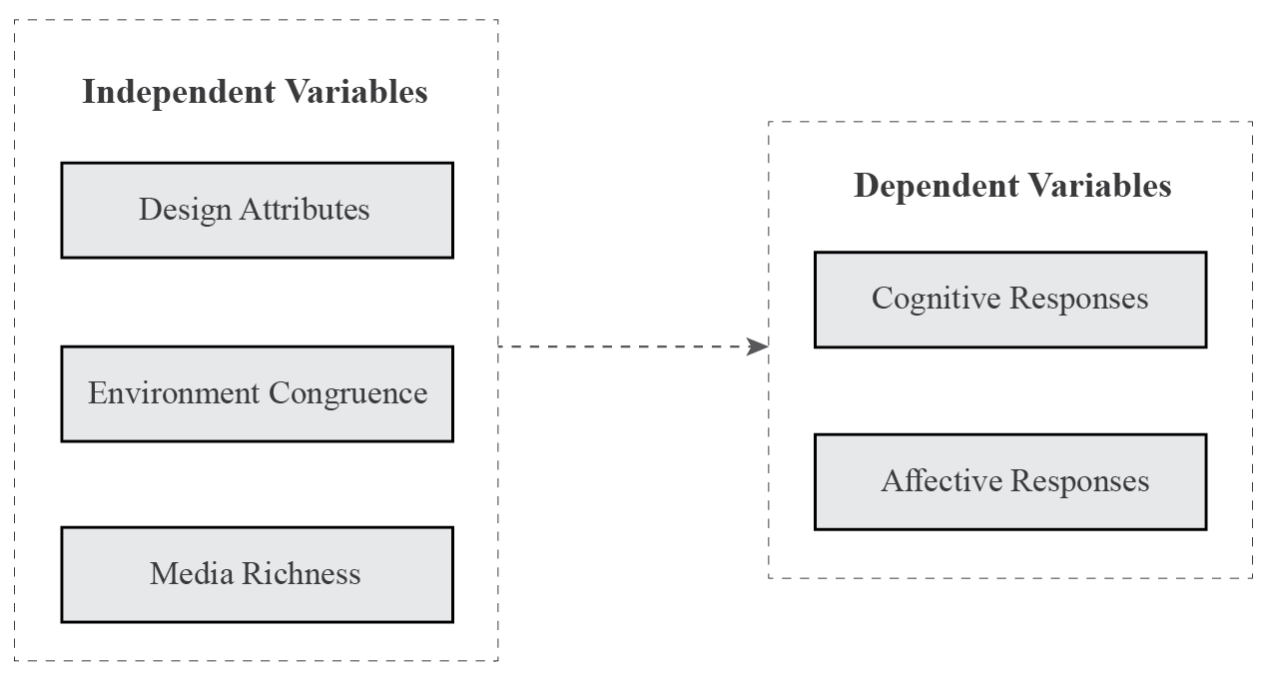

Figure 1: Independent and dependent variables 


\section{3. 1. The Influence of Product Design Cues on Users' Cognitive Responses}

Brands and product manufacturers try to communicate certain meaning through the product appearance to facilitate user decision making and brand recognition (Bloch, 1995; Van Rompay \& Pruyn, 2011). They employ knowledge about user perception and cognition as a guide in their product development process (Good, Spine, Whiteside, \& George, 1986). The perceived meanings help users to evaluate different aspects of a product including functions, aesthetic, symbolic, and ergonomic criteria (Blijlevens et al., 2009). But, tangible cues of product design are the most important visual factors for users because these design cues help them understand the product and make an informed purchase decision (Bearden \& Shimp, 1982)

Understanding the role of design cues in shaping and changing user perception is very important because designing of a successful product requires a perfect alignment between designer's intention and user perceptions for creating different product cues (Hassenzahl, 2001). If the major goal of a product is to satisfy hedonic qualities like novelty, social prestige, or aesthetic, it should be evident in product design and manifested in the product appearance.

Bloch (1995) argues that cognitive response is the consequence of product-related beliefs. He explains two different perspectives on cognitive perception: (a) the linear processing approach, and (b) the holistic visual perception approach. This concept is very similar to Heuristic-Systematic Model of Information Processing (Chaiken, 1980). Based on this model, on one hand, users employ knowledge that is stored in their memory to minimize 
the cognitive effort. On the other hand, they may systematically process analytic information. Bloch (1995) argues that users may continue product evaluation with a systematic information processing after an understanding of the product in a comprehensive, holistic way. Then he continues that the heuristic approach can be described by the theory of Gestalt psychology. Aligned with Bloch's (1995) position, Blijlevens et al. (2009) also support the idea of holistic user perception, because it describes how physical cues of product design influence perceptions. In fact, those appearance attributes together provide the consumer with an overall impression and understanding of the product (Blijlevens et al., 2009).

The mechanism of product design perception can be best explained by theories in cognitive psychology and neuropsychology. The basic model of object recognition (Riddoch \& Humphreys, 2001) identified four different stages of perception. First, users start to process the basic components of an object such as shape and color. Then, the object components are grouped to create an overall visual stimulus. In the third stage, the visual stimulus is evaluated based on stored information in the memory. Finally, symbolic and semantic attributes are applied to visual stimulus in the fourth stage. Aligned with this perspective, Leder, Carbon, and Kreuzbauer (2007) explain how the visual aspects of a product are carried out from retina to visual cortex to complete the information processing. They explain four stages of product design perception -retinal image, image-based processing, surface-based processing, and object-based processingbased on Palmer, Brooks, and Nelson's (2003) 4-stage model of object perception. 
The early hierarchical object recognition model of bottom-up processing theory (Gibson, 1966) suggests that all information that is perceived about the stimuli is directly acquired through the human senses. But, the top-down processing theory emphasizes the fact that stimulus information that is perceived through sensory channels is ambiguous and not sufficient for interpretation. So, users need to use the knowledge stored in their memory to evaluate what they perceive (Gregory, 1970).

There are quite a few studies examining the relationship between product design and user's cognitive perceptions. For instance, Hirschman and Holbrook (1982) demonstrated the positive impact of product experience on user's feeling of pleasantness. Blijlevens et al. (2009) investigated how product appearance is perceived by users. Bloch (1995) examined the effect of design on product related perceptions. Hassenzahl, Platz, Burmester, and Lehner (2000) studied hedonic and ergonomic aspects of user perception. In the most relevant study, Crilly et al. (2004) explained three components of users' perception including aesthetic, symbolic, and semantic which are evoked by product design. But their model was not tested in an experiment.

In fact, few-if any—studies have examined the effect of product design cues on the individual components of user cognitive perception. Based on the literature review of cognitive response, we propose the following hypotheses, assuming aesthetic perception, perceived usefulness, and perceived ease-of-use are the key elements of user's cognitive perception:

H1: Higher product design quality will elicit more positive aesthetic responses than product designs that have lower quality. 
H2: Higher product design quality will elicit more positive perception of usefulness than product designs that have lower quality.

H3: Higher product design quality will elicit more positive perceived ease-of-use responses than product designs that have lower quality.

\section{3. 2. The Influence of Product Design Cues on Users' Affective Responses}

Human interaction with products, surrounding objects, and environment may elicit a positive response that may lead to a product purchase. Affective response to a product is a factor of their commercial success and brand loyalty of customers. For example, Harley-Davidson motorcycles and Mini Cooper cars elicit very strong affective responses among their users that enable them to be successful in the market. Moreover, physical attributes of product design such as shape, color, texture, and performance, have a great influence on user experience in general and user affective responses in particular (Desmet, 2003a; Desmet \& Hekkert, 2007). In fact, product design can elicit a strong affective response among their users (Demirbilek \& Sener, 2003; Desmet, 2003b; Desmet, Hekkert, \& Jacobs, 2000; Desmet et al., 2001; Jordan, 1998; Seva \& Helander, 2009).

Desmet et al. (2001) explain that affective responses are elicited from the cues of product design. They continue it is a very personal experience, and it can be different for different users. So it is difficult to define a meaningful relationship between visual aspects of product and user affections (Desmet et al., 2001). 
There are some studies about the general influences of product design on users'

evaluation of a product and also their affective responses to the product (Mowen, Fang, \& Scott, 2010; Page \& Herr, 2002; Seva \& Helander, 2009). Fiore et al. (2000) went further in detail and examined the affective response as a consequence of "positively evaluated emotions or feelings evoked by or expresses through the qualities of the form of an object or environment." (p. 32). Bloch (1995) argues that affective responses are the consequence product perception. Kumar, Townsend, and Vorhies (2015) identified social, functional, emotional, and economic values as the drivers of the product affection. Westbrook (1987) studied users' affective response in post-purchase context. In another study Bahn et al. (2009) investigated the influence of luxuriousness in product design affection. But, the affective responses elicited from product design cues have been left ignored in both design and marketing research (Desmet et al., 2000). So there is still a lack of research about how cues of product design can influence users' affective responses to the product (Desmet et al., 2001). The fourth hypothesis of this study is proposed as:

H4: Higher quality product design will elicit more positive affective response compared to lower quality product design.

\section{3. 3. The Influence of Environment Congruence on Users' Cognitive Response}

Research in marketing has shown that design of environment is even more important than product price in user perception of product quality (Baker, Parasuraman, Grewal, \& Voss, 2002; Mazursky \& Jacoby, 1986). Research has also proved that congruence of the 
product with other related elements in the marketing mix -including promotional environment - has a positive effect on user response (Van Rompay \& Pruyn, 2011). In fact, products are perceived more appealing and purchased more frequently when they are presented in an environment with congruent visual cues (Berger \& Fitzsimons, 2008). The study by Wu et al. (2013) also supports this idea by showing how a well-coordinated product display increases aesthetic appeal and enhances user's evaluation of the product.

Situational cues stimulate restoring information in memory which leads greater product favorability (Higgins, Rholes, \& Jones, 1977). Therefore, more exposure to similar or related stimuli influences users' perception and evaluation of a certain product (Whittlesea, 1993). Kerfoot et al. (2003) found a positive impact of color coordination between product and the product display on user responses. They also observed the negative impact of uncoordinated color (between product and display) on user's perception of product, price, and store image. Similarly, Lam and Mukherjee (2005) found that with a non-congruent product display, the product is perceived and evaluated more negatively than when it is evaluated separately.

Van Rompay and Pruyn (2011) argue that experience of fluency and consistency stimulates the sense of beauty in users. In contrast, lack of congruence and inconsistency increases the information ambiguity leading to perception of lower product quality and usefulness (Van Rompay \& Pruyn, 2011).

Using Stimulus-Organism-Response model (Mehrabian \& Russell, 1974), many researchers investigated the role of environmental cues -e.g. ambient cues, design cues, and social cues (Spies et al., 1997; Wu et al, 2013) — on user cognitive and affective 
responses (Baker, Levy, \& Grewal, 1992; Bellizzi \& Hite, 1992; Donovan \& Rossiter, 1982; Spangenberg, Sprott, Grohmann, \& Tracy, 2006). In the most relevant study, Langrehr (1991) demonstrated the positive impact of overall retail environment experience on users' cognitive responses. But, the influence of product display congruence on user's cognitive response has rarely been investigated. Based on the above discussion about the concept of environment congruence, the following hypotheses are proposed:

H5: Product design presented in a congruent environment will elicit more positive aesthetic responses than those presented in a non-congruent environment.

H6: Product design presented in a congruent environment will elicit more positive perception of usefulness than those presented in a non-congruent environment.

\section{3. 4. The Influence of Environment Congruence on Users' Affective Responses}

A well-designed environment improves the interaction between the user and the product.

The influence of environment design on users' behavioral response and their purchase decision has been studied in consumer behavior, marketing, and merchandising literature (Baker et al., 2002; Fiore et al., 2000; Holbrook \& Hirschman, 1982; J. Park et al., 2008). In particular, the influence of environment on user affective response has also been studied in the marketing context (Babin \& Darden, 1996; Donovan \& Rossiter, 1982; Wakefield \& Baker, 1998). 
Bloch and Kamran-Disfani (2018) observed the influence of a store's exterior environment on affective responses which led to approach or avoidance behavior. Bloch et al. (2018) examined the positive impact of environmental design on creating feelings of pleasure and arousal which led to willingness to visit and experience with the environment. They also determined the moderating role of user characteristics on product display preference. Darden and Babin (1994) studied the influence of store environment on affective responses. Borrowing from environmental psychology, Donovan and Rossiter (1982) studied two dimensions of user's affective responses (emotional pleasure, and emotional arousal) in the retail environments. In a relevant study, Suryandari and Paswan (2014) examined the positive effect of congruence between online store environment and product on user's behavioral response in an online shopping context. But, in the context of online shopping with emerging technologies, there is a lack of research that investigates the influence of product display congruence on user affective responses. Based on the above, the following hypothesis is proposed:

H7: Product design presented in a congruent environment will elicit more positive affective responses than those presented in a non-congruent environment.

\section{3. 5. The Influence of Media Richness on Users' Cognitive Response}

User's cognitive and affective response to product and advertising has been studied in marketing research (Holbrook \& Hirschman, 1982). Lavidge and Steiner (1961) framework of Predictive Advertising Effectiveness also postulates that cognitive and affective responses are the functions of product presentation in the advertisement. 
It has been well established that messages conveyed through different media channels impacts users' cognitive responses differently (S. S. Liu \& Stout, 1987). In addition, passive, low involvement media, such as radio and TV, elicit less cognitive responses compared to an active and engaging medium such as text (Wright, 1981). Moreover, a text medium is more effective in justifying technical aspects of the product, but the appearance and physical attributes of the product can be effectively evaluated through a medium with visual modality.

Andrews, Akhter, Durvasula, and Muehling (1992) observed greater cognitive responses among participants with lower message-involvement in the product advertisement. Jiang and Benbasat (2007) examined the effect of different product presentation formats. They observed under a medium level task complexity that product presentation in $3 \mathrm{D}$ has a positive impact on user's perceived understanding of product compared to static images. To manipulate the task complexity, they made a different number of features available for each product (6 features in a sports watch which is used in a medium-level task complexity condition, and 17 features in PDA which is used in a high-level task complexity condition). The result can be explained by Miller's (1994) magic number of seven plus/minus two which represents the number of information chunks that people can hold in their working memory. In fact, when cognitive overload happens due to the product's complexity, it reduces the impact of media format on user responses. S. H. Liu, Liao, and Pratt (2009) found that presentation with richer media influences perceived ease of use and perceived usefulness. But, they operationalized the media richness with multimodality. Similarly, Lim and Benbasat (2000) argued that different levels of media modality richness could be associated with perceived usefulness of eLearning systems. 
S. F. Liu et al. (2015) investigated the effect of interactive displays on user's cognitive response to the product. They found that interactive displays help users to understand the product better. This better understanding is due to the product presentation on an interactive medium that simulates the real usage of a product for users. In another study, J. Park et al. (2008) found that product rotation in a three-dimensional environment has a positive influence on users' cognitive perception of the product. Similarly, Vessey and Galletta (1991) suggest that employing different product presentation formats improves the process of cognitive perception. Therefore, it is reasonable to expect that different levels of media richness in product presentation elicit different levels of cognitive thoughts and responses to product design. Based on this assumption, the next set of hypotheses are proposed:

H8: Product presentation in a rich medium will elicit more positive aesthetic responses to the product compared to a simpler medium.

H9: Product presentation in a rich medium will elicit more positive perception of usefulness compared to a simpler medium.

H10: Product presentation in a rich medium has a positive effect on perceived ease-of-use compared to a simpler medium.

\section{3. 6. The Influence of Media Richness on Users' Affective Response}

Users' affective response to product advertisement has been studied in consumer research (Batra \& Ray, 1986; Chaudhuri \& Buck, 1995; S. S. Liu \& Stout, 1987; Stout \& 
Leckenby, 1986). Recently, affective response in human-computer interaction has drawn the attention of researchers (Brave \& Nass, 2003; Hudlicka, 2003; McNeese, 2003; Peter \& Beale, 2008; Pfister, Wollstädter, \& Peter, 2011). Moreover, research has provided the evidence that different presentation modalities results in different affective responses to the advertised product (Dijkstra et al., 2005; S. S. Liu \& Stout, 1987). This happens because each sensory mode elicits cognitive and affective responses -that may also influence on responses of other sensory modes (Dijkstra et al., 2005).

Several studies have addressed the concept of affective response from different perspectives. Generally, product presentation via a medium can influence affective responses among users (J. Park et al., 2008). Szymanski and Hise (2000) found that product presentation positively influences user satisfaction. In another study, Batra and Ray (1986) showed that affective responses influence the acceptance of product advertising and brand attitude. Moreover, researchers have examined the role of media format and multimodality on affective responses. For instance, Chaudhuri and Buck (1995) observed that digital media elicit more affective responses compared to printed media which elicits more analytical responses. Pfister et al. (2011) also found that different presentation modalities influence users' affective responses to a computermediated message. Similarly, Adelaar et al. (2003) found different media formats causes different affective responses among users which may lead to impulse purchase behavior.

Aligned with the construct of media richness, Bezjian-Avery, Calder, and Iacobucci (1998) observed a positive correlation between media richness (depth) and affective responses. In a supportive study, (Simon \& Peppas, 2004) observed a more positive 
attitude toward the product and also a higher level of user satisfaction due to the product presentation through a richer medium. However, several studies found significant results for complex products, but for simple products the results were inconclusive. For example, E. J. Lee, Lee, and Schumann (2002) found that media richness (breadth) in product presentation is more effective for innovative products.

In the context of virtual shopping, Li, Daugherty, and Biocca (2003) state that product presentation in 3D can elicit affective responses similar to product presentation in reality. Therefore, we expect that product presentation with a richer 3D medium elicits more positive affective responses. Based on this assumption, the last hypothesis of the present study is proposed as:

H11: Product presentation in a rich medium elicits a greater affective response to the product compared to a simpler medium.

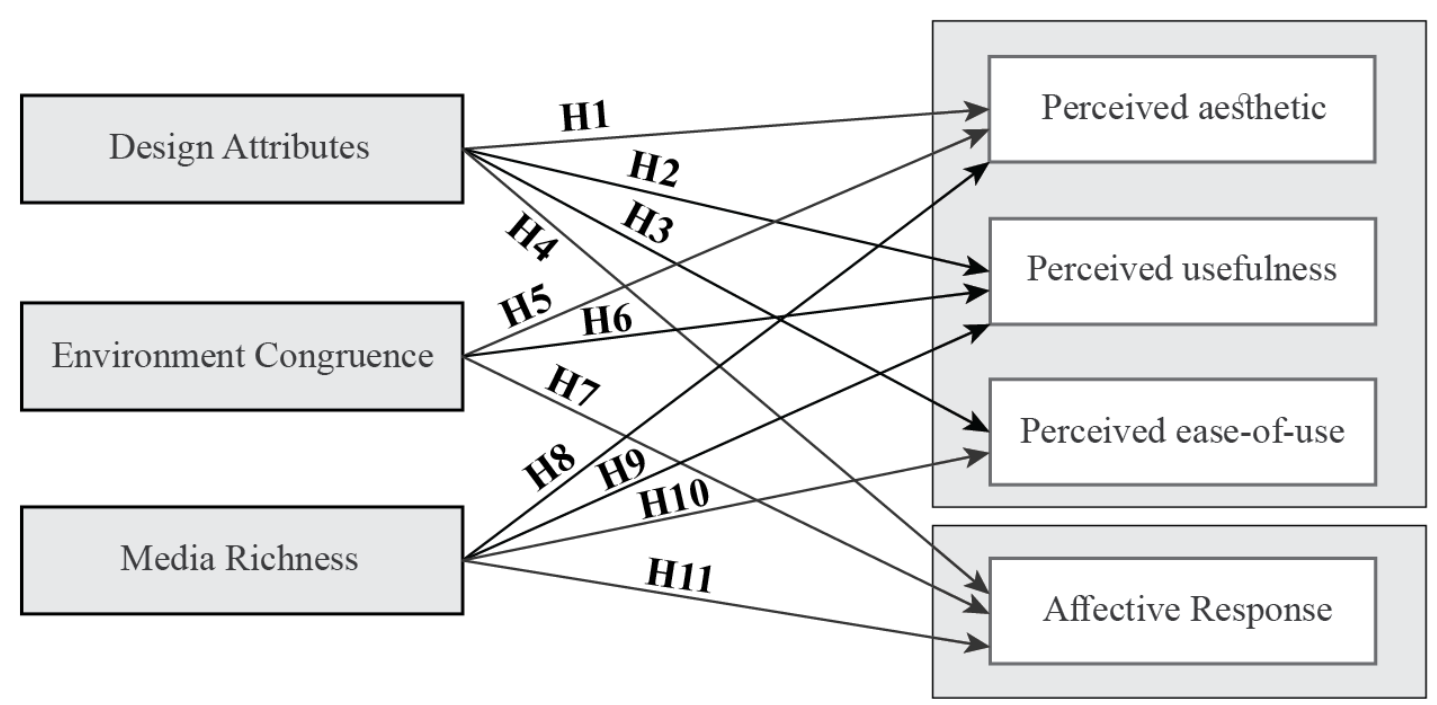

Figure 2: Summary of hypotheses 


\section{CHAPTER 2: RESEARCH METHODOLOGY}

This chapter elaborates on the research methodology including operationalization of concepts. It also provides a detailed description of the experimental design, stimulus, study protocol, and measures for dependent variables.

\section{1. Research Design}

A controlled experiment was determined as the most effective approach to address the research questions and hypotheses outlined in the previous chapter. A controlled experiment using a 2 (high-level design cues vs. low-level design cues) x 2 (congruent product display vs. non-congruent product display) x 2 (virtual reality Head-mounted Display (HMD) vs. 2D display) a between-subjects, full-factorial design was used in this study. Participants were randomly assigned into different combinations of the three independent variables (product design cues, product display congruence, and media richness) and their impact on the four dependent variables (DVs) were systematically measures as shown in table below.

\begin{tabular}{|c|c|}
\hline Independent Variables & Dependent Variables \\
\hline$\bullet$ Product Design Cues & $\bullet$ Perceived Aesthetic \\
$\bullet$ Product Display Congruence & $\bullet$ Perceived Usefulness \\
\hline Media Richness & $\begin{array}{l}\text { - Perceived Ease-of-use } \\
\end{array}$ \\
\hline
\end{tabular}

Table 1: Variables of study 
Each independent variable was implemented at two categorical levels. The resulting experiment design had eight different conditions given three independent variables, each at two levels, see Table 2 .

\begin{tabular}{|c|c|c|c|c|c|}
\hline & & \multicolumn{4}{|c|}{ Product Design Cues } \\
\cline { 3 - 6 } & & Lower quality product design & \multicolumn{2}{|c|}{ Higher quality product design } \\
\cline { 3 - 6 } & $\begin{array}{c}\text { Congruent } \\
\text { Environment }\end{array}$ & $\begin{array}{c}\text { Non-congruent } \\
\text { Environment }\end{array}$ & $\begin{array}{c}\text { Non-congruent } \\
\text { Environment }\end{array}$ & $\begin{array}{c}\text { Congruent } \\
\text { Environment }\end{array}$ \\
\cline { 2 - 6 } Richness & $\begin{array}{c}\text { High Media Richness } \\
\text { (HMD) }\end{array}$ & 1 & 2 & 3 & 4 \\
\cline { 2 - 6 } & $\begin{array}{c}\text { Low Media Richness } \\
\text { (2D Screen) }\end{array}$ & 5 & 6 & 7 & 8 \\
\hline
\end{tabular}

Table 2: Experimental conditions

\subsubsection{Experimental Setting}

The study was conducted at the Immersive Visualization Lab (iLab) in the Department of Architectural Studies at the University of Missouri. Two virtual reality testing workstations were set up to test the two levels of media richness. The Oculus Rift CV1, powered by an Alienware laptop PC was set up to for high level of media richness (Stereoscopic 3D) and a Sony 55" Full HD 1080 TV, powered by a Dell Precision 3600 Desktop PC and an Xbox controller were used to address the low level of media richness $(2.5 \mathrm{D})$.

\subsubsection{Stimulus}

A point-\&-shoot digital camera was selected as a stimulus of this study because users need further information in 3D environment to examine the mechanical aspects of this type of products ( $\mathrm{Li}$ et al., 2003). In addition, when users look at a camera from certain 
view angle, the product is occluded (Leder et al., 2007). Therefore, the 3D model of two point and shoot digital cameras were developed using SolidWorks and 3D Studio Max. They were carefully designed based on dimensions of an existing product platform, the Canon PowerShot S100. The overall dimensions of the designed product are width: 4.3", height: 2.8 ", depth: 1". The 3D models were pre-tested for the level of complexity, functionality perception and aesthetic.

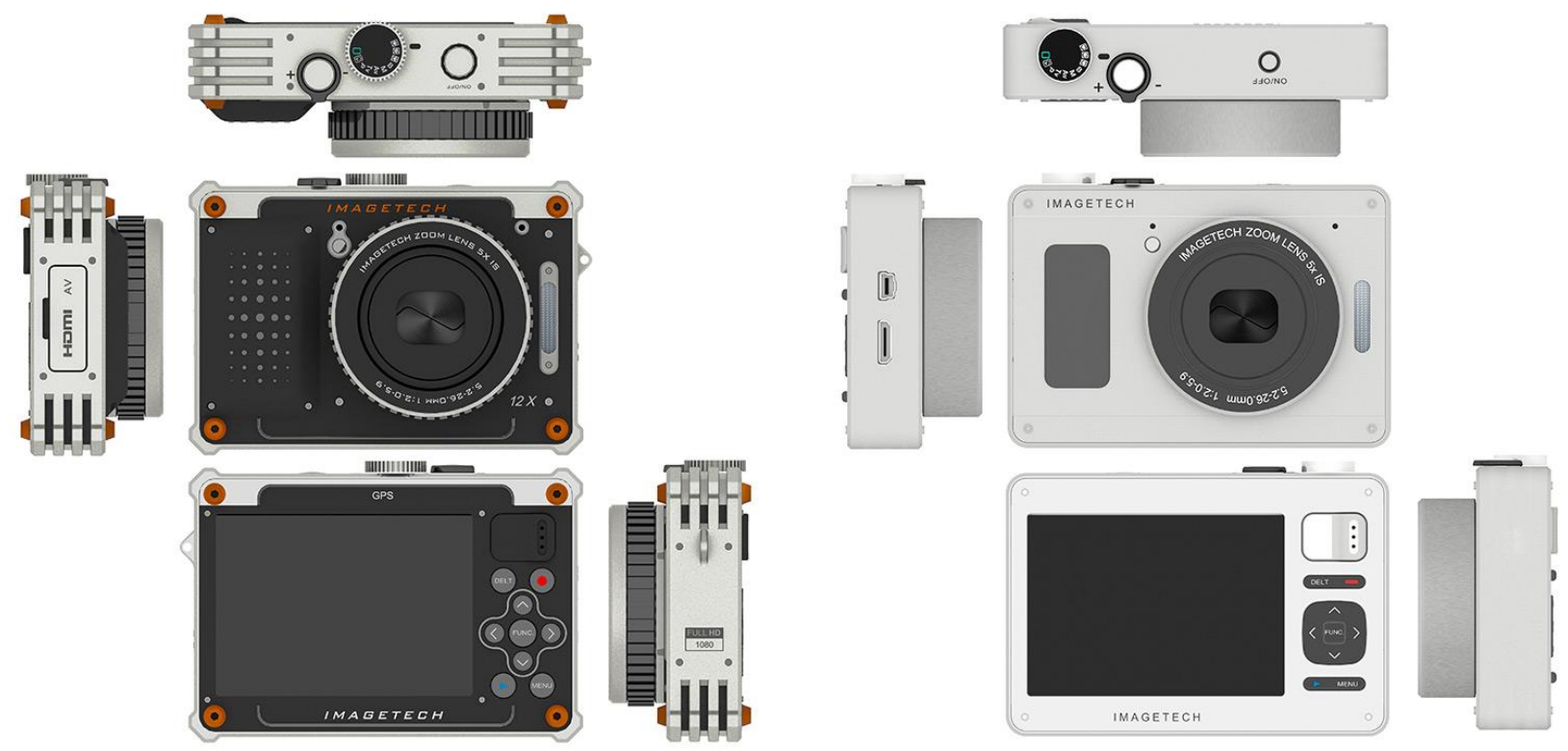

Figure 3: Stimuli for product design cues: higher-quality design (left) vs. Lower-quality design (right) 


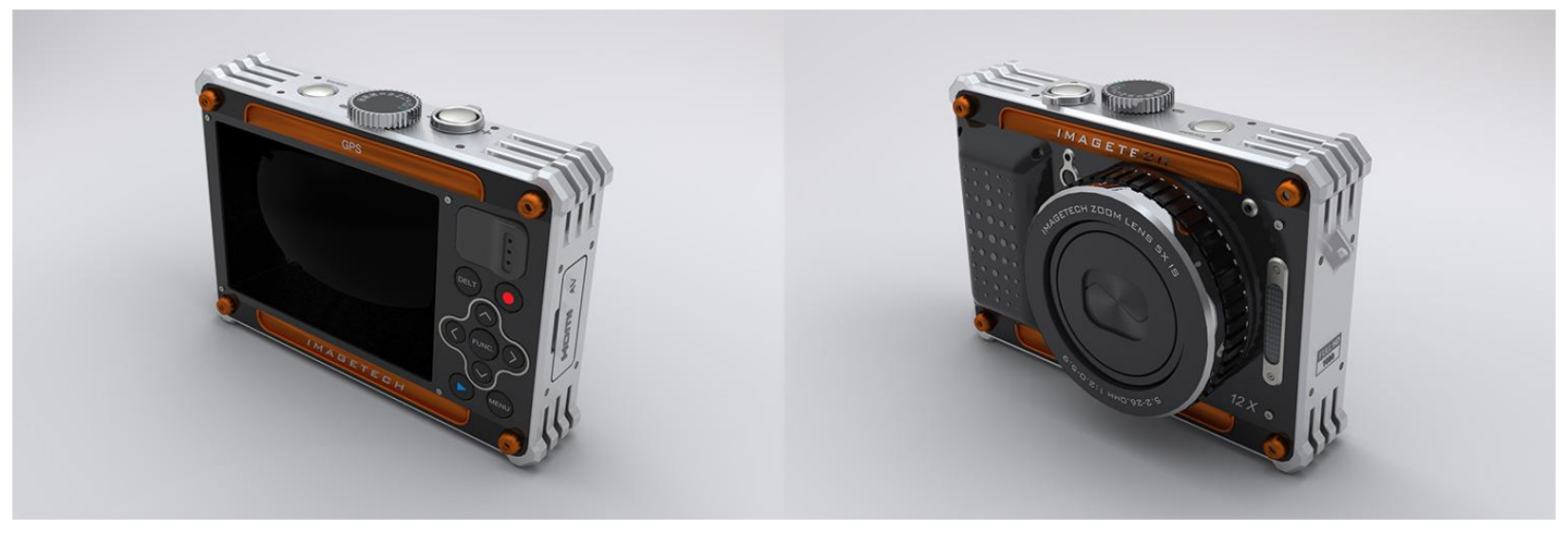

Figure 4: Product design cues: higher-quality design condition (perspective view)

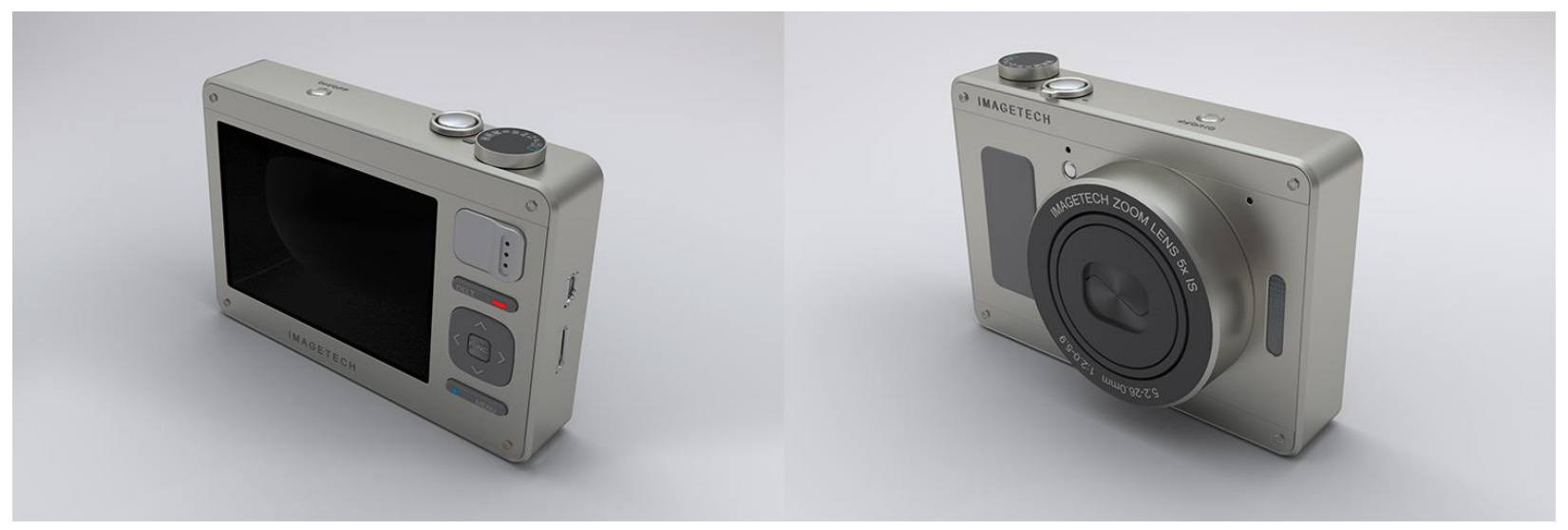

Figure 5: Product design cues: lower-quality design condition (perspective view) 


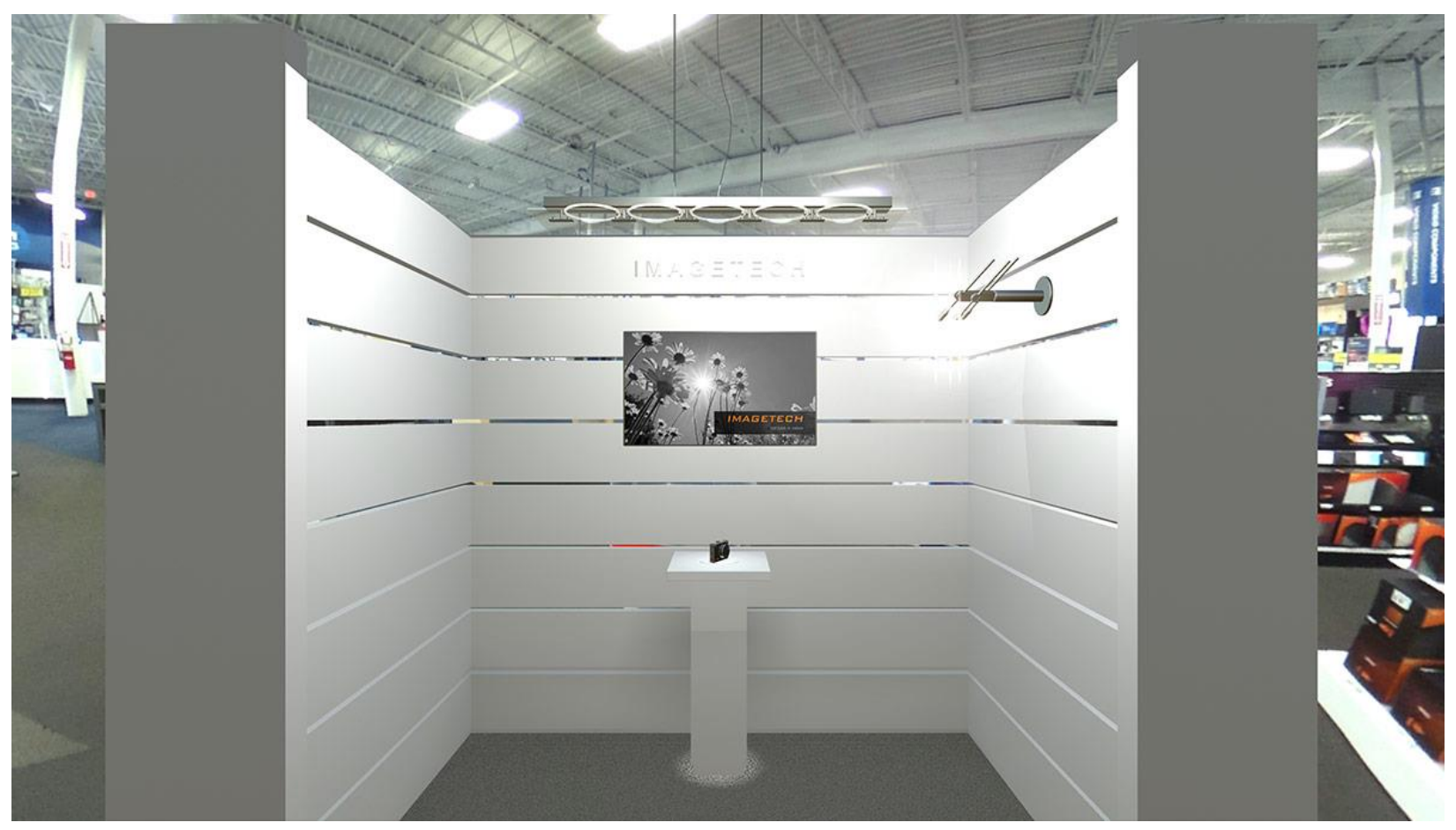

Figure 6: Non-congruent (generic) environment | low and high quality product design

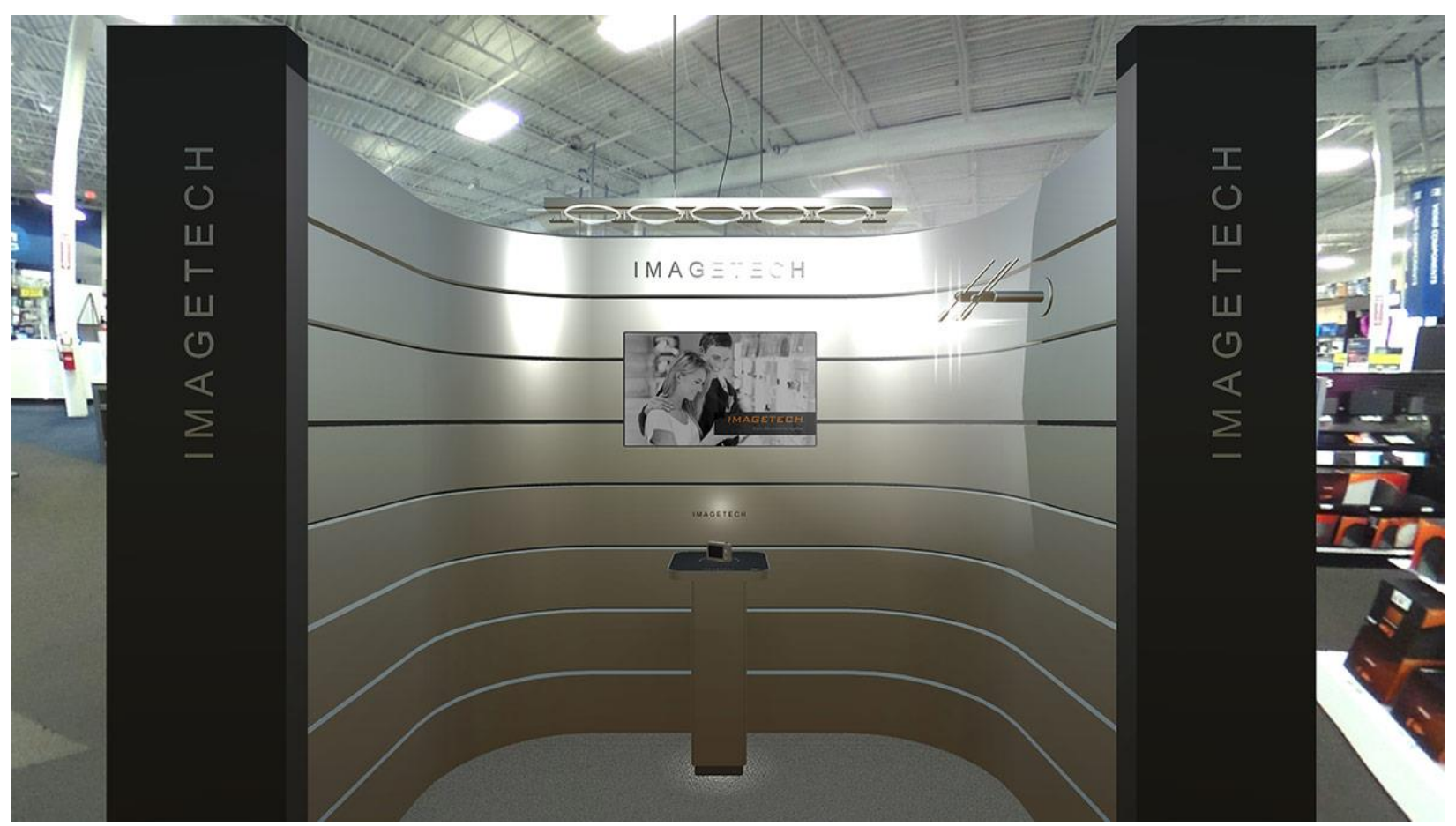

Figure 7: Congruent environment with lower-quality product design 


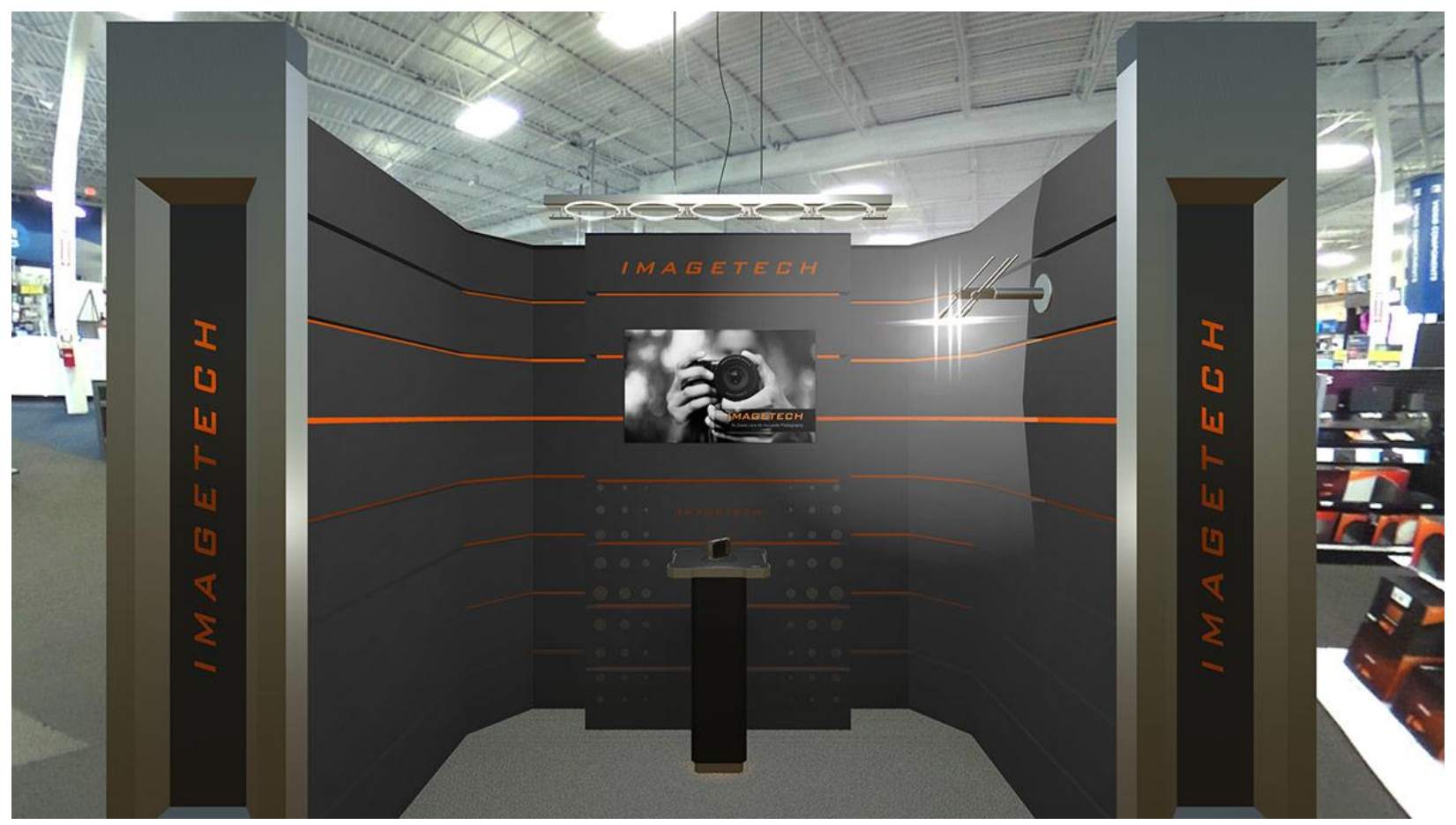

Figure 8: Congruent environment with higher-quality product design

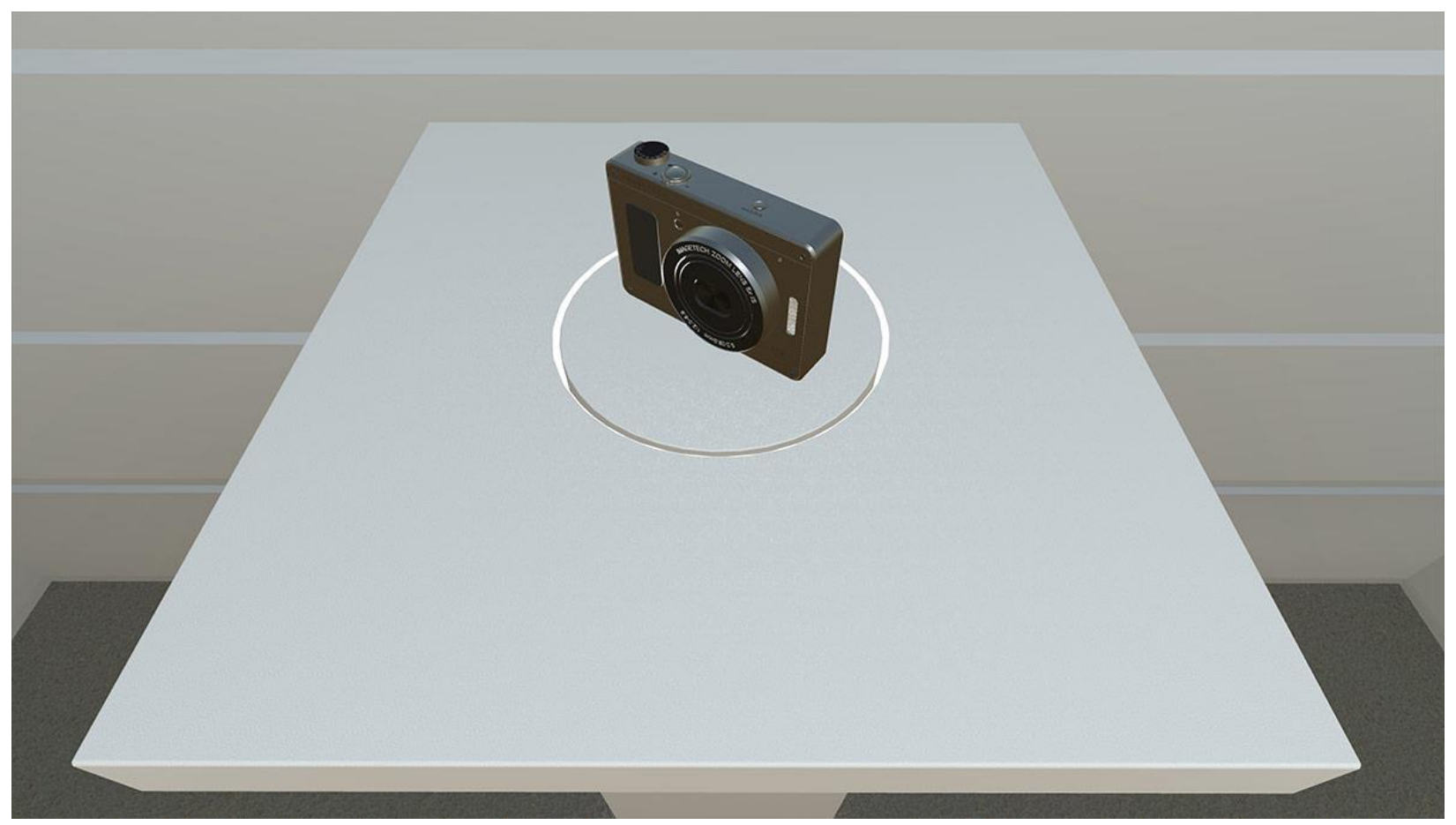

Figure 9: Non-congruent (generic) product display 


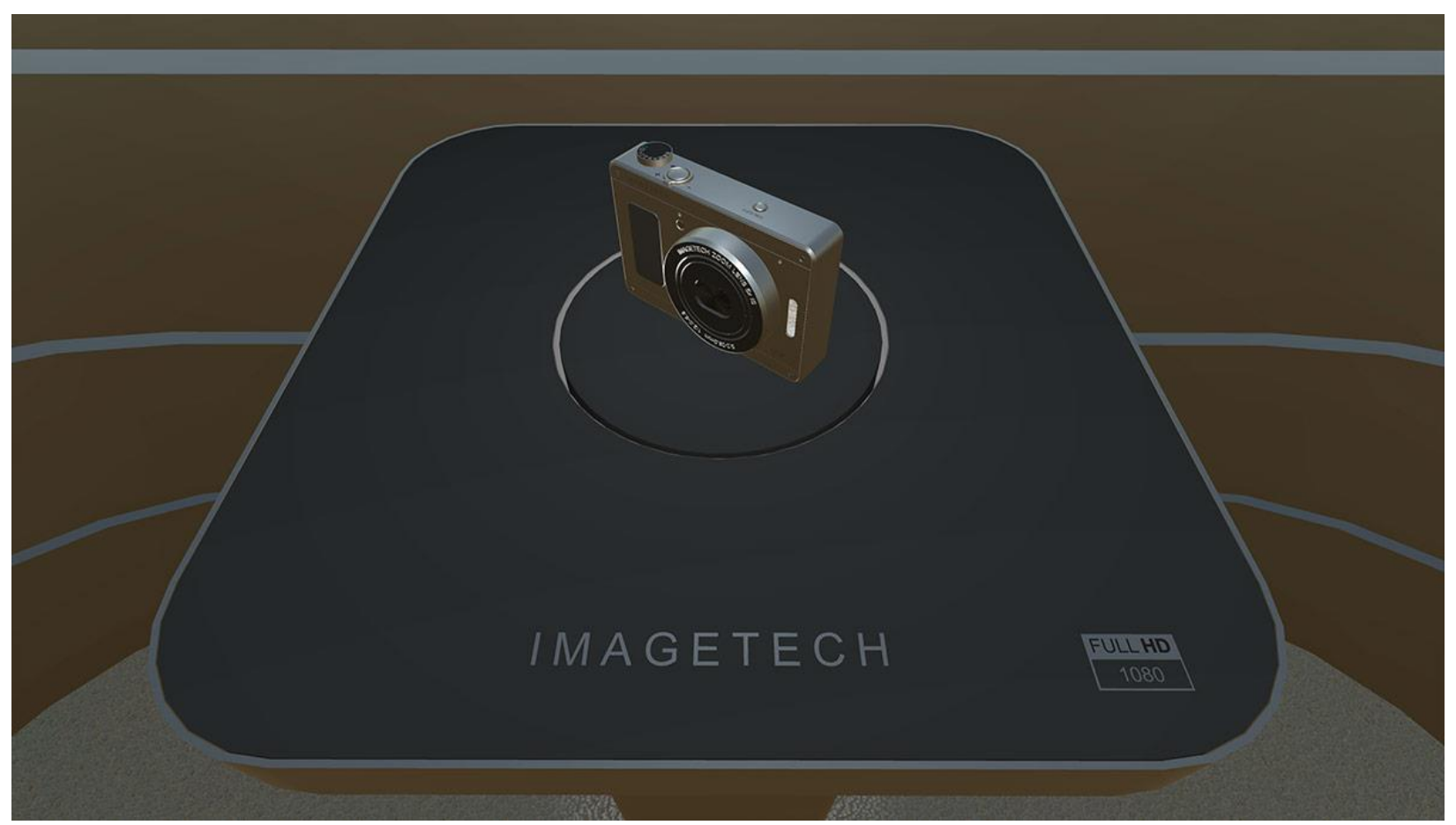

Figure 10: Product display: congruent with lower-quality product design

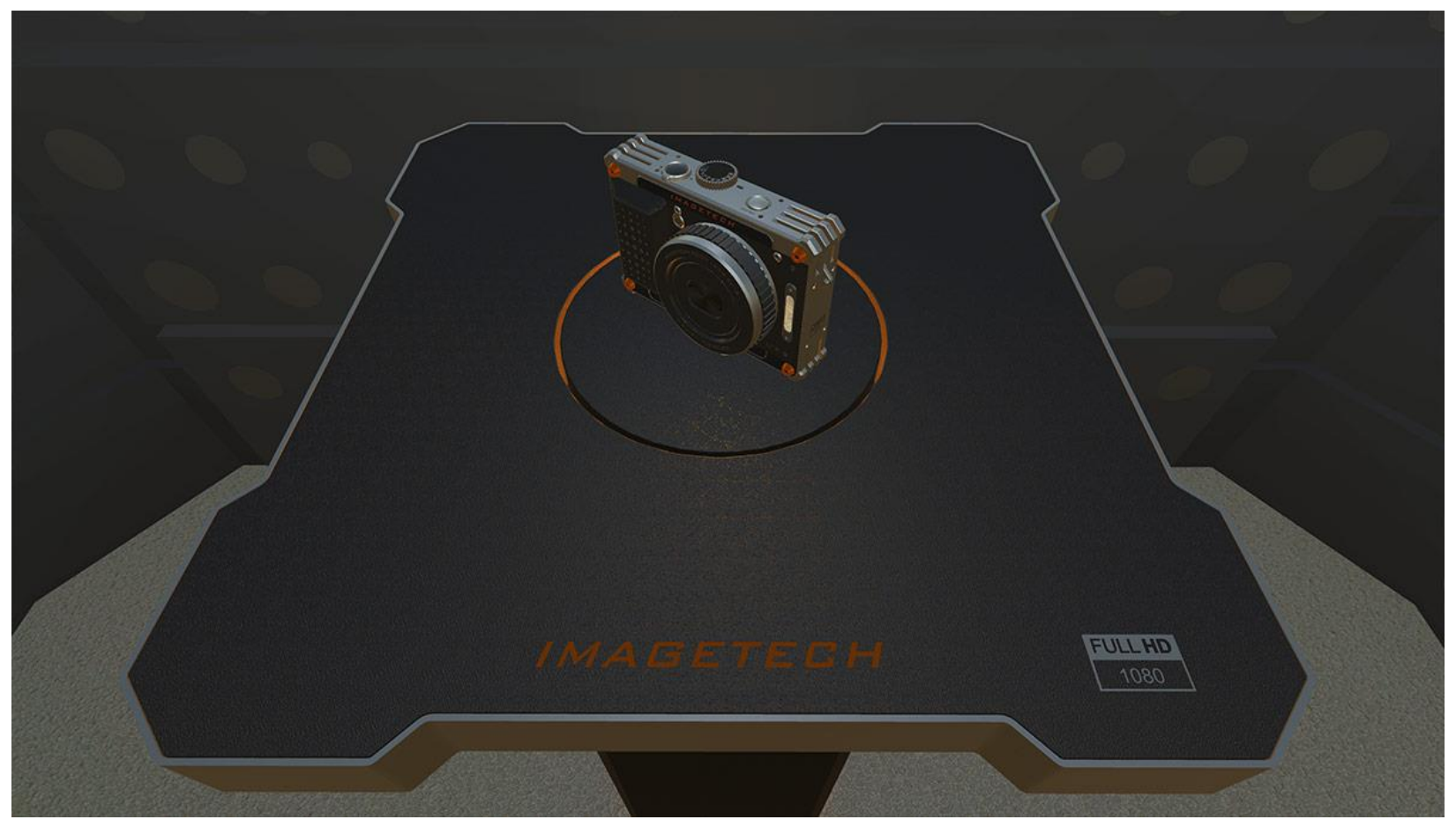

Figure 11: Product dis play: congruent with higher-quality product design 


\section{2. Operationalization of Independent Variables}

In this section, the independent variables of the study were assigned meanings by specifying the activities or operations necessary to measure or manipulate them.

\section{2. 1. Operationalizing Product Design Cues}

While the product appearance is defined as a mixture of several visual characteristics which are employed "to a achieve particular sensory effect" (p. 17) (Bloch, 1995; Hollins \& Pugh, 1990), the product design cues refer to certain tangible and intangible characteristics of the product which shape the appearance and meanings (S. Lee et al, 2011). Kotler and Rath (1984) define the design cues in the comprehensive context of business, manufacturing, and design. They identified five aspects of product design cues: (a) performance: which is associated with product functions; (b) quality: which is communicated through the visual feature of product craftsmanship and materials. (c) durability: which means the product should show a certain level of durability and reliability. (d) appearance: which is the most important aspect of design that indicates the visual desirability of the product. (e) cost: the product should exhibit the product class and category of the price range. But, other researchers went further in detail and identified different visual attributes of product design. There is an agreement about certain visual characteristics such as shape, size, proportion, materials, texture, reflectiveness, color, ornamentation, and graphic (Bloch, 1995; Hollins \& Pugh, 1990; Lawson, 2006; Noble \& Kumar, 2010). Blijlevens et al. (2009) added symmetry, orientation, and weight to the collection of physical properties of the product. Pye (1978) included product craftsmanship as another visual element of design. For this study, the 
product design attribute was operationalized through four different visual characteristics of product including form, texture/material finish, color, and typography style.

\section{2. 2. Operationalizing Environment Congruence}

A promotional environment is a complex configuration of several design elements which are hard to insolate in controlled experiments. Borrowing from the construct of atmospherics, this dissertation takes the environment as an important extrinsic cue which influences user cognitive and affective response to product. However, to reduce the aforementioned risk of research validity, the concept of environment was operationalized be the product presentation environment in the virtual shopping context. The promotional environment in this study refers to a virtually built environment which is used in online virtual stores to display and introduce the product to potential users.

Fiore et al. (2000) define a product display as a carefully designed presentation of a specific product in a well-defined area (e.g., storefront window or at the end of aisle), "highlighting the products and creating a mood and message with the intent to positively affect consumers' approach responses" (p. 29). Omar (1999) identified three types of displays including product display, point-of-sale display, and architectural display (as cited in (Kerfoot et al., 2003). Fiore et al. (2000) operationalized their research positing that product display works as part of a general store environment. A product display has similar components of a retail environment -such as form, color, texture, props, information, lighting, etc. - which are designed to elicit affective responses. In marketing and visual merchandising literature, the elements and characteristics of product display have been identified as the layout, fixtures, product, presentation medium, and 
color (Kerfoot et al., 2003), complexity and information rate (Spies et al., 1997), as well as color, style, and texture (Wu et al., 2013). Bloch et al. (2018) identified some characteristics of environmental design such as privacy, safety, spatial comfort, and aesthetic which were preferred by users in response to the promotional environment.

Bloch et al. (2018) identified four important components of design which are also considered as important elements of store design by retailers. These four elements are: level of detail, color, display layout, and overall form. In environmental psychology, the level of details refers to the complexity of environment (Kaplan, 1982). Color in environment influences users' perception of time, space, and perceived level of comfort (Tofle, Schwarz, Yoon, \& Max-Royale, 2003). It is also the key factor in eliciting users' affective responses (Bellizzi \& Hite, 1992; Seva \& Helander, 2009). Although, the role of color as an atmospheric cue has been studied as in-store environment research, it has not been investigated as an important design element of product displays (Bellizzi \& Hite, 1992; Wu et al., 2013). Form and layout refer to overall shape, configuration, and the relationship among physical elements of the environment. Particularly, (Fiore et al., 2000) argue, product display, consists of several design elements including background structure, fixtures, props, signage, lighting, and music which provide a comprehensive experience with users. For this study, four visual characteristics of environment were chosen to be manipulated to match the product design in the congruent condition and made to differ in non-congruent conditions. These include form, color, signage (typography), and lighting. 
The second independent variable, congruency of environment with a product, was manipulated by form, color, typography (graphic), and lighting. The product presentation environment was virtually developed with dimensions of $8^{\prime} 2 \frac{1}{2} 2^{\prime \prime}$ width, $8^{\prime} 2 \frac{1}{2}{ }^{\prime \prime}$ length, and 8 ' $2 \frac{1}{2}$ " height. A product stand was also virtually built with a 18 " x 18 " platform and 37 " height. In addition, to increase the ecological validity of research by increasing level of realism, a 360 photo of an electronic retail store was used in the background of the presentation environment.

\section{2. 3. Operationalizing Media Richness}

This dissertation focuses on depth of media richness as an important dimension of visual modality in product presentation. We define the depth of modality as amount and quality of visual information which is conveyed through different $3 \mathrm{D}$ product presentation media. Steuer (1992) identified media richness as an important factor of product advertising in 3D. In a related study, S. F. Liu et al. (2015) identified two types of product presentation modes: the static mode that refers to static content which is presented on a 2D screen and the dynamic mode that refers to the three-dimensional presentation in an interactive system which responds to user operation. In this study, stereoscopic 3D was the key factor of media richness construct. We manipulated media richness by employing a stereoscopic 3D head-mounted display for the high level of media richness that represents a dynamic mode of 3D presentation. On the other hand, for the low-level media richness condition, a 2.5D static mode of three-dimensional presentation was used. 


\subsection{Measurement of Dependent Variables}

Data for the dependent variables were collected through self-report and post-test measures. These correspond with the four intended dependent variables: perceived aesthetic, perceived usefulness, perceived ease-of-use, and affective response. With virtual reality research, self-report a well-established method for collecting data about user experiences. Several well-established instruments were adapted for each variable as described below. Please see appendix-E for the complete set of measures.

\section{3. 1. Measures of Cognitive Response}

This study measured the perceived aesthetic using Lavie and Tractinsky's (2004) Perceived Visual Aesthetic Scale. Five items of this scale (9-point Likert Scale) were used. It included questions such as "I found the design of the digital camera pleasant." In addition, three items were borrowed from Mathwick, Malhotra, and Rigdon (2001) to capture the perceived aesthetic. The perceived usefulness was captured using six items of Davis's (1989) 9-point semantic differential scale (extremely likely - extremely unlikely). Participants were asked to rate the statements about the effectiveness and performance of the product, for example, "Using this digital camera would enhance my effectiveness on digital photography." The perceived ease-of-use was measured using six items on a 9-point semantic differential scale (extremely likely - extremely unlikely) developed by Davis (1989) and one item from Childers, Carr, Peck, and Carson (2002). These items are more focused on learnability and understandability of product operation. For example, participants were asked to rate the clarity and understandability of interacting with the digital camera. 


\section{3. 2. Measures of Affective Response}

The affective response was measured by adopting three items (9-points Likert Scale: strongly agree - strongly disagree) from the scale developed by Desmet (2012). These items captured the overall positive feelings of participants toward the product. For instance, they were asked to rate the following statement: "Owning/using this digital camera evokes love."

In addition, three items (9-point semantic differential scale) of Pleasure and Arousal scale developed by Mehrabian and Russell (1974) and one item on a 9-point Likert Scale adapted from International Positive and Negative Affect Scale (Thompson, 2007) were used to capture the negative and positive feelings. For instance, subjects were asked to rate their level of sadness or happiness caused by interacting with the camera.

\section{3. 3. Other Measures}

In addition to the dependent variables of cognitive and affective response, several demographic variables were gathered through self-report methods as potential control variables. All scaled measures were in a 1-9 Likert-type format with strongly agree or strongly disagree or similar adjectives as opposite ends. The importance of aesthetics for each person was measured using five items of Centrality of Visual Product Aesthetic scale (CVPA) developed by Bloch et al. (2003) as a control variable. The demographic variables of gender, academic standing, and major of study were used as the control measures. Participant skill levels may vary and are controlled through a training session before data collection. In addition, previous experience with virtual reality and 3D 
systems, video games/computer games, and technology were assessed using a self-report component within the demographics portion of the questionnaire. Familiarity with 3D and video games consisted of four items developed for this study on a 9-point Likert-type format (e.g., How familiar are you with playing video games on Xbox, PlayStation, Nintendo, or PC?).

Three items on a 9-point Likert-type format were designed to measure if respondents in different conditions evaluated environment congruence (e.g., I found visual similarities between the design of digital camera and the design of product display environment) and product design qualities differently. Five items on a 9-point Likert scale were adopted from the User Satisfaction scale (Lund, 2001) to capture the user experience with the virtual reality system (e.g., I am satisfied with using this virtual reality system). To capture the sense of presence as a potential confounding variable of this study, three items from self-location (e.g., I felt as though I was physically present in the store environment I just viewed.), four items from possibilities of action (e.g., I felt like I could move around among the objects in the store display environment I just viewed.), and five items from experience of reality (e.g., To what extent was what you saw in the virtual world was similar to reality?) were added to the survey. Finally, five items on a 9-point Likert-type format were added to capture the purchase intention (e.g., I would buy this camera if I were in the market for a digital camera.)

\section{4. Experimental Manipulations}

The manipulations for each of the independent variables were implemented independently. The product design attribute was changed manually by replacing the 
virtual stimuli depending on the condition being presented. Participants in low-level design cues condition were asked to evaluate the point and shoot digital camera with lowdesign cues. On the other hand, participants in high-level design cues condition were asked to explore the point and shoot digital camera with high-design cues.

Based on a review of literature, several visual features of product design cues were identified. They include form and geometry, size, color, texture, material, reflectiveness, graphic (Bloch, 1995; Hollins \& Pugh, 1990; Lawson, 2006; Noble \& Kumar, 2010), craftsmanship (Pye, 1978), symmetry, orientation (Blijlevens et al., 2009), as well as intrinsic product design attributes such as performance, quality, durability, appearance, and cost (Kotler \& Rath, 1984) which are associated with the aforementioned visual cues. Then, four design cues were manipulated including form, texture, color, typography (graphic) - high vs. low product design condition - on the virtual prototypes to make sure that other variables are consistent across the two versions. To neutralize the negative effect of separate presentation of product cues on participants' over-rating (Enneking et al., 2007), we manipulated those four product design cues and presented them to participants at the same time.

To manipulate the congruency of product environment, color, form, typography (graphic), and ambient lighting were changed. For non-congruent condition, a generic product presentation station was designed with cubic/rectangular form in white color combined with white fluorescent ambient lighting. In the congruent condition, the overall form of product presentation environment, color, and typography (graphic) and ambient lighting were matched with the visual cues of the product. 
The media richness manipulations were implemented using Oculus Rift CV1 headmounted display for high-level media richness condition (Stereoscopic 3D), and a 70 inch UHD TV for low-level media richness condition (2.5D).

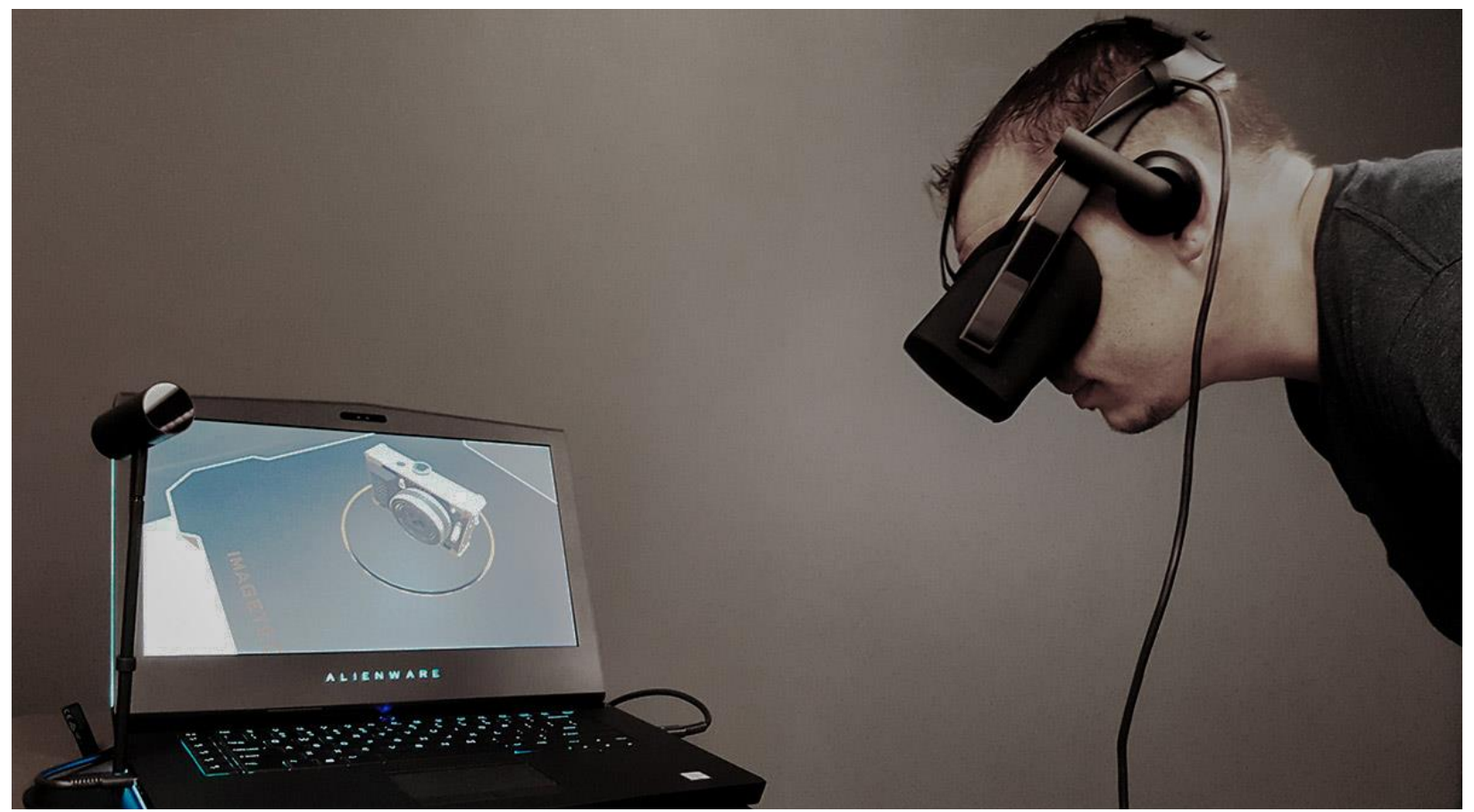

Figure 12: Oculus Rift CV1 head-mounted display is used for higher-level of media richness condition 


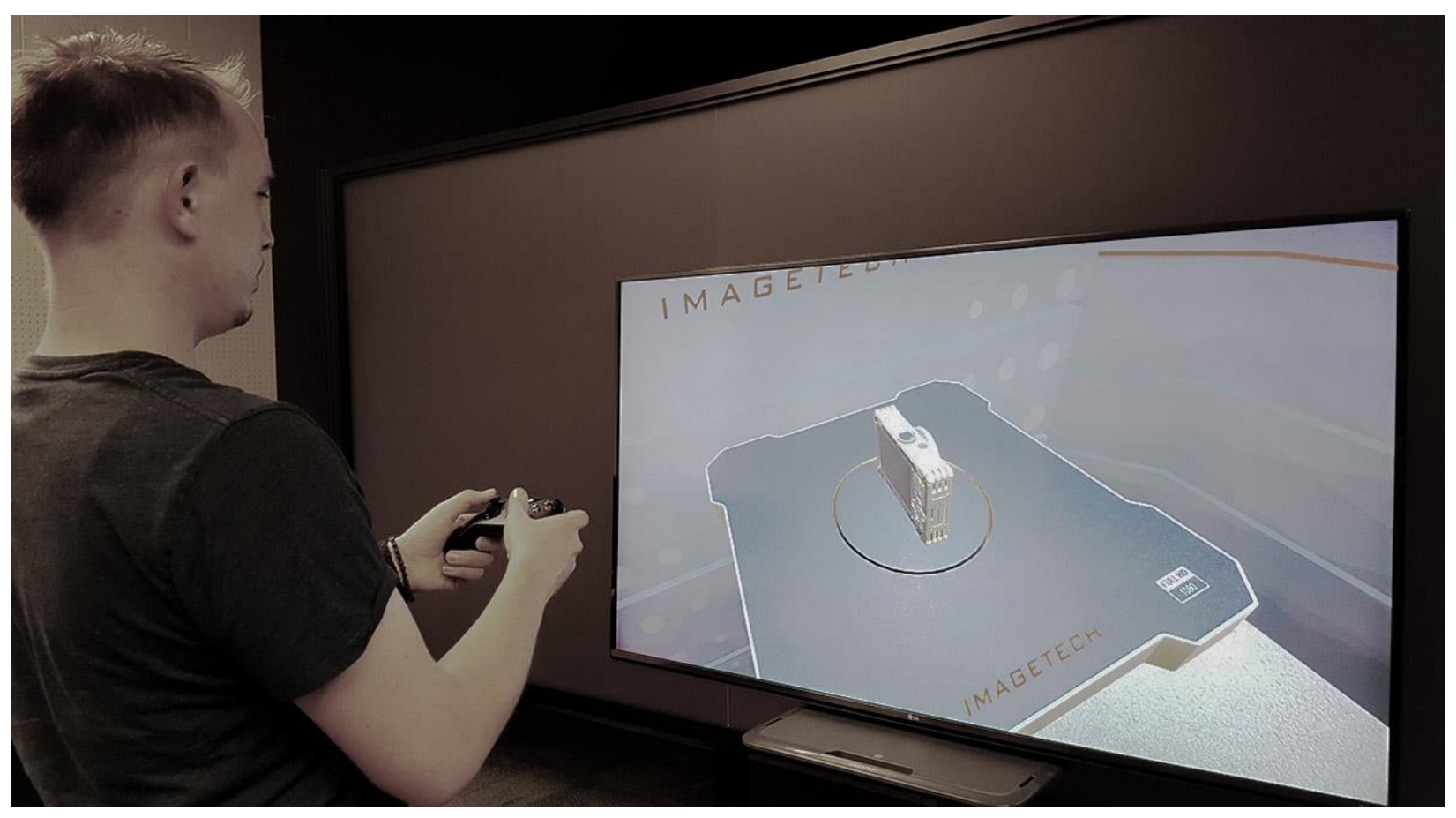

Figure 13: A 70 inch UHD TV is used for low level of media richness condition

\subsection{Sample}

Students enrolled in graduate and undergraduate level classes at a mid-western university were asked to participate in the study for an approximately 20-minute session. Students volunteered to participate in the study with no compensation. They were randomly assigned to one of the eight experimental conditions. The sample $(\mathrm{N}=181)$ consisted of 30 students who were architectural studies majors and minors while 151 were nonmajors. Participants were recruited from 44 different majors and 11 colleges. The class standing of the students consisted of 1 freshman, 12 sophomores, 68 juniors, 45 seniors and 55 graduate students. 


\subsection{Pre-Testing}

The experimental manipulations, as well as the measures, were pre-tested before the final study conducted to make refinements to manipulation of independent variables and questionnaire items. Pre-testing was conducted with eight graduate and undergraduate students from different colleges. Using this diverse group provided insight into how participants from different disciplines would react to each component of the study so that refinements could be made.

\section{7. Experiment Procedure}

A detailed research protocol (see appendix A) was developed with verbal scripts for instructions to ensure consistency and avoid researcher bias. Following the scripted protocol, participants were greeted and briefed about the study. Once the participants indicated that they understood study details and what is expected from their participation, formal verbal consent (see appendix B) was obtained in compliance with the Institutional Review Board approval. The study procedure included five main parts: filling out a demographics questionnaire, training on the Oculus Rift head-mounted display or the

joystick, listening to the narrative for task instructions, performing the task, and filling out the post-test questionnaire.

\subsubsection{Joystick Training}

When the participant had completed the first questionnaire, there was a short training session on how to use the joystick as well as to screen the participant for issues with 
simulator sickness. The training session lasted approximately two minutes until the participant could confidently navigate with the joystick. The participant was shown how the joystick worked as well as how to handle any issues he/she may encounter when using the joystick.

Once the instruction for using the joystick was finished, the participants were asked to use the joystick to move around a virtual environment freely. During the free exploration, more explanation and tips on use of the joystick were provided. In addition to the explanation and tips, the participant was prompted to make use of all the different movements the joystick condition provided. The training environment was a simple product presentation environment with minimal complexity and decoration.

\subsubsection{Study Task}

Participants were asked after the training if there were any further questions or concerns before moving on to the main task. Once the participant indicated there were no more questions or issues, the task procedure was explained. To aid with psychological immersion, it was important to help the participants maintain attention on the task. A scripted narrative was presented using a paper copy to provide details of the task to the participant. The script provided participants with the task details in written format.

Following the splash-screen, the environment for the task was loaded and participants were told they could start the task. The instructions indicated there was a five minute time limit. The five minute time limit was used to help control for the amount of time spent in the environment so it would remain consistent for all participants. The task started out at 
the entrance of the product presentation environment which was located at a consumer electronics retail store. 


\section{CHAPTER 3: ANALYSIS \& RESULTS}

This chapter reports the results of data analysis from the experiment. The first section discusses data screening and testing for assumptions. The next sections details the results of statistical tests to address the research question and hypotheses. Specifically, this study investigated the influence of media richness, product design, and environment congruence on cognitive and affective response to product design. The analysis was conducted using SPSS statistical analysis software. To address the overall research question and hypotheses, several statistical tests were conducted on each of the dependent measures.

\section{1. Sample Characteristics and Demographics}

Participants $(\mathrm{N}=181)$, aged between 18 and 52 years $(M=23.90, \mathrm{SD}=6.25)$, with 103 (56.9\%) males and $78(43.1 \%)$ females from a mid-western university volunteered to participate in this study. They included one freshman, 12 sophomores, 68 juniors, 45 seniors, and 55 graduate students from 42 different majors. A total of 30 students were architectural studies majors with 151 non-majors.

\section{2. Data Screening}

Before testing the hypotheses, the data was first screened for missing data and outliers, both univariate and multivariate. A total of two missing data points were found across the dependent variables and covariates. Missing data at random due to the subjects' failure to indicate a response were resolved using mean substitution, a method to estimate missing 
values in which missing values were replaced with the mean of the variable (Tabachnick \& Fidell, 2001).

The univariate outliers were detected by visual inspection of histograms with normal curves. In addition, extreme values three standard deviations from the mean were identified (Field, 2013). In some instances, the data showed outliers where the participants' responses were treated as special cases. One single outlier was detected for perceived aesthetics, perceived usefulness, presence, and involvement. Two outliers were detected at perceived ease-of-use and three outliers were detected at CPVA and User Experience. After examining them individually, it was decided to employ the winsorizing method to replace those extreme values (3 Standard Deviation cutoff) to preserve the sufficient power for data analysis (Salkind, 2010). Mahalanobis distance through a chisquare distribution was used to detect multivariate outliers. There were no multivariate outliers. Then, the data were tested for the assumptions of independence of observations, normality and multivariate normality, homogeneity of variance-covariance matrices, measurement error of covariates, linear relationships between covariate and dependent variables, and homogeneity of regression. To test the normality, a visual inspection of histograms, normal Q-Q plots, P-P plots, and box plots were used. The examination showed that all data were normally distributed. Assumptions were checked by visually observing histograms, skewness and Kurtosis values. A summary of the scales means, standard deviations, skewness, and kurtosis are summarized in Table 3.

Table 3: Descriptive statistics

\begin{tabular}{lcccc}
\hline & Mean & Std. Deviation & Skewness & Kurtosis \\
\hline Age & 23.90 & 6.25 & 1.99 & 4.24 \\
Familiarity & 4.83 & 1.59 & .05 & -.52 \\
Involvement & 6.34 & 1.29 & -.40 & -.05 \\
Perceived Aesthetic & 6.16 & 1.67 & -.56 & -.02 \\
Perceived Usefulness & 6.28 & 1.64 & -.64 & .04
\end{tabular}


Perceived Ease-of-use

Affective Response

CPVA

VR User Experience

Purchase Intention

Attention Allocation

Presence

Note Scores were on a scale of 0 to 9.
7.64

5.88

7.10

7.59

5.10

7.19

6.62
1.04

1.48

1.15

1.25

2.06

1.35

1.62
$-1.03$

$-.09$

$-.59$

$-.70$

$-.28$

$-.85$

$-.81$

Scatter plots were used to assess the linearity of the covariates and dependent variables. Homogeneity of variance-covariance matrices was evaluated using Levene's test and Box's $\mathrm{M}$ test. The null hypothesis was rejected for only one dependent variable, the perceived aesthetic. The homogeneity of variance was acceptable after running Hartley's F-Max test with the critical value $<10$ (Levy, 1975). Homogeneity of regression was checked to see if any interaction existed between the independent variables and covariates. There was no significant interaction between the independent variables and covariates. The design of the experiment accounted for having balanced cell sizes, after dealing with the missing data and outliers the cells were still well balanced, see Table 4 .

Table 4: Number of cases per manipulation

\begin{tabular}{|c|c|c|c|c|c|}
\hline \multirow{4}{*}{\begin{tabular}{|} 
Media \\
Richness
\end{tabular}} & \multicolumn{4}{|c|}{ Product Design Cues } \\
\cline { 3 - 6 } & $\begin{array}{c}\text { Low product design cues } \\
\text { High Media Richness } \\
\text { (HMD) }\end{array}$ & $\begin{array}{c}\text { Congruent } \\
\text { Environment }\end{array}$ & $\begin{array}{c}\text { Non-congruent } \\
\text { Environment }\end{array}$ & $\begin{array}{c}\text { Non-congruent } \\
\text { Environment }\end{array}$ & $\begin{array}{c}\text { Congruent } \\
\text { Environment }\end{array}$ \\
\cline { 2 - 6 } & $\begin{array}{c}\text { Low Media Richness } \\
\text { (2D Screen) }\end{array}$ & 22 & 23 & 22 & 23 \\
\hline
\end{tabular}

\section{3. Reliability Analysis for Dependent Variables and Covariates}

Cognitive response was measured using different scales to capture its three dimensions perceived aesthetic, perceived usefulness, and perceived ease-of-use. Indices for these three cognitive response dimensions were constructed by averaging individual items on 
the respective scales. Overall, the indexes created for perceived aesthetic (8 items; Cronbach's alpha $=0.93)$, perceived usefulness (6 items; Cronbach's alpha $=0.92)$, and perceived ease-of-use $(7$ items; Cronbach's alpha $=0.87)$ which formed three dimensions of cognitive response had good internal consistency. The index created for affective response ( 7 items; Cronbach's alpha $=0.86)$ also had good internal consistency. In addition to all dependent variables, indices for other dependent variables and covariates were constructed by averaging individual items on the respective scales and showed good reliability: Centrality of Visual Product Aesthetic (CPVA) (5 items; Cronbach's alpha = 0.76), User Experience (5 items; Cronbach's alpha =0.93), Purchase Intention (4 items; Cronbach's alpha $=0.96)$, Attention Allocation $(3$ items; Cronbach's alpha $=0.81)$, and Presence $(12$ items; Cronbach's alpha $=0.97)$ see Table 5.

Table 5: Reliability for dependent variables and covariates

\begin{tabular}{lccc}
\hline & Cronbach's $\alpha$ & Mean & Std. Deviation \\
\hline Perceived Aesthetic & 0.93 & 6.16 & 1.67 \\
Perceived Usefulness & 0.92 & 6.27 & 1.66 \\
Perceived Ease-of-use & 0.88 & 7.64 & 1.06 \\
Affective Response & 0.86 & 5.89 & 1.50 \\
CPVA & 0.76 & 7.08 & 1.20 \\
VR User Experience & 0.93 & 7.56 & 1.37 \\
Purchase Intention & 0.96 & 5.11 & 2.06 \\
Attention Allocation & 0.81 & 7.19 & 1.35 \\
Presence & 0.97 & 6.61 & 1.63 \\
\hline
\end{tabular}

Since these dependent variables were all measuring some aspect of a user's response, they were moderately correlated as revealed in table 6 given below.

Table 6: Bivariate correlations among cognitive and affective response scales

\begin{tabular}{lllll}
\hline & $\begin{array}{c}\text { Perceived } \\
\text { Aesthetic }\end{array}$ & $\begin{array}{c}\text { Perceived } \\
\text { Usefulness }\end{array}$ & $\begin{array}{c}\text { Perceived } \\
\text { Ease-of-use }\end{array}$ & $\begin{array}{c}\text { Affective } \\
\text { Response }\end{array}$ \\
\hline Perceived Aesthetic & - & & & \\
Perceived Usefulness & $.59^{* *}$ & - & - & - \\
Perceived Ease-of-use & .06 & $.29^{* *}$ & $.15^{*}$ & - \\
Affective Response & $.76^{* *}$ & $.60^{* *}$ & & \\
\hline
\end{tabular}


Note. Significant values are in bold-faced.

$* * p<.01 . * p<.05$.

\section{4. Manipulation Checks}

Manipulation check items were introduced in the questionnaire to assess the effectiveness of experimental manipulations of the independent variables (i.e., the two product design levels and the two levels of environment congruence). A $t$-test was used to determine whether there was a difference in subjects' rating of two different conditions of product design (high vs. low). The results obtained from the $t$-test shows that participants on average rated the design significantly higher score to the higher quality camera design $(M=7.24, S D=1.52)$ compared to the lower quality design one $(M=5.85, S D=1.73)$, $t(179)=-5.78, p<001$. Thus, this manipulation check passes as revealed in Table 7.

\section{Table 7: Independent samples test}

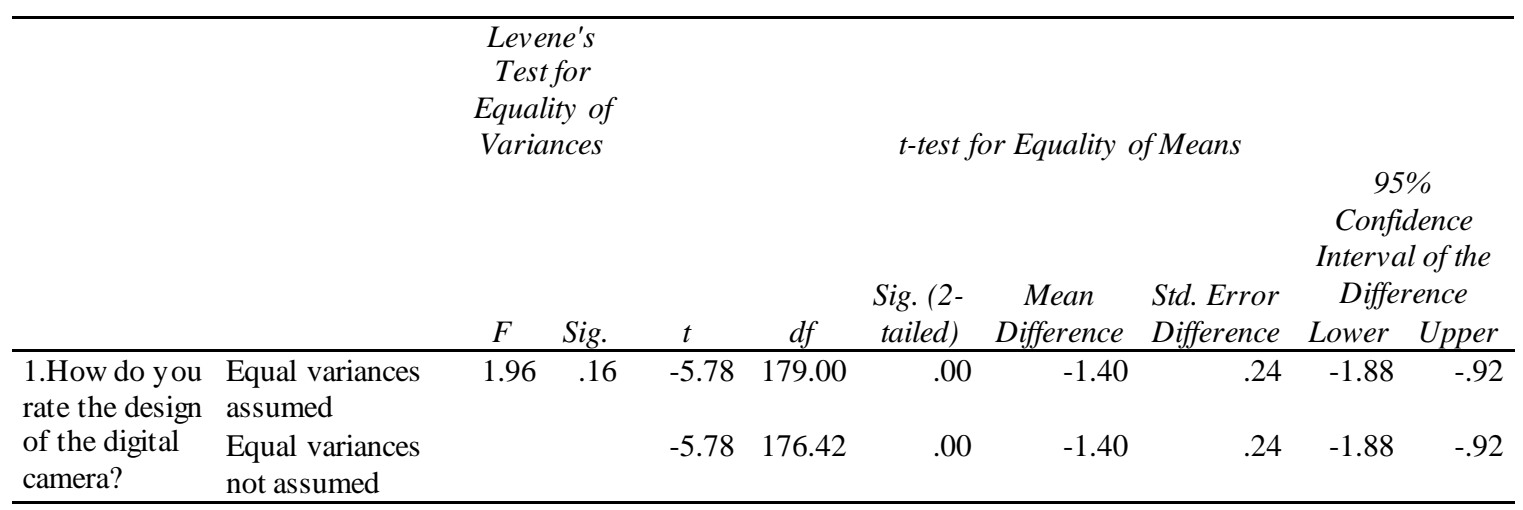

A separate $t$-test was conducted on the environment congruence manipulation check, "I found visual similarities between the design of digital camera and the design of product display environment." The results from the $t$-test confirmed that participants noticed a difference in congruence between the product and the environment. As shown in Table 8, 
non-congruent environment condition received a lower score $(M=6.16, S D=1.63)$ than the congruent environment condition $(M=7.74, S D=1.28), t(179)=-7.25, p<.001$. Therefore, the distinction in perceiving environmental congruence is apparent across the two manipulations.

Table 8: Independent samples test

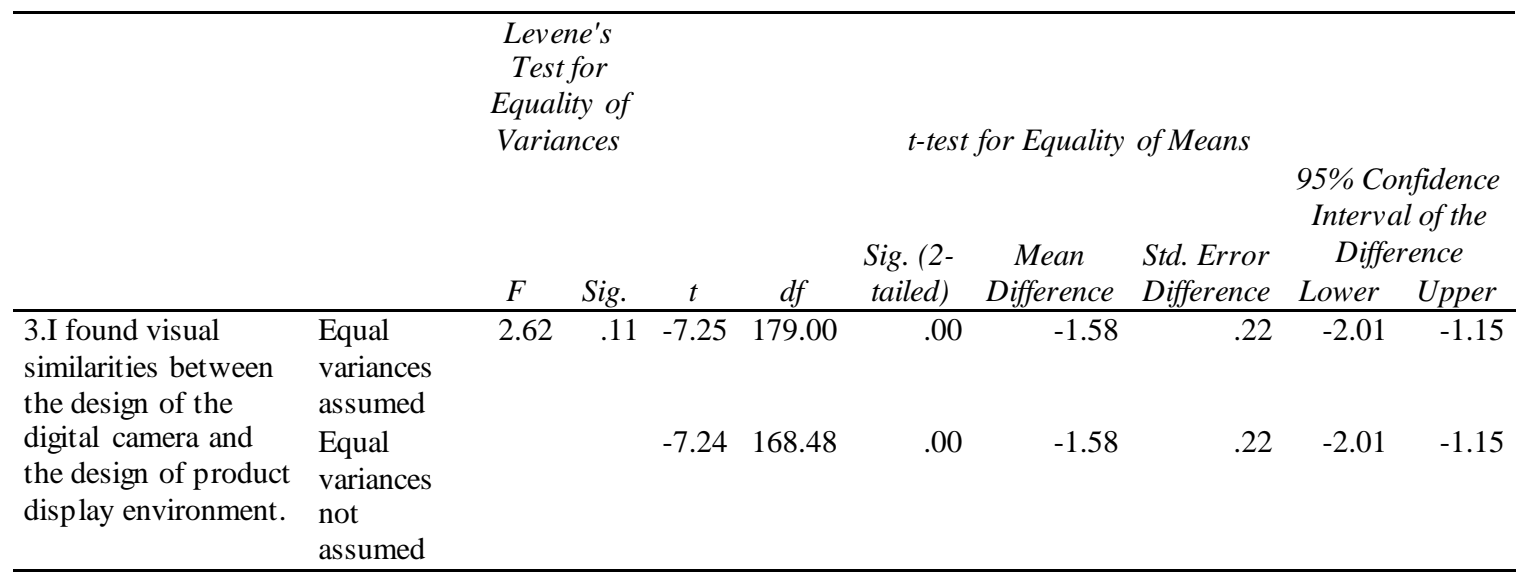

\section{5. Relationship Among Variables}

To conduct the analysis with covariates, it was important to examine the relationship between the dependent variables and covariates. Several bivariate correlations were conducted to examine the strength of the relationship between the variables (see Table 9). These correlations informed the use of covariates for the analysis.

Table 9: Correlations between dependent variables and covariates

\begin{tabular}{|c|c|c|c|c|c|c|c|c|c|c|c|}
\hline Variable & 1 & 2 & 3 & 4 & 5 & 6 & 7 & 8 & 9 & 10 & 11 \\
\hline 1. Familiarity & - & & & & & & & & & & \\
\hline 2. Involvement & $.25^{* *}$ & - & & & & & & & & & \\
\hline Perceived Aesthetic & .07 & $.18^{*}$ & - & & & & & & & & \\
\hline 4. Perceived Usefulness & -.01 & .04 & $.59^{* *}$ & - & & & & & & & \\
\hline 5. Perceived Ease of-use & .09 & .00 & .06 & $.29^{* *}$ & - & & & & & & \\
\hline 6. Affective Response & .01 & $.18^{*}$ & $.76^{* *}$ & $.60^{* *}$ & $.15^{*}$ & - & & & & & \\
\hline 7. CPVA & $.25^{* *}$ & $.30^{* *}$ & $.22^{* *}$ & $.25^{* *}$ & $.21^{* *}$ & $.32^{* *}$ & - & & & & \\
\hline 8. VR User Experience & .00 & .12 & $.46^{* *}$ & $.41^{* *}$ & $.28^{* *}$ & $.53^{* *}$ & $.33^{* *}$ & - & & & \\
\hline 9. Purchase Intention & .10 & $.15^{*}$ & $.71^{* *}$ & $.58^{* *}$ & $.18^{*}$ & $.67^{* *}$ & $.26^{* *}$ & $.42^{* *}$ & - & & \\
\hline
\end{tabular}




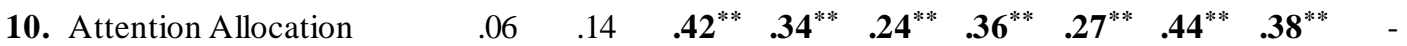

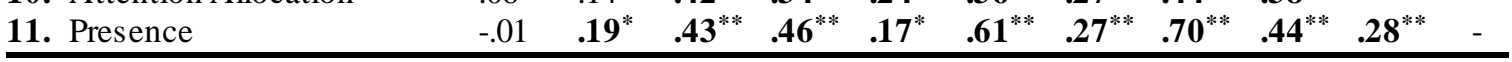

*significant at the $\mathrm{p}<0.05, * *$ significant at the $\mathrm{p}<0.01$.

\section{6. Hypothesis Testing}

The data were examined using the SPSS statistical analysis software for evidence to support the hypotheses at a significance level of 0.05. Multivariate Analysis of Covariance (MANCOVA) used for experimental research designs to test for statistical differences among groups when there are 1) more than one independent variables, 2) one or more covariates incorporated into the design, and 3) multiple correlated dependent variables while controlling for the correlation among the dependent variables (Tabachnick \& Fidell, 2001).

The hypotheses predicted that better design cues, a congruent environment, and richer presentation medium would each result in greater cognitive and affective response to product design among users. A full factorial multivariate analysis of covariance (MANCOVA) was conducted with Attention Allocation and Presence as covariates to evaluate above hypotheses and research question.

The MANCOVA analysis revealed significant main effect for design cues, Wilks' $\lambda=$ $0.808, F(4,168)=9.952, \mathrm{p}<.001$, partial $\eta^{2}=0.192$; a significant main effect for environment congruence, Wilks' $\lambda=0.901, F(4,168)=4.630, p<.05$, partial $\eta^{2}=0.099$; and a significant main effect for media richness, Wilks' $\lambda=0.877, F(4,168)=5.888$, $p<.001$, partial $\eta^{2}=0.123$. The two-way interaction between design cues and environment congruence was also significant, Wilks' $\lambda=0.934, F(4,168)=2.981$, $p<.05$, partial $\eta^{2}=0.066$ indicating that at the multivariate level, two independent 
variables had a combined effect on perceived aesthetic. Attention allocation Wilks' $\lambda=$ $0.835, F(4,168)=8.276, p<.001$, partial $\eta^{2}=0.165$ and presence, Wilks' $\lambda=0.725, F$ $(4,168)=15.961, p<.001$, partial $\eta^{2}=0.275$, were also significant predictors of all dependent variables at the multivariate level.

\section{6. 1. Hypotheses set I: Impact of design cues on users' cognitive and affective response}

H1: Higher product design quality will elicit more positive aesthetic responses than product designs that have lower quality.

H2: Higher product design quality will elicit more positive perception of usefulness than product designs that have lower quality.

H3: Higher product design quality will elicit more positive perceived ease-of-use responses than product designs that have lower quality.

H4: Higher quality product design elicits more positive affective response compared to lower quality product design.

Factorial analysis of covariance (ANCOVA) was conducted as a follow-up to the multivariate analysis to examine the impact of independent variables on each of the three dimensions of cognitive response as well as affective response. The design cues significantly impacted perceived aesthetic, $F(1,171)=33.996, \mathrm{p}<.001$, partial $\eta^{2}=0.166$ supporting H1. As expected, subjects in high-level of design cues condition perceived the product more beautiful $($ adj. $M=6.706$, S.E. $=0.133)$ compared to subjects in low-level 
design cues condition (adj. $\mathrm{M}=5.605$, S.E. 0.13 ). The design cues also provided a directional support for $\mathrm{H} 2$, perceived usefulness, $F(1,171)=3.106, \mathrm{p}=.080$, partial $\eta^{2}=$ 0.018; although, the difference between the high-level design cues condition (adj. $\mathrm{M}=$ 6.462 , S.E. $=.149$ ) and the low-level design cues condition (adj. $M=6.092$, S.E. $=.148$ ) was not statistically significant due to the limited power.

Similarly, the test for design cues, $F(1,171)=3.692, \mathrm{p}=.056$, partial $\eta^{2}=0.021$, did not reveal a statistical difference between the high-level design cues condition (adj. $\mathrm{M}=$ 7.497, S.E. $=.105)$ and the low-level design cues condition (adj. $\mathrm{M}=7.782$, S.E. $=.104)$ but it indicated a directional support for $\mathrm{H} 3$. For the fourth dependent variable, affective response, a significant main effect was found for design cues, $F(1,171)=23.503$, p < .001 , partial $\eta^{2}=0.121$, supporting $\mathrm{H} 4$. As expected, subjects in the higher quality design attribute condition were more positively dispose to the product (adj. M=6.253, S.E. $=$ .109) compared to subjects in the lower quality design attribute condition (adj. $\mathrm{M}=$ 5.507, S.E. $=.108)$

\section{6. 2. Hypotheses set II: Impact of environment congruence on users' cognitive and affective response}

H5: Product design presented in a congruent environment will elicit more positive aesthetic responses than those presented in a non-congruent environment.

H6: Product design presented in a congruent environment will elicit more positive perception of usefulness than those presented in a non-congruent environment. 
H7: Product design presented in a congruent environment will elicit more positive affective responses than those presented in a non-congruent environment.

For perceived aesthetic, there was a main effect for environment congruence, $F(1,171)$ $=8.470, \mathrm{p}<.005$, partial $\eta^{2}=0.047$, supporting H5. Subjects in the congruent environment condition perceived the product more aesthetically pleasing (adj. $\mathrm{M}=6.430$, S.E. $=0.133$ ) compared to those in the non-congruent environment condition (adj. $\mathrm{M}=$ 5.881, S.E. 0.133). For H6, the impact of environment congruence on perceived usefulness, $F(1,171)=2.606, \mathrm{p}=.108$, partial $\eta^{2}=0.015$, the results provide directional supports, but, subjects' responses in the congruent environment condition (adj. $\mathrm{M}=$ 6.447 , S.E. $=.148$ ) was not significantly different from subjects' responses in the noncongruent environment condition (adj. $\mathrm{M}=6.108$, S.E. $=.148$ ). For the affective response, there was a significant main effect for environment congruence, $F(1,171)=$ 18.573, $\mathrm{p}<.001$, partial $\eta^{2}=.098$, supporting H7. Subjects in the congruent environment condition felt greater affection (adj. $M=6.211$, S.E. $=.108$ ) while seeing the product compared to those in the non-congruent environmental condition (adj. $\mathrm{M}=5.549$, S.E. $=$ $.109)$.

The two-way interaction of environment congruence and design cues was found as a main effect on perceived aesthetic, $F(1,171)=9.599, \mathrm{p}<.001$, partial $\eta^{2}=0.053$. For lower quality design, there was hardly any difference for the perceived aesthetics between the congruent (adj. $M=5.587$, S.E.=.190) and non-congruent (adj. $M=5.623$, S.E. $=$.186) environments. However, for higher quality design, participants rated the 
perceived aesthetic score for the congruent environment (adj. M = 7.272, S.E.=.187) much higher than the non-congruent environment (adj. $M=6.140$, S.E.=.191).

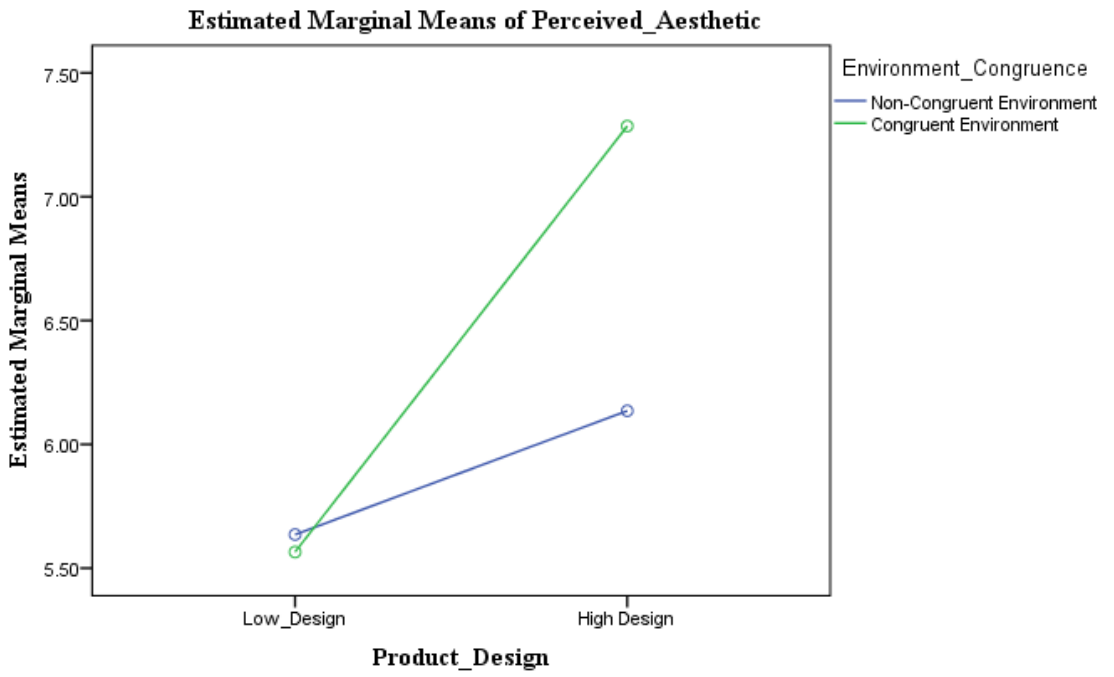

Figure 14: Significant interaction between Environment-Congruence*Product Design Cues on

Perceived Aes thetic

\section{6. 3. Hypotheses set III: Impact of media richness on users' cognitive and affective response:}

H8: Product presentation in a rich medium will elicit more positive aesthetic responses to the product compared to a simpler medium.

H9: Product presentation in a rich medium will elicit more positive perception of usefulness compared to a simpler medium.

H10: Product presentation in a rich medium has a positive effect on perceived ease-of-use compared to a simpler medium. 
H11: Product presentation in a rich medium elicits a greater affective response to the product compared to a simpler medium.

There was no statistically significant impact for media richness, on aesthetic response, $\mathrm{F}$ $(1,171)=0.058, p=.810$, partial $\eta 2=0.000$, thus failed to support H8. The aesthetic response of subjects in the higher level of media richness condition (adj. M=6.129, S.E. $=0.145)$ was almost similar those in the lower level media richness condition (adj. $\mathrm{M}=$ 6.182, S.E. 0.145). In addition, media richness, $F(1,171)=3.750, \mathrm{p}=.054$, partial $\eta^{2}=$ 0.021, was also not a statistically significant predictor of perceived usefulness due to the limited power. Contrary to predictions, participants in the lower level media richness condition perceived the product more useful (adj. $\mathrm{M}=6.546$, S.E. 0.161 ) compared to those in the non-congruent environment condition (adj. $M=6.039$, S.E. 0.162). However, the results provide directional supports for H9. For Perceived Ease-of-use, there was a significant main effect for media richness, $F(1,171)=5.925, \mathrm{p}<.05$, partial $\eta^{2}=0.033$. Contrary to expectation, subjects in the high-level of media richness condition perceived the ease-of-use to be lower (adj. $M=7.429$, S.E. $=0.114$ ) compared to low-level of media richness condition (adj. $\mathrm{M}=7.851, \mathrm{~S} . \mathrm{E} .=0.114$ ). For the affective response, there were significant main effects for media richness, $F(1,171)=5.704, p<.05$, partial $\eta^{2}=$ .032. Subjects in the higher level of media richness condition saw the product as more pleasant (adj. $M=6.095$, S.E. $=.118$ ) compared to subjects in the lower level of media richness condition (adj. $\mathrm{M}=5.665$, S.E. $=.118$ ). 


\section{7. Additional Analyses and Covariates}

In the pre-test questionnaire, when they were asked about familiarity with 3D and virtual reality systems $(1=$ not familiar at all, $9=$ very familiar $)$ participants reported an average of $4.83(\mathrm{SD}=1.59)$. Lastly, participants were asked to rate their tendency to become involved in different activities ( $1=$ not at all, $9=$ very much) and they reported an average of $6.33(\mathrm{SD}=1.28)$.

\section{7. 1. Attention Allocation}

The results also indicate that attention allocation as a covariate, was a significant predictor of perceived aesthetic, $F(1,171)=22.054, \mathrm{p}<.001$, partial $\eta^{2}=0.144$; perceived usefulness, $F(1,171)=10.417, \mathrm{p}<.05$, partial $\eta^{2}=0.057$; perceived ease-ofuse, $F(1,171)=9.573, \mathrm{p}<.005$, partial $\eta^{2}=.053$; and affective response, $F(1,171)=$ 12.620, $\mathrm{p}<.001$, partial $\eta^{2}=0.069$. As expected, there was a significant positive moderate correlation between attention allocation and perceived aesthetic, $r(179)=$ $0.418, \mathrm{p}<.001$, perceived usefulness, $r(179)=0.336, \mathrm{p}<.001$, and affective response, $r$ $(179)=0.364, p<.001$. In addition, a significant small positive correlation between attention allocation and perceived ease-of-use was detected, $r(179)=0.243, \mathrm{p}<.005$.

A t-test was used to determine whether there is a difference in subjects' rating of attention allocation in two different conditions of media richness. The results obtained from the t-test shows that participants on average rated the attention allocation higher score to the fully immersive stereoscopic 3D medium ( $\mathrm{M}=7.4, \mathrm{SD}=1.52), t(179)=-2.13$, 
$p<.05$, compared to presentation of virtual environment on a 2D screen $(M=6.98$, $\mathrm{SD}=1.49)$.

\subsubsection{Presence}

The other covariate, presence, was a significant predictor of perceived usefulness at the multivariate level, Wilks' $\lambda=0.725, F(4,168)=15.961, \mathrm{p}<.001$, partial $\eta^{2}=0.275$. As expected, there was a significant positive moderate correlation between presence and perceived usefulness, $r(179)=0.457, \mathrm{p}<.001$. In addition, presence significantly covaried perceived aesthetic, $F(1,171)=26.004, \mathrm{p}<.001$, partial $\eta^{2}=0.132$. A significant positive moderate correlation between presence and perceived aesthetic was detected, $r(179)=0.429, \mathrm{p}<.001$. Also, presence significantly covaried perceived easeof-use, $F(1,171)=6.396, \mathrm{p}<.05$, partial $\eta^{2}=.036$. A significant small positive correlation between presence and perceived ease-of-use was detected, $r(179)=0.173, p$ $<.05$. Finally, presence covaried affective response at the multivariate level, $F(1,171)=$ 52.900, $\mathrm{p}<.001$, partial $\eta^{2}=0.236$. As expected, there was a significant strong positive correlation between presence and affective response, $r(179)=0.606, \mathrm{p}<.001$.

A t-test was conducted on the impact of media richness on presence. The results from the $\mathrm{t}$-test confirmed that presence in the lower level of media richness condition received a lower score $(\mathrm{M}=5.78, \mathrm{SD}=1.53)$ than the higher level of media richness condition $(\mathrm{M}=7.47, \mathrm{SD}=1.21), \mathrm{t}(179)=-8.25, \mathrm{p}<.001$. 


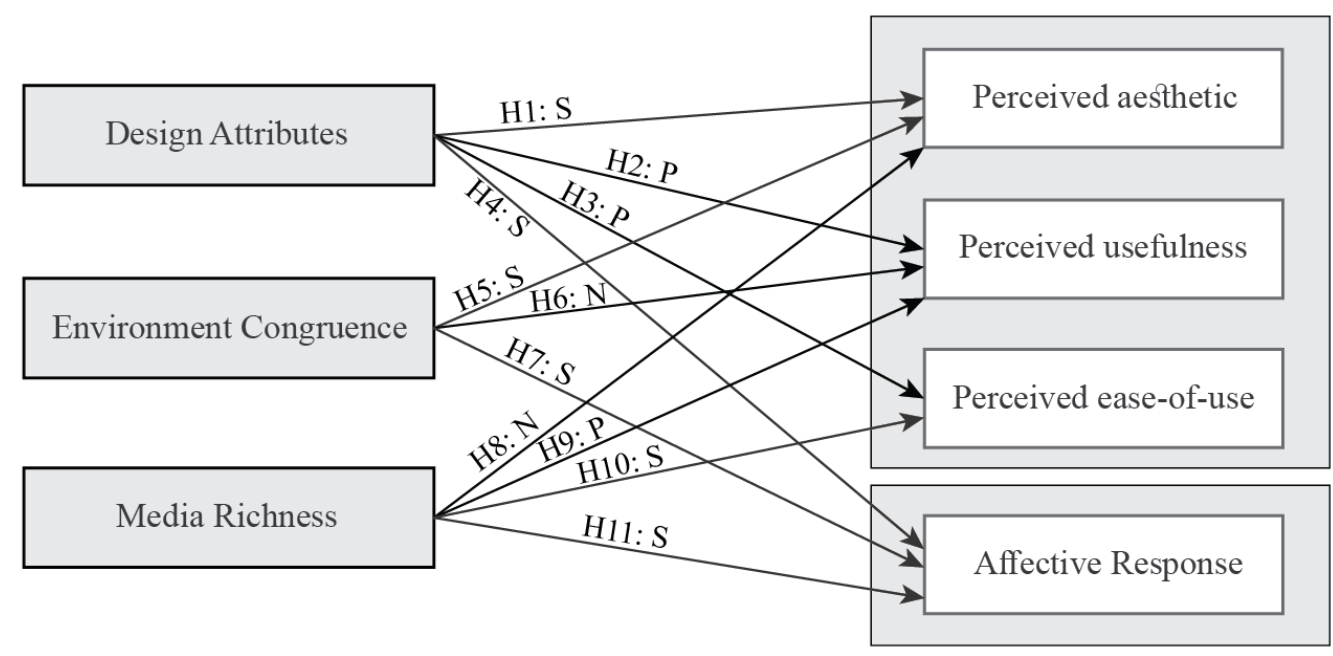

Figure 15: Summary of results for hypothesis testing ( $S$ - significant, $P$ - partially significant, $N$ - no significance) 


\begin{tabular}{|c|c|c|c|c|c|c|c|c|}
\hline \multicolumn{9}{|c|}{ Table 10: Test of between-subjects effect for covariates, independent variables, and interactions } \\
\hline & Dependent Variable & $\begin{array}{l}\text { Sum of } \\
\text { Squares }\end{array}$ & $d f$ & $\begin{array}{l}\text { Mean } \\
\text { Square }\end{array}$ & $F$ & Sig. & $\begin{array}{l}\text { Partial } \\
\text { Eta } \\
\text { Squared }\end{array}$ & $\begin{array}{c}\text { Observed } \\
\text { Power }^{e}\end{array}$ \\
\hline \multirow{4}{*}{$\frac{\text { Source }}{\text { Product Design Cues }}$} & Perceived Aesthetic & 54.185 & 1 & 54.185 & 33.996 & .000 & .166 & 1.000 \\
\hline & Perceived Usefulness & 6.134 & 1 & 6.134 & 3.106 & .080 & .018 & .418 \\
\hline & Perceived Ease-of-use & 3.632 & 1 & 3.632 & 3.692 & .056 & .021 & .480 \\
\hline & Affective Response & 24.847 & 1 & 24.847 & 23.503 & .000 & .121 & .998 \\
\hline \multirow[t]{4}{*}{ Environment Congruence } & Perceived Aesthetic & 13.499 & 1 & 13.499 & 8.470 & .004 & .047 & .825 \\
\hline & Perceived Usefulness & 5.147 & 1 & 5.147 & 2.606 & .108 & .015 & .362 \\
\hline & Perceived Ease-of-use & .276 & 1 & .276 & .281 & .597 & .002 & .082 \\
\hline & Affective Response & 19.635 & 1 & 19.635 & 18.573 & .000 & .098 & .990 \\
\hline \multirow[t]{4}{*}{ Media Richness } & Perceived Aesthetic & .093 & 1 & .093 & .058 & .810 & .000 & .057 \\
\hline & Perceived Usefulness & 7.406 & 1 & 7.406 & 3.750 & .054 & .021 & .486 \\
\hline & Perceived Ease-of-use & 5.828 & 1 & 5.828 & 5.925 & .016 & .033 & .677 \\
\hline & Affective Response & 6.030 & 1 & 6.030 & 5.704 & .018 & .032 & .661 \\
\hline \multirow{4}{*}{$\begin{array}{l}\text { Environment Congruence } \\
* \text { Product Design Cues }\end{array}$} & Perceived Aesthetic & 15.299 & 1 & 15.299 & 9.599 & .002 & .053 & .869 \\
\hline & Perceived Usefulness & 1.158 & 1 & 1.158 & .586 & .445 & .003 & .119 \\
\hline & Perceived Ease-of-use & .346 & 1 & .346 & .352 & .554 & .002 & .091 \\
\hline & Affective Response & .499 & 1 & .499 & .472 & .493 & .003 & .105 \\
\hline \multirow{4}{*}{$\begin{array}{l}\text { Media Richness * Product } \\
\text { Design Cues }\end{array}$} & Perceived Aesthetic & 3.673 & 1 & 3.673 & 2.305 & .131 & .013 & .326 \\
\hline & Perceived Usefulness & .567 & 1 & .567 & .287 & .593 & .002 & .083 \\
\hline & Perceived Ease-of-use & 1.678 & 1 & 1.678 & 1.706 & .193 & .010 & .255 \\
\hline & Affective Response & 1.881 & 1 & 1.881 & 1.779 & .184 & .010 & .264 \\
\hline \multirow{4}{*}{$\begin{array}{l}\text { Media Richness * } \\
\text { Environment Congruence }\end{array}$} & Perceived Aesthetic & .003 & 1 & .003 & .002 & .966 & .000 & .050 \\
\hline & Perceived Usefulness & 3.097 & 1 & 3.097 & 1.568 & .212 & .009 & .238 \\
\hline & Perceived Ease-of-use & .838 & 1 & .838 & .852 & .357 & .005 & .151 \\
\hline & Affective Response & .025 & 1 & .025 & .023 & .879 & .000 & .053 \\
\hline \multirow{4}{*}{$\begin{array}{l}\text { Media Richness * } \\
\text { Environment Congruence } \\
* \text { Product Design Cues }\end{array}$} & Perceived Aesthetic & .154 & 1 & .154 & .096 & .757 & .001 & .061 \\
\hline & Perceived Usefulness & .008 & 1 & .008 & .004 & .949 & .000 & .050 \\
\hline & Perceived Ease-of-use & .022 & 1 & .022 & .022 & .882 & .000 & .052 \\
\hline & Affective Response & .064 & 1 & .064 & .061 & .805 & .000 & .057 \\
\hline \multirow[t]{4}{*}{ Attention Allocation } & Perceived Aesthetic & 35.151 & 1 & 35.151 & 22.054 & .000 & .114 & .997 \\
\hline & Perceived Usefulness & 20.572 & 1 & 20.572 & 10.417 & .001 & .057 & .894 \\
\hline & Perceived Ease-of-use & 9.416 & 1 & 9.416 & 9.573 & .002 & .053 & .868 \\
\hline & Affective Response & 13.341 & 1 & 13.341 & 12.620 & .000 & .069 & .942 \\
\hline \multirow[t]{4}{*}{ Presence } & Perceived Aesthetic & 41.447 & 1 & 41.447 & 26.004 & .000 & .132 & .999 \\
\hline & Perceived Usefulness & 69.496 & 1 & 69.496 & 35.191 & .000 & .171 & 1.000 \\
\hline & Perceived Ease-of-use & 6.291 & 1 & 6.291 & 6.396 & .012 & .036 & .710 \\
\hline & Affective Response & 55.924 & 1 & 55.924 & 52.900 & .000 & .236 & 1.000 \\
\hline \multirow[t]{4}{*}{ Error } & Perceived Aesthetic & 272.552 & 171 & 1.594 & & & & \\
\hline & Perceived Usefulness & 337.695 & 171 & 1.975 & & & & \\
\hline & Perceived Ease-of-use & 168.189 & 171 & .984 & & & & \\
\hline & Affective Response & 180.776 & 171 & 1.057 & & & & \\
\hline \multirow[t]{4}{*}{ Total } & Perceived Aesthetic & 7367.873 & 181 & & & & & \\
\hline & Perceived Usefulness & 7626.139 & 181 & & & & & \\
\hline & Perceived Ease-of-use & 10763.715 & 181 & & & & & \\
\hline & Affective Response & 6653.388 & 181 & & & & & \\
\hline \multirow[t]{4}{*}{ Corrected Total } & Perceived Aesthetic & 500.705 & 180 & & & & & \\
\hline & Perceived Usefulness & 485.862 & 180 & & & & & \\
\hline & Perceived Ease-of-use & 194.320 & 180 & & & & & \\
\hline & Affective Response & 395.354 & 180 & & & & & \\
\hline
\end{tabular}




\section{CHAPTER 4: DISCUSSION}

This chapter will first summarize the results of the analysis and then discuss interpretation and implications of findings from the analysis. Then, theoretical and practical contributions to design research, media and virtual reality, marketing, and consumer research and related disciplines will be discussed. The chapter will conclude with limitations of this study and future research directions.

\section{1. Summary of Results and Theoretical Implications}

The results of the present study address three research questions: 1) What is the impact of product design cues on users' cognitive and affective responses? 2) What is the impact of environment congruence on users' cognitive and affective responses? And 3) What is the impact of media richness on users' cognitive and affective responses? These results discussed in the previous chapter can help to inform understanding of the relative impact of each independent variable as well as their interactive effect on the outcome variables and how they tie back to previous studies.

\section{1. 1. Product Design Cues}

The analyses indicated that overall, the manipulation of product design cues had a significant impact on users' cognitive and affective responses. As predicted individual analysis of each cognitive response dimension revealed that higher quality of product design did lead to a greater aesthetic score, $(p<.001)$. Also, as expected, higher quality product design cues led to more positive affective response $(p<.001)$. Although no 
statistical significance was found for the impact of product design cues on perceived usefulness, $(p=.080)$, and perceived ease-of-use, $(p=.056)$, it partially supports the prediction that higher quality design cues lead to the perception that they are more useful as well as easier to use.

The tangible attributes of product design are important factors that help users to develop an overall understanding of product (Bearden \& Shimp, 1982). Research in marketing and consumer science are usually operationalized to examine the impact of non-visual attributes of product design -such as price, performance, durability, on user responses. Some studies have confirmed the influence of some visual cues of the product design, but this present study was designed to measure the impact of other product design cues on user response.

The results of this study confirm that product design cues had a significant impact on affective response and perceived aesthetic. This finding supports Veryzer's (1993) study that suggests a higher level of unity and proportion in product design leads to greater perceived aesthetic which is consistent across different product categories. This finding is also aligned with (Hassenzahl) research that suggests hedonic qualities of a product have a positive impact on product's appeal. Users rely on heuristics when they evaluate the aesthetics of products and affective responses are the consequence of this evaluation.

The other finding of this study suggests that product design cues elicit affective responses among users. This finding supports results of the Desmet et al. (2000) study that indicated different aspects of product design elicit different levels of emotions. Similarly, this supports Jordan (1998) research that indicates product properties such as design features 
influence user's feelings. This can be explained by Hsiao \& Chen's (2006) study that postulates affective responses to product design that is the consequence of users'

perception. Results of this present study confirmed the impact of product design cues on both aesthetic perception and affective responses which provide support for the idea of stimulation of emotions under the influence of aesthetic judgment.

The results however, didn't show a significant influence of design cues on perceived usefulness and perceived ease-of-use. This result can be explained by HeuristicSystematic Model of Information Processing (Chaiken, 1980) that suggests people use their prior knowledge about objects to minimize the amount of cognitive effort, although, they may analyze and process the information that they obtain from the object. Even though it was expected that subjects systematically process the visual information of product design, prior knowledge was the major factor in cognitive response due to the existence of visual references in users' memory (Crilly et al., 2004).

In addition, young generations are more familiar with their smartphone camera, and they may have a little or no experience of using a point-\&-shoot digital camera -which was used as a stimulus in this study. Subjects may compare the visual cues of stimulus with a smartphone camera and conclude that this product is not as easy-to-use as their phone which is supported by Gregory's (1970) idea of people use their stored knowledge to evaluate what they perceive. 


\section{1. 2. Environment Congruence}

The influence of a store environment or store atmosphere on user perception and affective responses have been studied in marketing and atmospheric research (Kotler, 1973; Spies et al., 1997). Within this perspective, the shopping environment has been an extrinsic product cue which influences consumer response and behavior. These studies explore the impact of different elements of store environment -such as lighting, design, music, etc., on user behavior. But, this study examines the impact of visual match between environment design elements and product design elements on the users cognitive and affective response. This study postulates that a well-coordinated and consistent elements of product presentation environments and products will elicit greater cognitive and affective responses.

Looking at users' cognitive response dimensions, the results show that environmental congruence played a significant role but not always as predicted. For perceived aesthetics, we found a significant main effect, $(p<.005)$, that indicates in a congruent environment, users perceived the product aesthetic more appealing compared to a noncongruent environment. This finding is consistent with the research of Wu et al. (2013) that indicates product presentation in a thoughtfully-designed display enhances aesthetic appealing of a product. Products which are coordinated by similar appearance or style,

create a sense of unity which is a principle of aesthetics (Veryzer, 1993). It also supports the idea that holds products are purchased more frequently if they are presented in a congruent environment (Berger \& Fitzsimons, 2008). These authors argue that when users are exposed more frequently to product cues, they can process the visual 
information of products easier. This result can be explained in different ways. Van Rompay and Pruyn (2011) postulate that experience of consistency facilitates intuitive recognition of aesthetic quality that eventually leads to a positive aesthetic response. This finding also supports the idea of exposure to situational cues that enhances the experience of product perception (Higgins et al, 1977). The environmental preference theory also explains this by defining the coherence as an important factor that provides consistency among different elements of the environment (Kaplan, 1987). The cognitive dissonance theory (Festinger, 1962) also suggests consistency among different elements of a system eliminates cognitive dissonance among people. In fact, the repetition of situational cues in congruent environments, can be used to explain how information restoration in the users' memory elicits more positive responses to products among users (Higgins et al, 1977).

In addition, the cue-summation theory (Severin, 1967) explains as the number of cues increased, the users' understanding of objects is improved. In fact, the congruent environment could be considered as additional visual cues that facilitate understanding of products. Similarly, as expected, product presentation in a congruent environment, led to a more positive affective response $(p<.001)$. This is aligned with Suryandari \& Paswan's (2014) study that revealed users show more positive purchase behavior in a congruent shopping environment. However, they studied consumers' behavior in the context of online shopping.

Finally, the environment congruence was found to have no significant influence on perceived usefulness, $(p=.108)$. This result is contrary to predictions in the hypotheses 
that environment congruence would increase the level of product usefulness perception when compared to a non-congruent environment condition. This finding could be explained by the fact that a congruent environment alone, doesn't provide extra information about product functions and performance. Although the congruence of visual cues supports the product aesthetic perception, but they don't support the product semantics which is associated with product usefulness and functionalities. Despite aesthetics which seem to be perceived heuristically, users systematically explore product information when evaluating product functionality.

\section{1.3. Media Richness}

For media richness, no statistical significance was found for perceived aesthetic ( $p=$ $.810)$ and perceived usefulness $(p=.054)$, although, results provide directional supports for positive impact of media richness on perceived usefulness. But, as expected media richness revealed a significant main effect for affective response $(p<.05)$. The experience of users with a richer medium led to higher level of affective response. Results also show that media richness significantly predicted perceived ease-of-use but in an opposite direction $(p<.05)$. Contrary to expectations, higher level of perceived easeof-use was associated with lower level of media richness.

This finding confirms findings of the Li et al. (2002) study that suggests product presentation in 3D has a greater impact on user's product knowledge compared to a 2D presentation. This can be explained by cue summation theory (Severin, 1967) that holds when the amount of information increase within a channel, user's understanding of presented objects is improved (Moore et al., 2004). This study partially supports the S. H. 
Liu et al. (2009) study that holds presentation through a richer multimodal media (breadth) positively influences perceived ease-of-use and perceived usefulness. This result can be explained by Wrights (1981) study that suggests a text-based medium communicates the technical aspects of the product more effectively compared to other visual modes. A text-based medium is highly involving which requires cognitive effort from users. Therefore, it stimulates understanding and learning of more complex information. In addition, Gammack and Hodkinson (2003) explain lack of interactivity in virtual reality systems may lead to negative purchase behavior for performance related products. However, lack of interactivity of digital medium doesn't have a negative effect on consumer response to hedonic products like music CDs. Although, this study employed a visually rich medium, the virtual reality system didn't enable patricians to interact with the product. Therefore, we can expect significant main effect for media richness (breadth) on perceived usefulness and perceived ease-of-use if we add interactivity to virtual reality system combined with text-based information.

The results of this study confirm that media richness has a significant impact on affective response. This finding supports other studies that suggest different presentation media modalities, elicit different affective responses to the advertised product (Adelaar et al., 2003; Dijkstra et al., 2005; S. S. Liu \& Stout, 1987). It also supports the research findings that indicate digital media elicit higher level of affective response compared to printed media (Chaudhuri \& Buck, 1995). All these are aligned with the Bezjian-Avery et al. (1998) observation of a positive correlation between media richness and affective responses. 
Although studies above were operationalized by breath dimension of media richness, this study confirms that the depth in media richness similarly elicits a greater positive affective response. Those studies that focused on effect of media format or multimodality (media breadth) on users' affective resonses, explain the effect by either differences in “delivery mechanism" of media (Sundar, Narayan, Obregon, \& Uppal, 1998, p. 830), or by dual coding approach (Paivio, 1986) that holds that when users process the information through multiple channels the understanding and learning are improved. This study confirmed that media richness (depth) enhances the sense of presence. Therefore, the impact of media richness depth on affective responses could be explained through the improved enjoyment triggered by presence in the virtual reality context (Skalski, Tamborini, Shelton, Buncher, \& Lindmark, 2011).

Additional Findings: This study found a significant two-way interaction between environment congruence and product design cues as the main effect for perceived aesthetic $(p<.001)$. This finding indicated that participants viewed the high-quality product design as more beautiful in the congruent environment, while there was no significant difference of aesthetic perception between low-quality and high-quality product design in the non-congruent environment. The cue summation theory (Severin, 1967) can explain this effect. On the one hand, presence of more visual cues improves users' understanding of product. Thus, a congruent environment that provides more visual cues for a high-quality product design amplifies the aesthetic perception. On the other hand however, the increase in the number of visual cues for a non-beautiful product doesn't affect the aesthetic response among users. 
Contrary to expectations, CPVA was not found to be a covariate of aesthetic response at the multivariate level $(p=.21)$. The aesthetic response to higher quality product design among people with high CPVA is expected to be more intense compared to users with low CPVA (Bloch et al., 2003). The findings of the present study didn't provide support for this effect, although, manipulation checks confirmed that subjects understood the difference between high-quality and low-quality design conditions. Therefore, it seems logical to conclude high CPVA participants had higher standards for product aesthetic that were not discovered even in high-quality design condition of this study. In addition, aesthetic judgment has not been recognized as a universal concept (Kant, 1790), although some researchers have identified some aspects of universal aesthetic (Perrett et al., 1999). In fact, aesthetic preference can vary from person to person (Bloch et al., 2003) and culture to culture (Berlyne, 1971; Jacobsen, 2004).

Several individual factors were included in the study as covariates. The additional analysis revealed attention allocation significantly covaried perceived aesthetic ( $p<$ $.001)$, perceived usefulness ( $p<.05)$, perceived ease-of-use ( $p<.005)$, and affective response $(p<.001)$. Participants who reported a higher level of attention to stimulus during the experiment had a greater cognitive and affective response. In addition, media richness was found to be the significant predictor of attention allocation $(p<.05)$. This finding indicates that an increase in intensity and quality of information within a perceptual channel improves the attention allocation to stimulus. In addition to attention allocation, presence, significantly covaried all four dependent variables of this study including perceived aesthetic $(p<.001)$, perceived usefulness $(p<.001)$, perceived easeof-use ( $p<.05)$, and affective response ( $p<.001)$. Subjects who reported a higher level of 
presence in the virtual reality environment rated the cognitive and affective response better. Moreover, media richness revealed a main effect for sense of presence $(p<.001)$. Subjects reported a higher level of sense of presence in the fully immersive stereoscopic $3 \mathrm{D}$ virtual environment compared to the $2 \mathrm{D}$ screen-based virtual reality environment. This finding implies that a richer media (depth) improves the sense of presence among users.

\section{2. Practical Implication}

This study has practical implications across three domains including product design, marketing and retail merchandising, and communication and media studies.

\section{2. 1. Implications for Product Design and Development}

From a practical perspective, this study contributes to helping product designers, industrial designers, marketing managers and other product stakeholders who are involved in the early stage of decision making in product development process to better understand how different elements of design influence the user perception and response to the product. Results of this study indicate that product design cues including form, texture and material finish, color, and graphical typography improve aesthetic perception and affective response. Paying attention to these details is very important when the product mission statement has targeted aesthetic perception and feelings of consumers. The results suggest that the design and development team can manipulate the elements of design to improve the associated meanings of product design. This purposeful manipulation could help to improve product semantics when the design and development 
team is going to communicate product performance, durability, functionality, and quality through product appearance. Usually, buyers and end-users in the professional and business market segment make a purchase decision based on product performance and functionality. When there are several competitors in the market that offer similar products within the same price range, the design would be a major role player that enhances users' judgment of product usefulness. For example, a black drill could be perceived more durable and powerful compared to a yellow drill. Changing these four cues of design could also help the ergonomic perception specially in specific market segment that targeted non-professionals, home users, or do-it-yourself market.

\section{2. 2. Implications for Marketing, Consumer Behavior, and Retail Merchandising}

This study has practical implications for marketing, consumer behavior and retail merchandising. The environment congruence aspect can help marketing managers and retail merchandising professionals to improve consumer experience while they are shopping at a physical or virtual store. Although this study was designed around the virtual reality system, but the findings about the impact of environment on users' perceptions and affective responses are applicable to physical environment. If the product is presented in a presentation display, which is designed to be visually similar to the product, users perceive the product as more aesthetically appealing. Their positive affective response to the product will lead to increase in purchase behavior among consumers. Despite that, if a product is presented in a neutral generic display -like most displays at retail stores, even a well-designed product may not elicit enough positive aesthetic and affective response. Although visual similarities between product display 
and presented product enhances consumers' aesthetic perception and emotional arousal, it is not helpful when consumers evaluate the product performance and ergonomics. If the product is aimed at professional market segment where consumers look for performance and functional aspects of product, one has to go beyond designing a well-coordinated product display. Also, if the primary concern of a consumer is the product ergonomics for instance, an elderly consumer who looks for a bathtub handrail- product presentation in a congruent environment won't be helpful. In both cases, consumer has a buying agenda other than aesthetical appreciation and emotional pleasure.

The second practical implication for marketing and retail merchandising is the importance of the product presentation through a high-quality presentation medium. Whether the product is presented in an online shopping environment -regardless of conventional online shopping websites or virtual reality store environment, or a physical store where the product is accompanied by a screen that illustrates the product features and usage in the context, it is important to employ higher quality media to create a positive emotional impact on consumers. Media richness also helps consumers to develop a better understanding of product ease-of-use and ergonomics. If consumers' primary buying agenda is the product ergonomics, a rich medium can effectively communicate ergonomic aspects of design and improve product knowledge. This process may lead to a positive purchase behavior. In addition to individual positive impact of environment congruence and media richness on consumer responses, this study suggests that if a welldesigned product is presented on a well-designed display, the sense of aesthetic appreciation and affective response to that will dramatically increase. Marketing 
managers should not leave a well-designed product isolated in a generic display or environment.

\section{2.3. Implications for Communication and Media}

This study holds practical implication for communication studies and media, particularly a program that relies on the construct of media richness. Media can be used in a variety of formats for different purposes. It is used for entertainment, advertising, news, etc. Regardless of the purpose of employing the media, its emotional impact on audiences is an important function of media. The content influences the affective responses among the audiences, but, the intrinsic characteristics of medium also have a significant impact on audiences. While many studies suggest that multimodality and media format influences affective response, this study holds the depth of visual medium, and information intensity of media has a positive impact on affective responses among audiences. In addition, in the virtual reality context -with potential application in entertainment industry, training, and e-commerce, the depth of media richness improves the sense of presence which is a critical aspect of any VR system.

\section{3. Limitations}

Although all aspects of this experiment were carefully designed to precisely measure the impact of independent variables on user responses, like other studies, there are still limitations associated with this study. First, the subjects of this study were college age students although they represented different levels in college from freshman to graduate students from more than 40 different majors and departments. For example, the aesthetic 
perception and affective response are likely to be different among people of different ages, while our sample represents the younger generation. Therefore, the generalizability of the findings of this study is limited to the chosen sample.

The second limitation arises from the nature of using virtual reality equipment for the experiment. This area of technology is rapidly improving, but we still have some limitations with virtual reality equipment that may influence the implementation of experiment. Fatigue, simulator sickness, novelty, and believability are potential threats to this study. To reduce the risk of fatigue, pretesting was performed to identify the optimal time without fatigue. The stimulus in stereoscopic 3D conditions was presented on a fully immersive VR headset which was equipped with the motion tracker. That helped more natural and intuitive movement of participants in the lab environment which eventually reduced the risk of motion sickness. In addition, at the beginning of the experiment participants were asked about prior experiences of motion sickness or simulator sickness. If their answer was positive, they were excluded from the experiment. Even with all considerations, it is still impossible to eliminate this limitation of virtual reality systems. To minimize the potential threat of novelty, a few items were added to the demographic section of survey to control any prior experience with $3 \mathrm{D}$ and virtual reality systems.

Operationalization of product design cues and environmental congruence could be further refined. Previous studies have defined and operationalized the design cues and congruence in a myriad of ways. In addition, choice of camera as the stimulus of this study was based on prior research, but may not be as relevant or resonate with a younger generation that is familiar with the intuitive operation of smartphone cameras. Even a 
simple point- $\&$-shoot digital camera can be viewed more complicated and harder to operate when compared to a smartphone camera. In addition, this study employed a consumer electronic product which may elicit higher level of usefulness and ease-of-use response. But, other types of product (e.g., furniture and interior design elements) may not elicit the same level of users' response to usefulness and ease-of-use.

The other limitation of this study is that of believability. Even with telling participants that they experience a virtual shopping environment and with a high-fidelity virtual simulation of product and store environment, this study -like other studies, faces the challenge of believability. Although a very high fidelity virtual content was created, the internal limitation of technology such as resolution, limited space for physical movement and lack of interactivity can be still added to the issue of believability.

Controlled experiments involving virtual reality such as this one has pragmatic limitations regarding development time and recruiting a large number of participants. Additional subjects could have improved the statistical power of the study that could have detected the smaller effects.

\section{4. Conclusion and Future Directions}

This present study investigated the relationship between design cues, environment, presentation medium, and user responses to product design. This research particularly examined how different independent variables including product design cues, congruence of environment with the product, and the media richness influence perception of product aesthetic, usefulness, ease-of-use, and affective responses among the users in a virtual 
reality shopping context. Findings revealed that product design cues have a significant impact on perceived aesthetic and affective responses. Although the statistical analysis didn't' reveal significance for perceived usefulness and perceived ease of use, there is still a directional support for this hypothesis.

Design is a complex activity, and the dimensions of design quality are not easily reducible to conduct a controlled experiment. Future studies could build on this by adding other visual cues (i.e., size, geometry, ornamentation, etc.) and intangible aspects of design (i.e., novelty, prototypicality, value, etc.). In addition, future research can be conducted to examine the impact of other product design cues on perception of product semantics and semiotics. These design cues could be either design elements or design principles such as proximity, proportions, symmetry, and micro and macro elements form.

This research showed that visual similarities between presentation environment and the product improve the perception of aesthetic and affective response to product. But, study didn't produce significant results for impact of environment congruence on perceived usefulness and perceived ease-of-use. Further studies can examine the impact of other environmental conditions such as sound, ambient lighting, proportions and constraints, and different display configurations on the users' cognitive and affective responses. Moreover, operationalization of environmental congruence in the present study was narrowly limited to design aspects of the environment. In addition, further research can examine the impact of a neutrally designed environment on users' perceptions and behavior. 
Future work could expand on the idea of congruence such as the congruence between the product and retail type (online/instore) etc. Also, the effect of congruence between brand image and product design on user response could be investigated in other studies.

This study also showed the dimension of depth of media richness as having a positive impact on perceived ease-of-use and affective responses among the users. Another direction for furthering this line of research inquiry would be investigating how multimodal presentation influences product knowledge among users particularly its influence on perception of product usefulness and product aesthetic. In addition, the influence of media affordances -such as interactivity and immersion, on user responses can be instigated in further research.

The present study only used self-report measures. But, psychophysiological measures can be employed to measure the affective responses. This study aimed to focus on users' cognitive evaluation of the product and their affective responses. The further studies can investigate users' behavioral responses under the influence each of independent variables of this study. Eye tracking technology can be used to measure user behavior toward the stimulus of future studies.

Finally, this research contributes to multiple disciplines including product design, marketing and consumer behavior, and communication. Although, this study brings together variables that are not usually considered together. The interdisciplinary approach of this study can bridge disciplinary understanding and provide a better understanding of the psychological mechanisms at work. Psychological and behavioral responses of 
consumers are shaped in a complex context and under the influence of multiple factors. This research attempted to investigate these responses from different perspectives.

This study investigates users' responses in the virtual shopping context that eventually lead to purchase behavior. This type of research can help shape the retail shopping experience, especially for online stores. Findings of this research have implications for companies in how they can present products to enhance the customer experience and for consumers by helping them make more informed decisions. Similar approach can be employed in future research to investigate the use of immersive technologies to encourage more conscious purchasing behavior by significantly enhancing people's understanding of the products and services that they intend to purchase. 


\section{REFERENCES}

Adelaar, T., Chang, S., Lancendorfer, K. M., Lee, B., \& Morimoto, M. (2003). Effects of media formats on emotions and impulse buying intent. Journal of Information Technology, 18(4), 247-266.

Alba, J. W., \& Hutchinson, J. W. (1987). Dimensions of consumer expertise. Journal of consumer research, 13(4), 411-454.

Andrews, J. C., Akhter, S. H., Durvasula, S., \& Muehling, D. D. (1992). The effects of advertising distinctiveness and message content involvement on cognitive and affective responses to advertising. Journal of Current Issues \& Research in Advertising, 14(1), 45-58.

Arnold, M. B. (1960). Emotion and personality. New York: New York : Columbia University Press.

Babin, B. J., \& Darden, W. R. (1996). Good and bad shopping vibes: spending and patronage satisfaction. Journal of Business Research, 35(3), 201-206.

Bahn, S., Lee, C., Nam, C. S., \& Yun, M. H. (2009). Incorporating affective customer needs for luxuriousness into product design attributes. Human Factors and Ergonomics in Manufacturing \& Service Industries, 19(2), 105-127.

Baker, J., Levy, M., \& Grewal, D. (1992). An experimental approach to making retail store environmental decisions. Journal of retailing, 68(4), 445.

Baker, J., Parasuraman, A., Grewal, D., \& Voss, G. B. (2002). The influence of multiple store environment cues on perceived merchandise value and patronage intentions. Journal of marketing, 66(2), 120-141. 
Balakrishnan, B., \& Sundar, S. S. (2011). Where am I? How can I get there? Impact of navigability and narrative transportation on spatial presence. Human-Computer Interaction, 26(3), 161-204.

Ballantine, P. W., Jack, R., \& Parsons, A. G. (2010). Atmospheric cues and their effect on the hedonic retail experience. International Journal of Retail \& Distribution Management, 38(8), 641-653.

Bandura, A. (1982). Self-efficacy mechanism in human agency. American psychologist, $37(2), 122$.

Batra, R., \& Ray, M. L. (1986). Affective responses mediating acceptance of advertising. Journal of consumer research, 13(2), 234-249.

Beach, L. R., \& Mitchell, T. R. (1978). A contingency model for the selection of decision strategies. Academy of management review, 3(3), 439-449.

Bearden, W. O., \& Shimp, T. A. (1982). The use of extrinsic cues to facilitate product adoption. Journal of marketing research, 229-239.

Bei, L.-T., \& Widdows, R. (1999). Product knowledge and product involvement as moderators of the effects of information on purchase decisions: A case study using the perfect information frontier approach. The Journal of Consumer Affairs, $165-186$.

Bellizzi, J. A., \& Hite, R. E. (1992). Environmental color, consumer feelings, and purchase likelihood. Psychology \& Marketing, 9(5), 347-363.

Berger, J., \& Fitzsimons, G. (2008). Dogs on the street, pumas on your feet: How cues in the environment influence product evaluation and choice. Journal of marketing research, 45(1), 1-14. 
Berkowitz, M. (1987). Product shape as a design innovation strategy. Journal of Product Innovation Management, 4(4), 274-283.

Berlyne, D. E. (1971). Aesthetics and psychobiology (Vol. 336): JSTOR.

Berlyne, D. E. (1975). Behaviourism? Cognitive theory? Humanistic psychology? To Hull with them all. Canadian Psychological Review/Psychologie Canadienne, 16(2), 69-80. doi:10.1037/h0081798

Bevan, N., \& Macleod, M. (1994). Usability measurement in context. Behaviour \& information technology, 13(1-2), 132-145.

Bezjian-Avery, A., Calder, B., \& Iacobucci, D. (1998). New media interactive advertising vs. traditional advertising. Journal of advertising research, 38, 23-32.

Bitner, M. J. (1992). Servicescapes: The impact of physical surroundings on customers and employees. The Journal of Marketing, 57-71.

Blijlevens, J., Creusen, M. E., \& Schoormans, J. P. (2009). How consumers perceive product appearance: The identification of three product appearance attributes. International journal of design, 3(3).

Bloch, P. H. (1995). Seeking the ideal form: Product design and consumer response. The Journal of Marketing, 59(3), 16-29.

Bloch, P. H., Brunel, F. F., \& Arnold, T. J. (2003). Individual differences in the centrality of visual product aesthetics: Concept and measurement. Journal of consumer research, 29(4), 551-565.

Bloch, P. H., Gopalakrishna, S., Crecelius, A. T., \& Murarollia, M. S. (2018). Exploring Booth Design as a Determinant of Trade Show Success. Journal of Business to Business Marketing, 25(04), 1-20. 
Bloch, P. H., \& Kamran-Disfani, O. (2018). Outdoor Atmospherics: Influe nces on Shoppers, Society, and Firm Value. Academy of Marketing Science Review, Manuscript sumbitted for publication.

Bloch, P. H., \& Richins, M. L. (1983). Shopping without purchase: An investigation of consumer browsing behavior. Paper presented at the Advances in Consumer research, Ann Arbor, MI.

Bottomley, P. A., \& Doyle, J. R. (2006). The interactive effects of colors and products on perceptions of brand logo appropriateness. Marketing Theory, 6(1), 63-83.

Bradley, M. M., \& Lang, P. J. (1994). Measuring emotion: the self-assessment manikin and the semantic differential. Journal of behavior therapy and experimental psychiatry, 25(1), 49-59.

Brave, S., \& Nass, C. (2003). Emotion in human-computer interaction The humancomputer interaction handbook (pp. 81-96). Hillsdale, NJ: L. Erlbaum Associates Inc.

Canter, D. (1983). The Purposive Evaluation of Places A Facet Approach. Environment and Behavior, 15(6), 659-698.

Chaiken, S. (1980). Heuristic versus systematic information processing and the use of source versus message cues in persuasion. Journal of personality and social psychology, 39(5), 752-766.

Chaudhuri, A., \& Buck, R. (1995). Media differences in rational and emotional responses to advertising. Journal of Broadcasting \& Electronic Media, 39(1), 109-125. 
Childers, T. L., Carr, C. L., Peck, J., \& Carson, S. (2002). Hedonic and utilitarian motivations for online retail shopping behavior. Journal of retailing, 77(4), 511535.

Cooper, R. G., \& Kleinschmidt, E. J. (1987). New products: what separates winners from losers? Journal of Product Innovation Management, 4(3), 169-184.

Cowley, E., \& Mitchell, A. A. (2003). The moderating effect of product knowledge on the learning and organization of product information. Journal of consumer research, 30(3), 443-454.

Creusen, M. E., \& Schoormans, J. P. (2005). The different roles of product appearance in consumer choice. Journal of Product Innovation Management, 22(1), 63-81.

Crilly, N., Moultrie, J., \& Clarkson, P. J. (2004). Seeing things: consumer response to the visual domain in product design. Design studies, 25(6), 547-577.

Cytowic, R. E. (2002). Synesthesia: A union of the senses. Cambridge, MA: MIT Press.

Daft, R. L., \& Lengel, R. H. (1984). Information richness. A new approach to managerial behavior and organization design. Research in Organizational Behaviour, 6, 191233.

Darden, W. R., \& Babin, B. J. (1994). Exploring the concept of affective quality: expanding the concept of retail personality. Journal of Business Research, 29(2), 101-109.

Davis, F. D. (1986). A technology acceptance model for empirically testing new end-user information systems: Theory and results. MIT, Cambridge, MA.

Davis, F. D. (1989). Perceived Usefulness, Perceived Ease of Use, and User Acceptance of Information Technology. MIS quarterly, 13(3), 319-340. 
Demirbilek, O., \& Sener, B. (2003). Product design, semantics and emotional response. Ergonomics, 46(13-14), 1346-1360.

Desmet, P. (2003a). Measuring Emotion: Development and Application of an Instrument to Measure Emotional Responses to Products Funology (pp. 111-123): Springer.

Desmet, P. (2003b). A multilayered model of product emotions. The design journal, 6(2), 4-13.

Desmet, P. (2012). Faces of Product Pleasure: 25 Positive Emotions in Human-Product Interactions. International journal of design, 6(2). Retrieved from http://www.ijdesign.org/ojs/index.php/IJDesign/article/view/1190

Desmet, P., \& Hekkert, P. (2007). Framework of Product Experience. International journal of design, 1(1). Retrieved from http://www.ijdesign.org/ojs/index.php/IJDesign/article/view/66/15

Desmet, P., Hekkert, P., \& Jacobs, J. J. (2000). When a Car Makes You Smile: Development and Application of an Instrument to Measure Product Emotions. Advances in Consumer research, 27, 111-117. Retrieved from

Desmet, P., Overbeeke, K., \& Tax, S. (2001). Designing products with added emotional value: Development and appllcation of an approach for research through design. The design journal, 4(1), 32-47.

dictionary, M.-W. o. (2006). Retrieved from https://www.merriam-webster.com

Dijkstra, M., Buijtels, H. E., \& Van Raaij, W. F. (2005). Separate and joint effects of medium type on consumer responses: a comparison of television, print, and the Internet. Journal of Business Research, 58(3), 377-386. 
Dodds, W. B., Monroe, K. B., \& Grewal, D. (1991). Effects of Price, Brand, and Store Information on Buyers' Product Evaluations. Journal of marketing research, 28(3), 307-319.

Donovan, R., \& Rossiter, J. (1982). Store atmosphere: an environmental psychology approach. Journal of retailing, 58(1), 34-57.

Enneking, U., Neumann, C., \& Henneberg, S. (2007). How important intrinsic and extrinsic product attributes affect purchase decision. Food Quality and Preference, 18(1), 133-138.

Festinger, L. (1962). A Theory of Cognitive Dissonance (Vol. 2). Stanford, CA: Stanford University Press.

Field, A. (2013). Discovering statistics using IBM SPSS statistics (4 ed.): SAGE Publications Ltd.

Fiore, A. M. (2010). Understanding Aesthetics for the Merchandising and Design Professional (2 ed.): Fairchild Books.

Fiore, A. M., Yah, X., \& Yoh, E. (2000). Effects of a product display and environmental fragrancing on approach responses and pleasurable experiences. Psychology and Marketing, 17(1), 27-54.

Gammack, J., \& Hodkinson, C. (2003). Virtual reality, involvement and the consumer interface. Journal of End User Computing, 15(4), 78-96.

Gibson, J. J. (1966). The senses considered as perceptual systems. Boston: MA: Houghton Mifflin.

Good, M., Spine, T. M., Whiteside, J., \& George, P. (1986). User-derived impact analysis as a tool for usability engineering. ACM SIGCHI Bulletin, 17(4), 241-246. 
Govers, P., Hekkert, P., \& Schoormans, J. P. (2003). Happy, cute and tough: Can designers create a product personality that consumers understand. Paper presented at the Design and Emotion.

Gregory, L. R. L. (1970). The intelligent eye. New York: McGraw-Hill.

Griffith, D. A., Krampf, R. F., \& Palmer, J. W. (2001). The role of interface in electronic commerce: Consumer involvement with print versus on-line catalogs. International Journal of Electronic Commerce, 5(4), 135-153.

Grigorovici, D. M., \& Constantin, C. D. (2004). Experiencing Interactive Advertising beyond Rich Media: Impacts of Ad Type and Presence on Brand Effectiveness in 3D Gaming Immersive Virtual Environments. Journal of Interactive Advertising, 5(1), 22-36. doi:10.1080/15252019.2004.10722091

Gustafson, K. (2017). Online sales rake in a record $\$ 91.7$ billion over the holidays, rising 11\%. Retrieved from http://www.cnbc.com/2017/01/05/online-sales-rake-in-a$\underline{\text { record-917-billion-over-the-holidays-rising-11-percent.html }}$

Hassenzahl, M. (2001). The effect of perceived hedonic quality on product appealingness. International Journal of Human-Computer Interaction, 13(4), 481499.

Hassenzahl, M., Platz, A., Burmester, M., \& Lehner, K. (2000). Hedonic and ergonomic quality aspects determine a software's appeal. Paper presented at the SIGCHI conference on Human Factors in Computing Systems.

Hauser, J. R., \& Simmie, P. (1981). Profit maximizing perceptual positions: An integrated theory for the selection of product features and price. Management science, 27(1), 33-56. 
Haverkamp, M. (2013). Synesthetic Design: Handbook for a Multi-Sensory Approach: Birkhauser.

Hekkert, P. (2006). Design aesthetics: principles of pleasure in design. Psychology science, 48(2), 157.

Helander, M. G. (2002). Hedonomics-affective human factors design. Paper presented at the Human Factors and Ergonomics Society Annual Meeting.

Henderson, P. W., Giese, J. L., \& Cote, J. A. (2004). Impression management using typeface design. Journal of marketing, 68(4), 60-72.

Higgins, E. T., Rholes, W. S., \& Jones, C. R. (1977). Category accessibility and impression formation. Journal of Experimental Social Psychology, 13(2), 141154.

Hirschman, E. C., \& Holbrook, M. B. (1982). Hedonic consumption: emerging concepts, methods and propositions. Journal of marketing, 46, 92-101.

Holbrook, M. B., \& Hirschman, E. C. (1982). The experiential aspects of consumption: Consumer fantasies, feelings, and fun. Journal of consumer research, 9(2), 132140.

Hollins, B., \& Pugh, S. (1990). Successful product design: what to do and when. London England ; Boston: Butterworth.

Hsiao, K.-A., \& Chen, L.-L. (2006). Fundamental dimensions of affective responses to product shapes. International Journal of Industrial Ergonomics, 36(6), 553-564. doi:10.1016/j.ergon.2005.11.009

Hudlicka, E. (2003). To feel or not to feel: The role of affect in human-computer interaction. International journal of human-computer studies, 59(1), 1-32. 
Huffman, C., \& Kahn, B. E. (1998). Variety for sale: Mass customization or mass confusion? Journal of retailing, 74(4), 491-513.

Igbaria, M., Schiffman, S. J., \& Wieckowski, T. J. (1994). The respective roles of perceived usefulness and perceived fun in the acceptance of microcomputer technology. Behaviour \& information technology, 13(6), 349-361.

ISO. (1998). Ergonomic requirements for office work with visual display terminals (VDTs) The international organization for standardization (Vol. 9241-11).

Jacobsen, T. (2004). Individual and group modelling of aesthetic judgment strategies. British Journal of Psychology, 95(1), 41-56.

James, W. (1950). The Principles of Psychology (Vol. 1). New York: Dover Publications. Jeandrain, A.-C. (2001). Consumer reactions in a realistic virtual shop: Influence on buying style. Journal of Interactive Advertising, 2(1), 2-9.

Jiang, Z., \& Benbasat, I. (2007). The effects of presentation formats and task complexity on online consumers' product understanding. MIS quarterly, 31(3), 475-500.

Jin, S.-A. A. (2009). The roles of modality richness and involvement in shopping behavior in 3D virtual stores. Journal of Interactive Marketing, 23(3), 234-246.

Johnson, E. J., \& Payne, J. W. (1985). Effort and accuracy in choice. Management science, 31(4), 395-414.

Jordan, P. W. (1998). Human factors for pleasure in product use. Applied ergonomics, 29(1), 25-33.

Jordan, P. W. (1999). Pleasure with products: Human factors for body, mind and soul. In W. Green \& P. W. Jordan (Eds.), Human factors in product design: Current practice and future trends (pp. 206-217). London: Tylor \& Francis. 
Kant, I. (1790). Critique of Judgment (W. S. Pluhar, Trans. 1st ed.). Indianapolis, IN: Hackett Publishing.

Kaplan, S. (1982). Where cognition and affect meet: A theoretical analysis of preference. In P. Bart, A. Chen, \& G. Francescato (Eds.), Knowledge for Design (pp. 183188). Washington, D.C: EDRA.

Kaplan, S. (1987). Aesthetics, affect, and cognition environmental preference from an evolutionary perspective. Environment and Behavior, 19(1), 3-32.

Kerfoot, S., Davies, B., \& Ward, P. (2003). Visual merchandising and the creation of discernible retail brands. International Journal of Retail \& Distribution Management, 31(3), 143-152.

Klatzky, R. L., Lederman, S. J., \& Matula, D. E. (1993). Haptic exploration in the presence of vision. Journal of Experimental Psychology: Human Perception and Performance, 19(4), 726.

Ko, S., \& Rhee, E. (1994). Consumers' impulse buying process of clothing products. Paper presented at the Annual Meeting of the International Textiles \& Apparel Assocation, Monument, CO.

Kopec, D. A. (2006). Environmental psychology for design. New York: Fairchild.

Kotler, P. (1973). Atmospherics as a marketing tool. Journal of retailing, 49(4), 48-64.

Kotler, P., \& Armstrong, G. (2010). Principles of marketing: pearson education.

Kotler, P., \& Rath, G. A. (1984). Design: A powerful but neglected strategic tool. Journal of business strategy, 5(2), 16-21.

Krippendorff, K. (1989). On the essential contexts of artifacts or on the proposition that "design is making sense (of things)". Design Issues, 5(2), 9-39. 
Kumar, M., Townsend, J. D., \& Vorhies, D. W. (2015). Enhancing consumers' affection for a brand using product design. Journal of Product Innovation Management, 32(5), 716-730.

Kurosu, M., \& Kashimura, K. (1995). Apparent usability vs. inherent usability: experimental analysis on the determinants of the apparent usability. Paper presented at the Conference companion on Human factors in computing systems.

Lam, S. Y., \& Mukherjee, A. (2005). The effects of merchandise coordination and juxtaposition on consumers' product evaluation and purchase intention in storebased retailing. Journal of retailing, 81(3), 231-250.

Lang, J. (1988). Symbolic aesthetics in architecture: toward a research agenda. In j. L. Nasar (Ed.), Environmental aesthetics: Theory, research, and application (pp. 1126): Cambridge University Press.

Langrehr, F. W. (1991). Retail shopping mall semiotics and hedonic consumption. Advances in Consumer research, 18, 428-433.

Larcker, D. F., \& Lessig, P. V. (1980). PERCEIVED USEFULNESS OF INFORMATION: A PSYCHOMETRIC EXAMINATION. Decision Sciences, $11(1), 121-134$.

Lavidge, R. J., \& Steiner, G. A. (1961). A model for predictive measurements of advertising effectiveness. Journal of marketing, 25(6), 59-62.

Lavie, T., \& Tractinsky, N. (2004). Assessing dimensions of perceived visual aesthetics of web sites. International journal of human-computer studies, 60(3), 269-298.

Lawson, B. (2006). How designers think: The design process demystified (4 ed.). Oxford ; Burlington, MA: Elsevier/Architectura. 
Lazarus, R. S. (2001). Relational meaning and discrete emotions. In K. R. Scherer, A. Schorr, \& T. Johnstone (Eds.), Appraisal processes in emotion : theory, methods, research (pp. 37-67). New York: Oxford University Press.

Leder, H., Carbon, C.-C., \& Kreuzbauer, R. (2007). Product-design perception and brand strength. Thexis, 24(2), 4-7.

Lee, E. J., Lee, J., \& Schumann, D. W. (2002). The influence of communication source and mode on consumer adoption of technological innovations. Journal of Consumer Affairs, 36(1), 1-27.

Lee, M., \& Lou, Y.-C. (1995). Consumer reliance on intrinsic and extrinsic cues in product evaluations: A conjoint approach. Journal of Applied Business Research, 12(1), 21-29.

Lee, S., Ha, S., \& Widdows, R. (2011). Consumer responses to high-technology products: Product attributes, cognition, and emotions. Journal of Business Research, 64(11), 1195-1200.

Levy, K. J. (1975). An empirical comparison of several multiple range tests for variances. Journal of the American Statistical Association, 70(349), 180-183.

Li, H., Daugherty, T., \& Biocca, F. (2001). Characteristics of virtual experience in electronic commerce: A protocol analysis. Journal of Interactive Marketing, 15(3), 13-30.

Li, H., Daugherty, T., \& Biocca, F. (2002). Impact of 3-D advertising on product knowledge, brand attitude, and purchase intention: The mediating role of presence. Journal of advertising, 31(3), 43-57. 
Li, H., Daugherty, T., \& Biocca, F. (2003). The Role of Virtual Experience in Consumer Learning. Journal of Consumer Psychology, 13(4), 395-407. doi:http://dx.doi.org/10.1207/S15327663JCP1304_07

Lightfoot, C., \& Bullock, M. (1990). Interpreting contradictory communications: Age and context effects. Developmental Psychology, 26(5), 830-836.

Lightner, N. J., \& Eastman, C. M. (2002). User Preference for Product Information in Remote Purchase Environments. Journal of Electronic Commerce Research, 3(3), 174-186.

Lim, K. H., \& Benbasat, I. (2000). The effect of multimedia on perceived equivocality and perceived usefulness of information systems. MIS quarterly, 449-471.

Liu, S. F., Cheng, J. H., \& Chen, W. J. (2015). A study of product experience obtained from multimodal interactive displays. Multimedia Tools and Applications, 75(11), 1-30.

Liu, S. H., Liao, H. L., \& Pratt, J. A. (2009). Impact of media richness and flow on elearning technology acceptance. Computers \& Education, 52(3), 599-607.

Liu, S. S., \& Stout, P. A. (1987). Effects of Message Modality and Appeal on Advertising Acceptance. Psychology \& Marketing, 4(3), 167-187.

Lund, A. M. (2001). Measuring Usability with the USE Questionnaire. Usability interface, 8(2), 3-6.

Marshall, A. (1892). Elements of Economics of Industry: Being the First Volume of Elements of Economics. London: Macmillan \& Co. 
Mathwick, C., Malhotra, N., \& Rigdon, E. (2001). Experiential value: conceptualization, measurement and application in the catalog and Internet shopping environment. Journal of retailing, 77(1), 39-56.

Mazursky, D., \& Jacoby, J. (1986). Exploring the development of store images. Journal of retailing, 62(2), 145-165.

McNeese, M. D. (2003). New visions of human-computer interaction: making affect compute. International journal of human-computer studies, 59(1-2), 33-53. doi:http://dx.doi.org/10.1016/S1071-5819(03)00059-4

Mehrabian, A., \& Russell, J. A. (1974). An approach to environmental psychology. Cambridge, MA: MIT Press.

Meyers-Levy, J., \& Tybout, A. M. (1989). Schema congruity as a basis for product evaluation. Journal of consumer research, 16(1), 39-54.

Michie, R., \& Forty, A. (1987). Objects of Desire: Design and Society, 1750-1980. Business History, 29(1), 107-108.

Milgrom, P., \& Roberts, J. (1986). Price and advertising signals of product quality. The Journal of Political Economy, 94, 796-821.

Miller, G. A. (1994). The Magical Number Seven, Plus or Minus Two: Some Limits on Our Capacity for Processing Information. Psychological review, 101(2), 343-352.

Mills, K., Paul, J., \& Moorman, K. (1995). Apparel visual merchandising: Englewood Cliffs, NJ: Prentice-Hall.

Mitchell, A. A., \& Dacin, P. A. (1996). The assessment of alternative measures of consumer expertise. Journal of consumer research, 23(3), 219-239. 
Moore, D. M., Burton, J. K., \& Myers, R. J. (2004). Multiple-Channel Communications: The Theoretical and Research Foundations of Multimedia. In D. H. Jonassen (Ed.), Handbook of research for educational communications and technology (2nd ed., pp. 979-1006). Mahwah, NJ: Taylor \& Francis.

Mowen, J. C., Fang, X., \& Scott, K. (2010). Visual product aesthetics: A hierarchical analysis of its trait and value antecedents and its behavioral consequences. European Journal of Marketing, 44(11/12), 1744-1762.

Nedungadi, P. (1990). Recall and consumer consideration sets: Influencing choice without altering brand evaluations. Journal of consumer research, 17(3), 263-276.

Nielsen, J. (1994). Usability Engineering. San Diego, CA: Elsevier.

Nielsen, J. (2012). Usability 101: Introduction to Usability. Retrieved from Nielsen Norman Group: Evidence-Based User Experience Research, Training, and Consulting website: https://www.nngroup.com/articles/usability-101-introduction$\underline{\text { to-usability/ }}$

Noble, C. H., \& Kumar, M. (2010). Exploring the appeal of product design: A grounded, value-based model of key design elements and relationships. Journal of Product Innovation Management, 27(5), 640-657.

Norman, D. A. (2004). Emotional Design: Why We Love (or Hate) Everyday Things. New York, NY: Basic books.

Norman, D. A. (2013). The Design of Everyday Things: Revised and Expanded Edition. New York, NY: Basic books.

Omar, O. (1999). Retail Marketing. London: Pitman Publishing. 
Orth, U. R., \& Malkewitz, K. (2008). Holistic package design and consumer brand impressions. Journal of marketing, 72(3), 64-81.

Ortony, A., Clore, G. L., \& Collins, A. (1990). The Cognitive Structure of Emotions. New York, NY: Cambridge University Press.

Overbeeke, K. C., \& Wensveen, S. (2003). From perception to experience, from affordances to irresistibles. Paper presented at the international conference on designing pleasurable products and interfaces.

Page, C., \& Herr, P. M. (2002). An investigation of the processes by which product design and brand strength interact to determine initial affect and quality judgments. Journal of Consumer Psychology, 12(2), 133-147.

Paivio, A. (1986). Mental representations : a dual coding approach. New York: New York : Oxford University Press.

Palmer, S. E., Brooks, J. L., \& Nelson, R. (2003). When does grouping happen? Acta psychologica, 114(3), 311-330.

Park, C. W., \& Lessig, V. P. (1981). Familiarity and its impact on consumer decision biases and heuristics. Journal of consumer research, 8(2), 223-230.

Park, H. J., \& Stoel, L. (2002). Apparel shopping on the Internet: Information availability on US apparel merchant Web sites. Journal of Fashion Marketing and Management: An International Journal, 6(2), 158-176.

Park, J., Stoel, L., \& Lennon, S. J. (2008). Cognitive, affective and conative responses to visual simulation: The effects of rotation in online product presentation. Journal of Consumer Behaviour, 7(1), 72-87.

Payne, J. W. (1982). Contingent decision behavior. Psychological bulletin, 92(2), 382. 
Pegler, M. M. (2006). Visual merchandising and display (5th ed.). New York, NY: Fairchild Publications.

Perrett, D. I., Burt, D. M., Penton-Voak, I. S., Lee, K. J., Rowland, D. A., \& Edwards, R. (1999). Symmetry and human facial attractiveness. Evolution and human behavior, 20(5), 295-307.

Peter, C., \& Beale, R. (2008). Affect and emotion in human-computer interaction: From theory to applications. Berlin; New York: Springer.

Pfister, H.-R., Wollstädter, S., \& Peter, C. (2011). Affective responses to system messages in human-computer-interaction: Effects of modality and message type. Interacting with computers, 23(4), 372-383.

Picard, R. W. (1997). Affective Computing (321). Retrieved from Cambridge, MA: https $/ /$ www.pervasive.jku.at/Teaching/_2009SS/Seminara usPervasiveComputing /Begleitmaterial/Related\%20Work\%20(Readings)/1995_Affective\%20computing Picard.pdf

Posner, J., Russell, J. A., \& Peterson, B. S. (2005). The circumplex model of affect: An integrative approach to affective neuroscience, cognitive development, and psychopathology. Development and psychopathology, 17(03), 715-734.

PricewaterhouseCoopers. (2015). Total Retail: Retailers and the Age of Disruption. Retrieved from https://www.pwc.ie/media-centre/assets/publications/2015-pwcireland-total-retail-february.pdf

PricewaterhouseCoopers. (2016). Internet Advertising Revenue Report. Retrieved from https:/www.iab.com/news/digital-ad-revenues-grow-19-year-year-first-half-2016/ Pye, D. (1978). Nature and aesthetics of design. New York, NY: Van Nostrand Reinhold. 
Ramirez, J., Artemio, \& Burgoon, J. K. (2004). The effect of interactivity on initial interactions: the influence of information valence and modality and information richness on computer-mediated interaction. Communication Monographs, 71(4), 422-447.

Rao, A. R., \& Monroe, K. B. (1988). The moderating effect of prior knowledge on cue utilization in product evaluations. Journal of consumer research, 15(2), 253-264.

Riddoch, M. J., \& Humphreys, G. W. (2001). Object recognition. In B. Rapp (Ed.), Handbook of Cognitive Neuropsychology: What Deficits Reveal About the Human Mind (1st ed., pp. 45-74). New York, NY: Psychology Press.

Robinson, R. (1993). What to Do with a Human Factor: A Manifesto of Sorts. American Center for Design Journal, Special Issue: New Human Factors, 7(1), 63-73.

Rolls, E. T. (2005). Emotion explained. Oxford ; New York

Oxford: Oxford ; New York : Oxford University Press.

Rose, G., Khoo, H., \& Straub, D. W. (1999). Current technological impediments to business-to-consumer electronic commerce. Communications of the AIS, 1(5).

Ryan, K. (2017, 01/20/2017). Coming Soon to Amazon: Shopping in Virtual Reality? Retrieved from https://www.inc.com/kevin-j-ryan/amazon-wants-you-to-shop-in$\underline{\text { virtual-reality.html }}$

Saadé, R., \& Bahli, B. (2005). The impact of cognitive absorption on perceived usefulness and perceived ease of use in on-line learning: an extension of the technology acceptance model. Information \& management, 42(2), 317-327.

Salkind, N. J. (2010). Encyclopedia of research design. London; Los Angeles, CA: Sage. 
Schachter, S., \& Singer, J. (1962). Cognitive, social, and physiological determinants of emotional state. Psychological review, 69(5), 379-399. doi:10.1037/h0046234

Scherer, K. R. (1984). On the nature and function of emotion: A component process approach. In P. Ekman \& K. R. Scherer (Eds.), Approaches to emotion (Hillsdale, NJ ed., pp. 293-317): Psychology Press.

Scherer, K. R., Schorr, A., \& Johnstone, T. (2001). Appraisal processes in emotion: Theory, methods, research: Oxford University Press.

Schlosberg, H. (1952). The description of facial expressions in terms of two dimensions. Journal of experimental psychology, 44(4), 229.

Schmitt, B. H. (1999). Experiential marketing: How to get customers to sense, feel, think, act and relate to your company and brand. New York, NY: Free Press.

Schultz, R. L., \& Slevin, D. P. (1973). Implementation and organizational validity: An empirical investigation: Institute for Research in the Behavioral, Economic, and Management Sciences, Purdue University.

Seva, R. R., \& Helander, M. G. (2009). The influence of cellular phone attributes on users' affective experiences: A cultural comparison. International Journal of Industrial Ergonomics, 39(2), 341-346.

Severin, W. (1967). Another look at cue summation. AV communication review, 15(3), 233-245. doi:10.1007/BF02768608

Shannon, C. E. (1948). A Mathematical Theory of Communication. Bell System Technical Journal, 27(3), 379-423. doi:10.1002/j.1538-7305.1948.tb01338.x 
Silvia, P. J. (2005). Cognitive Appraisals and Interest in Visual Art: Exploring an Appraisal Theory of Aesthetic Emotions. Empirical Studies of the Arts, 23(2), 119-133. doi:10.2190/12AV-AH2P-MCEH-289E

Simon, S. J., \& Peppas, S. C. (2004). An examination of media richness theory in product web site design: An empirical study. info, 6(4), 270-281.

Skalski, P., Tamborini, R., Shelton, A., Buncher, M., \& Lindmark, P. (2011). Mapping the road to fun: Natural video game controllers, presence, and game enjoyment. New Media and Society, 13(2), 224-242. doi:10.1177/1461444810370949

Spangenberg, E. R., Sprott, D. E., Grohmann, B., \& Tracy, D. L. (2006). Gendercongruent ambient scent influences on approach and avoidance behaviors in a retail store. Journal of Business Research, 59(12), 1281-1287.

Spies, K., Hesse, F., \& Loesch, K. (1997). Store atmosphere, mood and purchasing behavior. International Journal of Research in Marketing, 14(1), 1-17.

Steuer, J. (1992). Defining virtual reality: Dimensions determining telepresence. Journal of communication, 42(4), 73-93.

Stewart, D. W., \& Pavlou, P. A. (2002). From consumer response to active consumer: Measuring the effectiveness of interactive media. Journal of the Academy of marketing Science, 30(4), 376-396.

Stout, P. A., \& Leckenby, J. D. (1986). Measuring emotional response to advertising. Journal of advertising, 15(4), 35-42.

Sujan, M. (1985). Consumer Knowledge: Effects on Evaluation Strategies Mediating Consumer Judgments. Journal of consumer research, 12(1), 31-46. 
Sundar, S. S., Narayan, S., Obregon, R., \& Uppal, C. (1998). Does Web Advertising Work? Memory for Print vs. Online Media. Journalism \&amp; Mass Communication Quarterly, 75(4), 822-835. doi:10.1177/107769909807500414

Suryandari, R. T., \& Paswan, A. K. (2014). Online customer service and retail typeproduct congruence. Journal of Retailing and Consumer Services, 21(1), 69-76. doi:http://dx.doi.org/10.1016/j.jretconser.2013.08.004

Swanson, E. B. (1987). Information channel disposition and use. Decision Sciences, $18(1), 131-145$.

Szybillo, G. J., \& Jacoby, J. (1974). Intrinsic versus extrinsic cues as determinants of perceived product quality. Journal of Applied Psychology, 59(1), 74.

Szymanski, D. M., \& Hise, R. T. (2000). E-satisfaction: an initial examination. Journal of retailing, 76(3), 309-322.

Tabachnick, B. G., \& Fidell, L. S. (2001). Using multivariate statistics (4th ed.). Boston, MA: Allyn and Bacon.

Teas, R. K., \& Agarwal, S. (2000). The effects of extrinsic product cues on consumers' perceptions of quality, sacrifice, and value. Journal of the Academy of marketing Science, 28(2), 278-290.

Then, N. K., \& DeLong, M. R. (1999). Apparel shopping on the web. Journal of Family and Consumer Sciences, 91(3), 65.

Thompson, E. R. (2007). Development and validation of an internationally reliable shortform of the positive and negative affect schedule (PANAS). Journal of crosscultural psychology, 38(2), 227-242. 
Tofle, R., Schwarz, B., Yoon, S., \& Max-Royale, A. (2003). Color in healthcare environments. Retrieved from San Francisco, CA: https $/ /$ www.healthdesign.org/sites/default/files/color_in_hc_environ.pdf

Tornatzky, L. G., \& Klein, K. J. (1982). Innovation characteristics and innovation adoption-implementation: A meta-analysis of findings. IEEE Transactions on engineering management, EM-29(1), 28-45.

Tractinsky, N. (1997). Aesthetics and apparent usability: empirically assessing cultural and methodological issues. Paper presented at the Proceedings of the ACM SIGCHI Conference on Human factors in computing systems.

Unnava, H. R., Burnkrant, R. E., \& Erevelles, S. (1994). Effects of presentation order and communication modality on recall and attitude. Journal of consumer research, 21(3), 481-490.

Van Rompay, T. J., \& Pruyn, A. T. (2011). When Visual Product Features Speak the Same Language: Effects of Shape-Typeface Congruence on Brand Perception and Price Expectations. Journal of Product Innovation Management, 28(4), 599-610.

Veryzer, R. W. (1993). Aesthetic Response and the Influence of Design Principles on Product Preferences. Advances in Consumer research, 20, 224-228.

Vessey, I., \& Galletta, D. (1991). Cognitive fit: An empirical study of information acquisition. Information systems research, 2(1), 63-84.

Wakefield, K. L., \& Baker, J. (1998). Excitement at the mall: determinants and effects on shopping response. Journal of retailing, 74(4), 515-539.

Westbrook, R. A. (1987). Product/Consumption-Based Affective Responses and Postpurchase Processes. Journal of marketing research, 24(3), 258-270. 
Westcott, M. (2014). Design-Driven Companies Outperform S\&P by 228\% Over Ten Years - The DMI Design Value Index. Retrieved from http://www.dmi.org/blogpost/1093220/182956/Design-Driven-CompaniesOutperform-S-P-by-228-Over-Ten-Years--The-DMI-Design-Value-Index

Whittlesea, B. W. (1993). Illusions of familiarity. Journal of Experimental Psychology: Learning, Memory, and Cognition, 19(6), 1235.

Wolfinbarger, M., \& Gilly, M. C. (2001). Shopping online for freedom, control, and fun. California Management Review, 43(2), 34-55.

Wright, P. L. (1981). Cognitive responses to mass media advocacy. In R. E. Petty, T. M. Ostorm, \& T. C. Brock (Eds.), Cognitive responses in persuasion (pp. 263-282). Hillsdale, NJ: Erlbaum.

Wu, J., Won Ju, H., Kim, J., Damminga, C., Kim, H.-Y., \& KP Johnson, K. (2013). Fashion product display: An experiment with Mockshop investigating colour, visual texture, and style coordination. International Journal of Retail \& Distribution Management, 41(10), 765-789.

Wyer Jr, R. S., \& Srull, T. K. (2014). Memory and Cognition in Its Social Context (1st ed.). New York, NY: Psychology Press. 


\title{
APPENDIX
}

\section{Appendix A: Experiment Protocol}

\author{
EXAMINING THE INFLUENCE OF PRODUCT DESIGN CUES, MEDIA \\ RICHNESS, AND ENVIRONMENT CONGRUENCE ON USERS' COGNITIVE AND \\ AFFECTIVE RESPONSES TO PRODUCT DESIGN
}

\section{Research Protocol:}

\section{Responsibilities: Day Before the study}

Ehsan should send an email to subject with the following information

Time slot signed up for:

Directions to come to the iLab (233 Stanley) \& wait in the chair outside until the ongoing session is over. The research assistant will come out and let you in at the right time.

Please wait for at least 5 minutes before knocking on the door in case an ongoing session runs is running late.

\section{Before the subjects are seated at the study}

- Hang "Research Session in Progress Until XX:XX. Please do not enter!" Outside the iLab

- Turn the Oculus Rift (or PC and TV) on

- Ensure interactive stimuli is working

- Have the sign-in sheet ready

- Have 2 copies of informed consent forms ready

- Have handouts for virtual product presentation exercise

- Have one copy of the questionnaire ready

- Mark the condition number on the questionnaire

$\left(M \_E_{-} P_{-}{ }_{-}\right)$

M: Media Richness O/T (Oculus, TV)

E: Environment Congruence C/N (Congruent, Non-congruent)

P: Product Design H/L (High-quality design Attributes, Low-quality design Attributes) 

O_C_H
O_N_H
T_N_H
T_C_H
O_C_L
O_N_L
T_N_L
T_C_L

\section{Welcome \& Overall instructions}

\section{On arrival of participants for a given session}

Greet the subjects, ask to sign in and give an overview of the study.

\section{Script:}

Thanks for coming. Really appreciate your participation and if you can please turn your mobile phones off or put it on mute, we can start with the study which will take around 30 minutes.

We are interested in your perceptions of consumer products. You are requested to walkthrough a virtual store environment on (HTC Vive Virtual Reality Head-mounted Display / large TV) and explore an interactive virtual presentation of consumer product for 5 minutes. You are encouraged to explore the product display environment and product itself. After this, you will complete a brief questionnaire. Overall, this study should take approximately 30 minutes. Please undertake the tasks in relaxed manner, as you would normally explore a consumer electronic product in the retail store, taking as much time as you need.

\section{Informed Consent Form}

Go through the consent form. Answer any questions

Get signature on consent form. Hand one signed copy back to the subject for their records.

\section{Administer the experiment stimulus}

\section{Script:}


You can go ahead and explore the product presentation in virtual reality.

\section{Administer Questionnaire}

If the subject is running late, check on the next subject and start with the study while the current subject is completing the questionnaire.

\section{Debriefing \& Thank You!}

On completion thank the subjects for their participation; clarify any further questions regarding the experimental procedures, data analysis or use of data.

\section{Post Experiment session}

File the Informed Consent forms in the folder assigned for the same.

Mark serial number (Experiment Condition) and date on the questionnaires used in the experimental session and file them in the folder assigned for the same.

Lock up the Informed Consent Form and Completed Surveys in iLab cabinet.

Check sufficiency of consent forms, questionnaire for next session / next day. (If insufficient, print required copies) 


\title{
Appendix B: Informed Consent Form
}

\section{Campus Institutional Review Board \\ INFORMEDCONSENT DOCUMENT}

\author{
Researcher's Name: Ehsan Naderi \\ Researcher's Contact Information: ehsan.naderi@mail.missouri.edu (682-582-0835) \\ Faculty Advisor: Dr. Bimal Balakrishnan \\ Faculty Contact Information: balakrishnanb@missouri.edu
}

\section{Project Title:}

EXAMINING THE INFLUENCE OF PRODUCT DESIGN CUES, MEDIA RICHNESS, AND ENVIRONMENT CONGRUENCE ON USERS' COGNITIVE AND AFFECTIVE RESPONSES TO PRODUCT DESIGN

\section{Propose of Research:}

This research is being conducted to improve understanding of how people experience and react to product design in the retail environment. Please ask the researcher to explain any words or information that you do not understand.

\section{What will I be asked to do?}

If you agree to participate in this study, you will be asked to interact with product presentation in a virtual environment. Then, you will be asked to take a survey about your experience. The study will take approximate 30 minutes.

\section{What about confidentiality?}

All data will be anonymous and no personal identifiers linked to your responses. In any report we make public, we will not include any information that will make it possible to identify you individually. All materials we collect in any format will be stored securely 
by the researchers in locked office cabinets and in password protected computers. We will destroy all of the data we collect after seven years of the study.

\section{Are there any risks involved in this study?}

Even though the probability of experiencing discomfort with watching 3D images is extremely low, there is a potential for some participants to experience a general discomfort or eye strain. If you are uncomfortable when experiencing the virtual environment, you are free to notify the researcher and withdraw from the study at any time without penalty.

\section{What are the benefits of this research?}

This study is designed to help investigators to learn more about how people react to product design in the retail environment.

\section{Do I have to be in this research? May I stop participating at any time?}

Your participation is voluntary. You do not have to be in the study if you do not want to. If you do not want to continue to be in the study, you may stop at any time without penalty or loss of benefits to which you are otherwise entitled.

\section{What if I have questions?}

This research is being conducted by Ehsan Naderi from the Department of Architectural Studies at the University of Missouri-Columbia. If you have any questions about the research study itself, please contact Ehsan Naderi at ehsan.naderi@ mail.missouri.edu (682-582-0835), or his advisor, Dr. Bimal Balakrishnan at balakrishnanb@ missouri.edu .

If you have any questions or concerns regarding your rights as a participant in this study, you may contact the Institutional Review Board (IRB) at 573-882-9585 or access their website at https://research.mis souri.edu/cirb/.

You will be given a copy of this form to keep for your records.

\section{Statement of age of subject and consent}

- Your signature indicates that:

- You are at least 18 years of age;

- The research has been explained to you; 
- Your questions have been answered;

- You freely and voluntarily choose to participate in this research project.

I hereby acknowledge my free and willing participation in a "product design" research project. 


\section{Appendix C: IRB Approval}

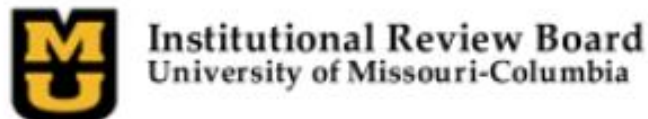

190 Galena Hall; De074.00

Columbia, MO 65212

573-882-3181

irbemissouri.edu

June 12, 2017

Principal Investigator: Ehsan Naderi

Department: Architectural Studies

Your IRB Application to project entitled Examining the Influence of Product Design Cues, Media Richness, and Environment Congruence on Users' Cognitive and Affective Responses was reviewed and approved by the MU Institutional Review Board according to the terms and conditions described below:

$\begin{array}{ll}\text { IRB Project Number } & 2008335 \\ \text { IRB Review Number } & 225713 \\ \text { Initial Application Approval Date June 12, 2017 } \\ \text { IRB Expiration Date } & \text { June 12,2018 } \\ \text { Level of Review } & \text { Exempt } \\ \text { Project Status } & \text { Active - Open to Enrollment } \\ \text { Exempt Categories } & 45 \text { CFR 46.101b(2) } \\ \text { Risk Level } & \text { Minimal Risk } \\ \text { Type of Consent } & \text { Exempt (Consent Script) } \\ \text { Internal Funding } & \text { Personal funds } \\ \text { Protocol Version/Date } & \end{array}$

The principal investigator $(\mathrm{PI})$ is responsible for all aspects and conduct of this study. The PI must comply with the following conditions of the approval:

1. No subjects may be involved in any study procedure prior to the IRB approval date or after the expiration date.

2. All unanticipated problems and deviations must be reported to the IRB within 5 business days.

3. All changes must be IRB approved prior to implementation unless they are intended to reduce immediate risk.

4. All recruitment materials and methods must be approved by the IRB prior to being used.

5. The Continuing Review Report (CRR) must be submitted to the IRB for review and approval at least 30 days prior to the project expiration date. If the study is complete, the Completion/Withdrawal Form may be submitted in lieu of the CRR.

6. Maintain all research records for a period of seven years from the project completion date.

7. Utilize the IRB stamped consent documents and other approved research documents located within the document storage section of eCompliance. These documents are highlighted green.

If you are offering subject payments and would like more information about research participant payments, please click here to view the MU Business Policy and Procedure: http//bppm.missouri.edu/chapter $2 / 2 \quad 250 \mathrm{html}$

If you have any questions, please contact the IRB at 573-882-3181 or irbemissouri.edu.

Thank you,

MU Institutional Review Board 


\section{Appendix D: Recruitment Flier}

\section{An Invitation to Participate in Product Design Study}

What: You are invited to participate in a product design study at the University of Missouri. You will be asked to interact with a virtual presentation of a consumer product and give your opinion on different aspects of product design.

The study will take approximately 30 to 35 minutes. This study involves research.

Where: 233 Stanley Hall

Immersive Visualization Lab

Department of Architectural Studies

University of Missouri

When:Summer 2017

Benefits: Yourfeedback will help investigators to improve their understanding of how people perceive and react to product design in the retail environment.

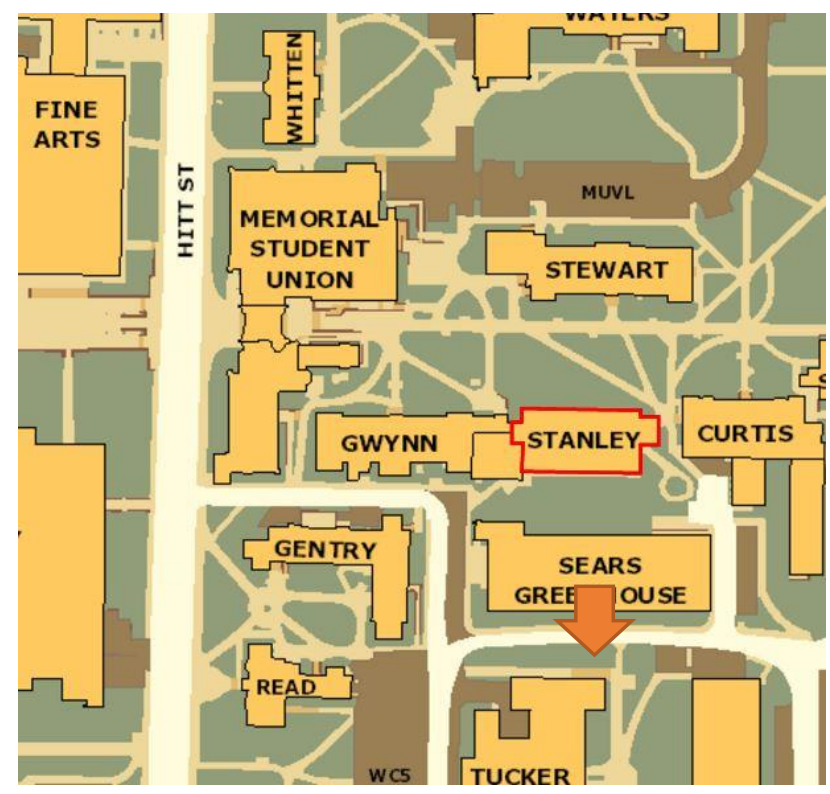

If you are comfortable with watching TV, 3D movies and playing video games, you are eligible to participate.

If you are interested in participating in this study, please contact Ehsan Naderiat ehsan.naderi@mail.missouri.edu orat682-582-0835.

Thank you for your help! 


\section{Appendix E: Survey}

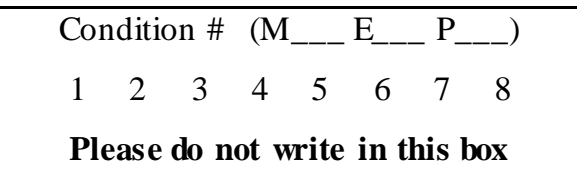

1. Age:

2. Gender: $\square$ Male $\square$ Female

3. Academic Standing: $\square$ Freshman $\quad$ Sophomore $\quad$ Junior $\quad \square$ Senior $\quad \square$ Graduate

4. Academic Major:

5. Are you Architectural Studies student? $\square$ Yes $\square$ No

Please indicate how familiar you are with each of the following. Please circle a single number between 1 and 9 (where $1=$ not at all familiar and $9=$ very familiar).

1. How familiar are you with playing video games on Xbox, PlayStation, Nintendo, or PC?

$\begin{array}{lllllllllll}\text { Not at all familiar } & 1 & 2 & 3 & 4 & 5 & 6 & 7 & 8 & 9 & \text { Very familiar }\end{array}$

2. How familiar are you with watching 3D movies? (this can include theaters, and 3D TV)

$$
\begin{array}{l|llllllllll}
\text { Not at all familiar } & 1 & 2 & 3 & 4 & 5 & 6 & 7 & 8 & 9 & \text { Very familiar }
\end{array}
$$

3. How familiar are you with 3D online virtual world? (e.g. second life, Wonderland, etc.)

\begin{tabular}{l|llllllllll} 
Not at all familiar & 1 & 2 & 3 & 4 & 5 & 6 & 7 & 8 & 9 & Very familiar
\end{tabular}

4. How familiar are you with 3D modeling software? (e.g. Rhino, AutoCAD, SolidWorks, CATIA, SketchUp, 3Ds Max, SolidThinking, Pro Engineer, etc.)

\begin{tabular}{l|llllllllll} 
Not at all familiar & 1 & 2 & 3 & 4 & 5 & 6 & 7 & 8 & 9 & Very familiar
\end{tabular}


Please indicate how well you identify with each of the following questions. Please circle a single number between 1 and 9 (where $1=$ not at all and $9=$ very much).

1. How good are you at blocking out external distractions when you are involved in something?

$\begin{array}{llllllllllll}\text { Not at all } & 1 & 2 & 3 & 4 & 5 & 6 & 7 & 8 & 9 & \text { Very much }\end{array}$

2. To what extent have you ever become so involved in doing something that you lose all track of time?

$\begin{array}{llllllllllll}\text { Not at all } & 1 & 2 & 3 & 4 & 5 & 6 & 7 & 8 & 9 & \text { Very much }\end{array}$

3. To what extent have you ever become so involved in a movie that you are not aware of things happening around you?

$\begin{array}{llllllllllll}\text { Not at all } & 1 & 2 & 3 & 4 & 5 & 6 & 7 & 8 & 9 & \text { Very much }\end{array}$

4. To what extent have you ever become so involved in a television program or book that people have problems getting your attention?

\begin{tabular}{l|lllllllllll} 
Not at all & 1 & 2 & 3 & 4 & 5 & 6 & 7 & 8 & 9 & Very much
\end{tabular} 


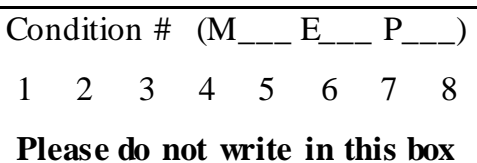

Please indicate to what extent you agree or disagree with each of the following statements. Please circle a single number between 1 and 9 (where $1=$ Strongly Disagree and $9=$ Strongly Agree).

1. I found the design of digital camera pleasant.

$\begin{array}{lllllllllll}\text { Strongly Disagree } & 1 & 2 & 3 & 4 & 5 & 6 & 7 & 8 & 9 & \text { Strongly Agree }\end{array}$

2. I found the design of digital camera sophisticated.

\begin{tabular}{l|llllllllll} 
Strongly Disagree & 1 & 2 & 3 & 4 & 5 & 6 & 7 & 8 & 9 & Strongly Agree
\end{tabular}

3. I found the design of digital camera creative.

$\begin{array}{llllllllllll}\text { Strongly Disagree } & 1 & 2 & 3 & 4 & 5 & 6 & 7 & 8 & 9 & \text { Strongly Agree }\end{array}$

4. I found the design of digital camera fascinating.

\begin{tabular}{l|lllllllll|l} 
Strongly Disagree & 1 & 2 & 3 & 4 & 5 & 6 & 7 & 8 & 9 & Strongly Agree
\end{tabular}

5. I found the design of digital camera original.

\begin{tabular}{l|lllllllllll} 
Strongly Disagree & 1 & 2 & 3 & 4 & 5 & 6 & 7 & 8 & 9 & Strongly Agree
\end{tabular}

6. I found the design of digital camera attractive.

$\begin{array}{lllllllllll}\text { Strongly Disagree } & 1 & 2 & 3 & 4 & 5 & 6 & 7 & 8 & 9 & \text { Strongly Agree }\end{array}$

7. The digital camera was aesthetically appealing.

\begin{tabular}{l|lllllllll|l} 
Strongly Disagree & 1 & 2 & 3 & 4 & 5 & 6 & 7 & 8 & 9 & Strongly Agree
\end{tabular}

8. I like the way the digital camera looked.

\begin{tabular}{l|llllllllll} 
Strongly Disagree & 1 & 2 & 3 & 4 & 5 & 6 & 7 & 8 & 9 & Strongly Agree
\end{tabular}


For each of the following statements, please indicate the likelihood that this digital camera would enhance your photography. Please circle a single number between 1 and 9 (where $1=$ Extremely Unlikely and $9=$ Extremely Likely).

1. Using this digital camera would enable me to accomplish photography tasks more quickly. $\begin{array}{llllllllllllll}\text { Extremely } & \text { Unlikely } & 1 & 2 & 3 & 4 & 5 & 6 & 7 & 8 & 9 & \text { Extremely Likely }\end{array}$

2. Using this digital camera would improve my photography performance.

$\begin{array}{lllllllllllll}\text { Extremely } & \text { Unlikely } & 1 & 2 & 3 & 4 & 5 & 6 & 7 & 8 & 9 & \text { Extremely Likely }\end{array}$

3. Using this digital camera would increase my productivity in photography.

$\begin{array}{llllllllllllll}\text { Extremely } & \text { Unlikely } & 1 & 2 & 3 & 4 & 5 & 6 & 7 & 8 & 9 & \text { Extremely Likely }\end{array}$

4. Using this digital camera would enhance effectiveness of my photography.

$\begin{array}{lllllllllllll}\text { Extremely } & \text { Unlikely } & 1 & 2 & 3 & 4 & 5 & 6 & 7 & 8 & 9 & \text { Extremely Likely }\end{array}$

5. Using this digital camera would make photography easier.

$\begin{array}{lllllllllllll}\text { Extremely } & \text { Unlikely } & 1 & 2 & 3 & 4 & 5 & 6 & 7 & 8 & 9 & \text { Extremely Likely }\end{array}$

6. I found this digital camera useful in photography.

$\begin{array}{lllllllllllll}\text { Extremely } & \text { Unlikely } & 1 & 2 & 3 & 4 & 5 & 6 & 7 & 8 & 9 & \text { Extremely Likely }\end{array}$ 
For each of the following statements, please indicate the likelihood that you would find this digital camera easy to use. Please circle a single number between 1 and 9 (where $1=$ Extremely Unlikely and $9=$ Extremely Likely).

1. Learning to operate this digital camera would be easy for me.

$\begin{array}{llllllllllll}\text { Extremely } & \text { Unlikely } & 1 & 2 & 3 & 4 & 5 & 6 & 7 & 8 & 9 & \text { Extremely Likely }\end{array}$

2. I would find it easy to get this digital camera to do what I want to do.

$\begin{array}{lllllllllllll}\text { Extremely } & \text { Unlikely } & 1 & 2 & 3 & 4 & 5 & 6 & 7 & 8 & 9 & \text { Extremely Likely }\end{array}$

3. It was clear that how I should interact with this digital camera.

$\begin{array}{llllllllllll}\text { Extremely } & \text { Unlikely } & 1 & 2 & 3 & 4 & 5 & 6 & 7 & 8 & 9 & \text { Extremely Likely }\end{array}$

4. I would find this digital camera to be flexible to interact with.

$\begin{array}{lllllllllllll}\text { Extremely } & \text { Unlikely } & 1 & 2 & 3 & 4 & 5 & 6 & 7 & 8 & 9 & \text { Extremely Likely }\end{array}$

5. It would be easy for me to become skillful at using this digital camera.

$\begin{array}{lllllllllllll}\text { Extremely } & \text { Unlikely } & 1 & 2 & 3 & 4 & 5 & 6 & 7 & 8 & 9 & \text { Extremely Likely }\end{array}$

6. I would find this digital camera easy to use.

$\begin{array}{lllllllllllll}\text { Extremely } & \text { Unlikely } & 1 & 2 & 3 & 4 & 5 & 6 & 7 & 8 & 9 & \text { Extremely Likely }\end{array}$

Please indicate to what extent you agree or disagree with the following statement. Please circle a single number between 1 and 9 (where $1=$ Strongly Disagree and $9=$ Strongly Agree).

7. Using and interacting with this digital camera would not require a lot of mental effort.

$\begin{array}{lllllllllllll}\text { Strongly Disagree } & 1 & 2 & 3 & 4 & 5 & 6 & 7 & 8 & 9 & \text { Strongly Agree }\end{array}$


Please indicate to what extent you agree or disagree with each of the following statements. Please circle a single number between 1 and 9 (where $1=$ Strongly Disagree and $9=$ Strongly Agree) .

1. Using this digital camera evokes love.

$\begin{array}{llllllllllll}\text { Strongly Disagree } & 1 & 2 & 3 & 4 & 5 & 6 & 7 & 8 & 9 & \text { Strongly Agree }\end{array}$

2. Other users and owners of this digital camera evoke admiration.

$\begin{array}{lllllllllllll}\text { Strongly Disagree } & 1 & 2 & 3 & 4 & 5 & 6 & 7 & 8 & 9 & \text { Strongly Agree }\end{array}$

3. Seeing this digital camera represents or symbolizes something that brings on dreaminess.

$\begin{array}{llllllllllll}\text { Strongly Disagree } & 1 & 2 & 3 & 4 & 5 & 6 & 7 & 8 & 9 & \text { Strongly Agree }\end{array}$

For the following questions, please indicate your emotional state while interacting with the digital camera. Please circle a single number between 1 and 10.

$\begin{array}{rlllllllllll}\text { Calm } & 1 & 2 & 3 & 4 & 5 & 6 & 7 & 8 & 9 & \text { Excited } \\ \text { Relaxed } & 1 & 2 & 3 & 4 & 5 & 6 & 7 & 8 & 9 & \text { Stimulated } \\ \text { Sad } & 1 & 2 & 3 & 4 & 5 & 6 & 7 & 8 & 9 & \text { Happy }\end{array}$

$\begin{array}{lllllllllll}\text { Annoyed } & 1 & 2 & 3 & 4 & 5 & 6 & 7 & 8 & 9 & \text { Pleased }\end{array}$


Please indicate to what extent you agree or disagree with each of the following statements. Please circle a single number between 1 and 9 (where $1=$ Strongly Disagree and $9=$ Strongly Agree)

1. Owning products of superior design makes me feel good about myself.

$\begin{array}{lllllllllllll}\text { Strongly Disagree } & 1 & 2 & 3 & 4 & 5 & 6 & 7 & 8 & 9 & \text { Strongly Agree }\end{array}$

2. I enjoy seeing displays of products that have superior design.

$\begin{array}{llllllllllll}\text { Strongly Disagree } & 1 & 2 & 3 & 4 & 5 & 6 & 7 & 8 & 9 & \text { Strongly Agree }\end{array}$

3. Being able to see subtle differences in product design is one skill that I have developed over time. $\begin{array}{llllllllllll}\text { Strongly Disagree } & 1 & 2 & 3 & 4 & 5 & 6 & 7 & 8 & 9 & \text { Strongly Agree }\end{array}$

4. I see things in a product's design that other people tend to pass over.

$\begin{array}{lllllllllllll}\text { Strongly Disagree } & 1 & 2 & 3 & 4 & 5 & 6 & 7 & 8 & 9 & \text { Strongly Agree }\end{array}$

5. Sometimes the way a product looks seems to reach out and grab me.

$\begin{array}{lllllllllllll}\text { Strongly Disagree } & 1 & 2 & 3 & 4 & 5 & 6 & 7 & 8 & 9 & \text { Strongly Agree }\end{array}$

1. How do you rate the design of the digital camera?

$\begin{array}{lllllllllllll}\text { Very poorly designed } & 1 & 2 & 3 & 4 & 5 & 6 & 7 & 8 & 9 & \text { Very well designed }\end{array}$

2. The design of this digital camera is comparable with other well-designed cameras in the market. $\begin{array}{llllllllllll}\text { Strongly Disagree } & 1 & 2 & 3 & 4 & 5 & 6 & 7 & 8 & 9 & \text { Strongly Agree }\end{array}$

3. I found visual similarities between the design of digital camera and the design of product display environment.

$\begin{array}{lllllllllllll}\text { Strongly Disagree } & 1 & 2 & 3 & 4 & 5 & 6 & 7 & 8 & 9 & \text { Strongly Agree }\end{array}$


Please indicate to what extent you agree or disagree with each of the following statements. Please circle a single number between 1 and 9 (where $1=$ Strongly Disagree and $9=$ Strongly Agree)

1. I am satis fied with using this virtual reality system.

2.

$\begin{array}{lllllllllllll}\text { Strongly Disagree } & 1 & 2 & 3 & 4 & 5 & 6 & 7 & 8 & 9 & \text { Strongly Agree }\end{array}$

3. This virtual reality systemwas pleasant to use.

$\begin{array}{lllllllllllll}\text { Strongly Dis agree } & 1 & 2 & 3 & 4 & 5 & 6 & 7 & 8 & 9 & \text { Strongly Agree }\end{array}$

4. This virtual reality systemwas fun to use.

$\begin{array}{lllllllllllll}\text { Strongly Disagree } & 1 & 2 & 3 & 4 & 5 & 6 & 7 & 8 & 9 & \text { Strongly Agree }\end{array}$

5. This virtual reality systemworked the way I wanted it to work.

$\begin{array}{llllllllllll}\text { Strongly Disagree } & 1 & 2 & 3 & 4 & 5 & 6 & 7 & 8 & 9 & \text { Strongly Agree }\end{array}$

6. I would recommend this virtual reality systemto a friend.

$\begin{array}{llllllllllll}\text { Strongly Disagree } & 1 & 2 & 3 & 4 & 5 & 6 & 7 & 8 & 9 & \text { Strongly Agree }\end{array}$

1. I would buy this camera if I were in the market for a digital camera.

$\begin{array}{lllllllllllll}\text { Strongly Disagree } & 1 & 2 & 3 & 4 & 5 & 6 & 7 & 8 & 9 & \text { Strongly Agree }\end{array}$

2. The probability that I would considerbuying this camera is:

$$
\begin{array}{llllllllllll}
\text { Very low } & 1 & 2 & 3 & 4 & 5 & 6 & 7 & 8 & 9 & \text { Very high }
\end{array}
$$

3. The likelihood of purchasing this camera is:

$$
\begin{array}{lllllllllllll}
\text { Very low } & 1 & 2 & 3 & 4 & 5 & 6 & 7 & 8 & 9 & \text { Very high }
\end{array}
$$

4. My willingness to buy this camera is:

$\begin{array}{lllllllllllll}\text { Very low } & 1 & 2 & 3 & 4 & 5 & 6 & 7 & 8 & 9 & \text { Very high }\end{array}$

5. How much are you willing to pay for this digital camera? 
Please indicate to what extent you agree or disagree with each of the following statements. Please circle a single number between 1 and 9 (where $1=$ Strongly Disagree and $9=$ Strongly Agree)

1. I concentrated on the digital camera.

$\begin{array}{lllllllllllll}\text { Strongly Disagree } & 1 & 2 & 3 & 4 & 5 & 6 & 7 & 8 & 9 & \text { Strongly Agree }\end{array}$

2. I directed my attention to the digital camera.

$\begin{array}{llllllllllll}\text { Strongly Disagree } & 1 & 2 & 3 & 4 & 5 & 6 & 7 & 8 & 9 & \text { Strongly Agree }\end{array}$

3. My attention was caught by the digital camera.

$\begin{array}{lllllllllllll}\text { Strongly Disagree } & 1 & 2 & 3 & 4 & 5 & 6 & 7 & 8 & 9 & \text { Strongly Agree }\end{array}$

Please indicate how well you identify with each of the following questions. Please circle a single number between 1 and 9 (where $1=$ not at all and $9=$ very much).

1. I felt like I was actually there in the store environment I just viewed.

$\begin{array}{llllllllllll}\text { Not at all } & 1 & 2 & 3 & 4 & 5 & 6 & 7 & 8 & 9 & \text { Very much }\end{array}$

2. It was as though my true location had shifted into the store environment I just viewed.

$$
\begin{array}{llllllllllll}
\text { Not at all } & 1 & 2 & 3 & 4 & 5 & 6 & 7 & 8 & 9 & \text { Very much }
\end{array}
$$

3. I felt as though I was physically present in the store environment I just viewed.

$\begin{array}{llllllllllll}\text { Not at all } & 1 & 2 & 3 & 4 & 5 & 6 & 7 & 8 & 9 & \text { Very much }\end{array}$

4. It seemed as though I actually took part in the action in the store display environment I just viewed.

$\begin{array}{llllllllllll}\text { Not at all } & 1 & 2 & 3 & 4 & 5 & 6 & 7 & 8 & 9 & \text { Very much }\end{array}$

5. I felt I could participate in the store display environment I just viewed.

$\begin{array}{llllllllllll}\text { Not at all } & 1 & 2 & 3 & 4 & 5 & 6 & 7 & 8 & 9 & \text { Very much }\end{array}$


6. I felt like I could move around among the objects in the store display environment I just viewed.

$$
\begin{array}{lllllllllll}
\text { Not at all } & 1 & 2 & 3 & 4 & 5 & 6 & 7 & 8 & 9 & \text { Very much }
\end{array}
$$

7. The objects in the store display environment I just viewed gave me the feeling that I could do things with them.

\begin{tabular}{l|llllllllll} 
Not at all & 1 & 2 & 3 & 4 & 5 & 6 & 7 & 8 & 9 & Very much
\end{tabular}

8. To what extent was what you saw in the virtual world was similar to reality?

$$
\begin{array}{l|llllllllll}
\text { Not at all } & 1 & 2 & 3 & 4 & 5 & 6 & 7 & 8 & 9 & \text { Very much }
\end{array}
$$

9. To what extent did the experience seem real to you?

$\begin{array}{lllllllllll}\text { Not at all } & 1 & 2 & 3 & 4 & 5 & 6 & 7 & 8 & 9 & \text { Very much }\end{array}$

10. To what extent did your interactions with the virtual world seem natural to you, like in the real world?

$$
\begin{array}{lllllllllll}
\text { Not at all } & 1 & 2 & 3 & 4 & 5 & 6 & 7 & 8 & 9 & \text { Very much }
\end{array}
$$

11. How real did the virtual objects seem to you?

$\begin{array}{lllllllllll}\text { Not at all } & 1 & 2 & 3 & 4 & 5 & 6 & 7 & 8 & 9 & \text { Very much }\end{array}$

12. To what extent did what you experience in the virtual world congruent to other experiences in the real world?

\begin{tabular}{l|llllllllll} 
Not at all & 1 & 2 & 3 & 4 & 5 & 6 & 7 & 8 & 9 & Very much
\end{tabular} 


\section{Appendix F: Reliability Analysis of Measures}

\begin{tabular}{|} 
Case Processing Sum mary \\
\begin{tabular}{|ll|r|r|}
\hline & \multicolumn{1}{|c|}{$\mathrm{N}$} & \multicolumn{1}{c|}{$\%$} \\
\hline Cases & Valid & 181 & 100.0 \\
& Excluded & \\
& & 0 & .0 \\
& Total & 181 & 100.0 \\
\hline
\end{tabular}
\end{tabular}

a. Listwise deletion based on all variables in the procedure.

\section{IV1: Perceived Aesthetic}

Reliability Statistics

\begin{tabular}{|r|r|}
\hline $\begin{array}{l}\text { Cronbach's } \\
\text { Alpha }\end{array}$ & N of ltems \\
\hline .932 & 8 \\
\hline
\end{tabular}

Item-Total Statistics

\begin{tabular}{|c|c|c|c|c|}
\hline & $\begin{array}{l}\text { Scale Mean if } \\
\text { Item Deleted }\end{array}$ & $\begin{array}{l}\text { Scale Variance } \\
\text { if Item Deleted }\end{array}$ & $\begin{array}{c}\text { Corrected Item- } \\
\text { Total } \\
\text { Correlation }\end{array}$ & $\begin{array}{l}\text { Cronbach's } \\
\text { Alpha if Item } \\
\text { Deleted }\end{array}$ \\
\hline $\begin{array}{l}\text { 1.I found the design of } \\
\text { digital camera pleasant. } \\
2 . I \text { found the design of } \\
\text { digital camera sophisticated. } \\
\text { 3.I found the design of } \\
\text { digital camera creative. } \\
4 . I \text { found the design of } \\
\text { digital camera fascinating. } \\
5 . I \text { found the design of } \\
\text { digital camera original. } \\
\text { 6.I found the design of } \\
\text { digital camera attractive. } \\
7 . \text { The digital camera was } \\
\text { aestheticallyappealing. } \\
\text { 8.I like the way the digital } \\
\text { camera looked. }\end{array}$ & $\begin{array}{l}42.46 \\
42.95 \\
43.61 \\
43.52 \\
43.70 \\
43.03 \\
42.83 \\
42.76\end{array}$ & $\begin{array}{l}146.839 \\
136.281 \\
136.517 \\
131.429 \\
140.846 \\
136.860 \\
137.472 \\
140.329\end{array}$ & $\begin{array}{l}.760 \\
.767 \\
.783 \\
.854 \\
.608 \\
.801 \\
.797 \\
.782\end{array}$ & $\begin{array}{l}.921 \\
.915 \\
.936 \\
.920\end{array}$ \\
\hline
\end{tabular}




\section{IV2: Perceived Usefulness}

Reliability Statistics

\begin{tabular}{|r|r|}
\hline $\begin{array}{c}\text { Cronbach's } \\
\text { Alpha }\end{array}$ & N of Items \\
\hline .922 & 6 \\
\hline
\end{tabular}

Item-Total Statistics

\begin{tabular}{|c|c|c|c|c|}
\hline & $\begin{array}{l}\text { Scale Mean if } \\
\text { Item Deleted }\end{array}$ & $\begin{array}{l}\text { Scale Variance } \\
\text { if Item Deleted }\end{array}$ & $\begin{array}{c}\text { Corrected Item- } \\
\text { Total } \\
\text { Correlation }\end{array}$ & $\begin{array}{c}\text { Cronbach's } \\
\text { Alpha if Item } \\
\text { Deleted }\end{array}$ \\
\hline $\begin{array}{l}\text { 1.Using this digital camera } \\
\text { would enable me to } \\
\text { accomplish photography } \\
\text { tasks more quickly. } \\
2 . \text { Using this digital camera } \\
\text { would improve my } \\
\text { photographyperformance. } \\
\text { 3.Using this digital camera } \\
\text { would increase my } \\
\text { productivity in photography. } \\
4 . \text { Using this digital camera } \\
\text { would enhance } \\
\text { effectiveness of my } \\
\text { photography. } \\
5 . \text { ining this digital camera } \\
\text { would make photography } \\
\text { easier. } \\
6 . I \text { found this digital camera } \\
\text { useful in photography. }\end{array}$ & 31.57 & $\begin{array}{l}72.722 \\
68.735 \\
69.231\end{array}$ & .684 & .920 \\
\hline
\end{tabular}




\section{IV3: Perceived Ease-of-Use}

Reliability Statistics

\begin{tabular}{|r|r|}
\hline $\begin{array}{c}\text { Cronbach's } \\
\text { Alpha }\end{array}$ & N of ltems \\
\hline .878 & 7 \\
\hline
\end{tabular}

Item-Total Statis tics

\begin{tabular}{|c|c|c|c|c|}
\hline & $\begin{array}{l}\text { Scale Mean if } \\
\text { Item Deleted }\end{array}$ & $\begin{array}{l}\text { Scale Variance } \\
\text { if Item Deleted }\end{array}$ & $\begin{array}{c}\text { Corrected Item- } \\
\text { Total } \\
\text { Correlation }\end{array}$ & $\begin{array}{c}\text { Cronbach's } \\
\text { Alpha if Item } \\
\text { Deleted }\end{array}$ \\
\hline $\begin{array}{l}\text { 1. Learning to operate this } \\
\text { digital camera would be } \\
\text { easy for me. } \\
2 . I \text { would find it easy to get } \\
\text { this digital camera to do } \\
\text { what I want to do. } \\
\text { 3.It was clear that how I } \\
\text { should interact with this } \\
\text { digital camera. } \\
\text { 4.I would find this digital } \\
\text { camera to be flexible to } \\
\text { interact with. } \\
\text { 5.It would be easy for me to } \\
\text { become skillful at using this } \\
\text { digital camera. } \\
6 . \text { I would find this digital } \\
\text { camera easy to use. } \\
7 . \text { Using and interacting with } \\
\text { this digital camera would not } \\
\text { require a lot of mental effort. }\end{array}$ & $\begin{array}{l}46.20 \\
45.74 \\
45.46\end{array}$ & $\begin{array}{l}40.982 \\
40.460 \\
40.939\end{array}$ & .701 & $\begin{array}{l}.846 \\
.877\end{array}$ \\
\hline
\end{tabular}




\section{IV4: Affective Response}

Reliability Statistics

\begin{tabular}{|r|r|}
\hline $\begin{array}{c}\text { Cronbach's } \\
\text { Alpha }\end{array}$ & N of Items \\
\hline .863 & 7 \\
\hline
\end{tabular}

Item-Total Statis tics

\begin{tabular}{|c|c|c|c|c|}
\hline & $\begin{array}{l}\text { Scale Mean if } \\
\text { Item Deleted }\end{array}$ & $\begin{array}{l}\text { Scale Variance } \\
\text { if Item Deleted }\end{array}$ & $\begin{array}{c}\text { Corrected Item- } \\
\text { Total } \\
\text { Correlation }\end{array}$ & $\begin{array}{c}\text { Cronbach's } \\
\text { Alpha if Item } \\
\text { Deleted }\end{array}$ \\
\hline $\begin{array}{l}\text { 1.Using this digital camera } \\
\text { evokes love. } \\
\text { 2.Other users and owners of } \\
\text { this digital camera evoke } \\
\text { admiration. } \\
\text { 3.Seeing this digital camera } \\
\text { represents or symbolizes } \\
\text { something that brings on } \\
\text { dreaminess. } \\
\text { calm_excited } \\
\text { relaxed_stimulated } \\
\text { sad_happy } \\
\text { annoyed_pleased }\end{array}$ & $\begin{array}{l}36.24 \\
35.17 \\
35.20 \\
34.10 \\
33.98\end{array}$ & $\begin{array}{l}78.149 \\
81.176 \\
80.516 \\
87.146 \\
90.844\end{array}$ & $\begin{array}{l}.701 \\
.648 \\
.617 \\
.550 \\
.450\end{array}$ & $\begin{array}{l}.834 \\
\\
.842 \\
.847 \\
.855 \\
.866\end{array}$ \\
\hline
\end{tabular}




\section{Centrality of Visual Product Aesthetic}

Reliability Statistics

\begin{tabular}{|r|r|}
\hline $\begin{array}{c}\text { Cronbach's } \\
\text { Alpha }\end{array}$ & N of Items \\
\hline .758 & 5 \\
\hline
\end{tabular}

Item-Total Statistics

\begin{tabular}{|c|c|c|c|c|}
\hline & $\begin{array}{l}\text { Scale Mean if } \\
\text { Item Deleted }\end{array}$ & $\begin{array}{l}\text { Scale Variance } \\
\text { if Item Deleted }\end{array}$ & $\begin{array}{c}\text { Corrected Item- } \\
\text { Total } \\
\text { Correlation } \\
\end{array}$ & $\begin{array}{c}\text { Cronbach's } \\
\text { Alpha if Item } \\
\text { Deleted } \\
\end{array}$ \\
\hline $\begin{array}{l}\text { 1.Owning products of } \\
\text { superior design makes me } \\
\text { feel good about mys elf. } \\
2 . \text { l enjoy seeing dis plays of } \\
\text { products that have superior } \\
\text { design. } \\
\text { 3.Being able to see subtle } \\
\text { differences in product } \\
\text { design is one skill that I } \\
\text { have developed over time. } \\
4 . I \text { see things in a product's } \\
\text { design that other people } \\
\text { tend to pass over. } \\
5 . \text { Sometimes the way a } \\
\text { product looks seems to } \\
\text { reach out and grab me. }\end{array}$ & 27.50 & $\begin{array}{l}22.600 \\
23.152\end{array}$ & .546 & $\begin{array}{r}.726 \\
.713 \\
\end{array}$ \\
\hline
\end{tabular}




\section{User Experience with Virtual Reality}

Reliability Statistics

\begin{tabular}{|r|r|}
\hline \multicolumn{1}{|c|}{$\begin{array}{c}\text { Cronbach's } \\
\text { Alpha }\end{array}$} & N of ltems \\
\hline .926 & 5 \\
\hline
\end{tabular}

Item-Total Statistics

\begin{tabular}{|c|c|c|c|c|}
\hline & $\begin{array}{l}\text { Scale Mean if } \\
\text { Item Deleted }\end{array}$ & $\begin{array}{l}\text { Scale Variance } \\
\text { if Item Deleted }\end{array}$ & $\begin{array}{c}\text { Corrected Item- } \\
\text { Total } \\
\text { Correlation }\end{array}$ & $\begin{array}{l}\text { Cronbach's } \\
\text { Alpha if Item } \\
\text { Deleted }\end{array}$ \\
\hline $\begin{array}{l}\text { 1.I am satis fied with using } \\
\text { this virtual reality system. } \\
\text { 2.This virtual reality system } \\
\text { was pleasant to use. } \\
\text { 3.This virtual reality system } \\
\text { was fun to use. } \\
\text { 4.This virtual reality system } \\
\text { worked the way I wanted it } \\
\text { to work. } \\
5 . I \text { would recommend this } \\
\text { virtual reality system to a } \\
\text { friend. }\end{array}$ & $\begin{array}{l}30.29 \\
30.18 \\
29.99 \\
30.47 \\
30.20\end{array}$ & $\begin{array}{l}30.975 \\
30.872 \\
31.028 \\
30.139 \\
29.471\end{array}$ & $\begin{array}{l}.814 \\
.858 \\
.764 \\
.759\end{array}$ & $\begin{array}{l}.907 \\
.899 \\
.917 \\
.919\end{array}$ \\
\hline
\end{tabular}




\section{Purchase Intention}

Reliability Statistics

\begin{tabular}{|r|r|}
\hline \multicolumn{1}{|c|}{$\begin{array}{c}\text { Cronbach's } \\
\text { Alpha }\end{array}$} & N of ltems \\
\hline .960 & 4 \\
\hline
\end{tabular}

Item-Total Statistics

\begin{tabular}{|c|c|c|c|c|}
\hline & $\begin{array}{l}\text { Scale Mean if } \\
\text { Item Deleted }\end{array}$ & $\begin{array}{l}\text { Scale Variance } \\
\text { if Item Deleted }\end{array}$ & $\begin{array}{c}\text { Corrected Item- } \\
\text { Total } \\
\text { Correlation }\end{array}$ & $\begin{array}{l}\text { Cronbach's } \\
\text { Alpha if Item } \\
\text { Deleted }\end{array}$ \\
\hline $\begin{array}{l}\text { 1.I would buy this camera if I } \\
\text { were in the market for a } \\
\text { digital camera. } \\
\text { 2.The probability that I } \\
\text { would consider buying this } \\
\text { camera is: } \\
\text { 3.The likelihood of } \\
\text { purchasing this camera is: } \\
\text { 4.My willingness to buy this } \\
\text { camera is: }\end{array}$ & $\begin{array}{l}15.04 \\
15.07 \\
15.60 \\
15.55\end{array}$ & $\begin{array}{l}39.004 \\
38.611 \\
39.209 \\
38.282\end{array}$ & $\begin{array}{l}.892 \\
.889 \\
.912 \\
.911\end{array}$ & $\begin{array}{l}.950 \\
\\
.951 \\
.944 \\
.944\end{array}$ \\
\hline
\end{tabular}

\section{Attention Allocation}

\begin{tabular}{|r|r|}
\hline \multicolumn{2}{|c|}{ Reliability Statistics } \\
\begin{tabular}{|r|} 
Cronbach's \\
Alpha
\end{tabular} & N of Items \\
\hline .810 & 3 \\
\hline
\end{tabular}

Item-Total Statistics

\begin{tabular}{|c|c|c|c|c|}
\hline & $\begin{array}{l}\text { Scale Mean if } \\
\text { Item Deleted }\end{array}$ & $\begin{array}{l}\text { Scale Variance } \\
\text { if Item Deleted }\end{array}$ & $\begin{array}{c}\text { Corrected Item- } \\
\text { Total } \\
\text { Correlation }\end{array}$ & $\begin{array}{l}\text { Cronbach's } \\
\text { Alpha if Item } \\
\text { Deleted }\end{array}$ \\
\hline $\begin{array}{l}\text { 1.I concentrated on the } \\
\text { digital camera. } \\
2 . \text { I directed my attention to } \\
\text { the digital camera. } \\
\text { 3.My attention was caught } \\
\text { by the digital camera. }\end{array}$ & $\begin{array}{l}14.29 \\
14.20 \\
14.64\end{array}$ & $\begin{array}{l}8.184 \\
8.149 \\
7.520\end{array}$ & $\begin{array}{l}.723 \\
.716 \\
.567\end{array}$ & $\begin{array}{l}.682 \\
.687 \\
.859\end{array}$ \\
\hline
\end{tabular}




\section{Presence}

Reliability Statistics

\begin{tabular}{|r|r|}
\hline \multicolumn{1}{|c|}{$\begin{array}{c}\text { Cronbach's } \\
\text { Alpha }\end{array}$} & N of ltems \\
\hline .967 & 12 \\
\hline
\end{tabular}

Item-Total Statistics

\begin{tabular}{|c|c|c|c|c|}
\hline & $\begin{array}{c}\text { Scale } \\
\text { Mean if } \\
\text { Item } \\
\text { Deleted }\end{array}$ & $\begin{array}{c}\text { Scale } \\
\text { Variance } \\
\text { if Item } \\
\text { Deleted }\end{array}$ & $\begin{array}{l}\text { Corrected } \\
\text { Item-Total } \\
\text { Correlation }\end{array}$ & $\begin{array}{c}\text { Cronbach's } \\
\text { Alpha if } \\
\text { Item } \\
\text { Deleted } \\
\end{array}$ \\
\hline $\begin{array}{l}1 . I \text { felt like I was actually there in the store environment } \\
\text { I just viewed. }\end{array}$ & 72.48 & 320.773 & .867 & .963 \\
\hline $\begin{array}{l}\text { 2.It was as though my true location had shifted into the } \\
\text { store environment I just viewed. }\end{array}$ & 72.67 & 317.523 & .868 & .963 \\
\hline $\begin{array}{l}3 . I \text { felt as though I was physicallypresent in the store } \\
\text { environment I just viewed. }\end{array}$ & 72.82 & 309.535 & .887 & .962 \\
\hline $\begin{array}{l}\text { 4.It seemed as though I actually took part in the action } \\
\text { in the store displayenvironment I just viewed. }\end{array}$ & 72.64 & 319.609 & .877 & .962 \\
\hline $\begin{array}{l}5 . I \text { felt I could participate in the store display } \\
\text { environment I just viewed. }\end{array}$ & 72.61 & 320.240 & .829 & .964 \\
\hline $\begin{array}{l}\text { 6.I felt like I could move around among the objects in } \\
\text { the store display environment I just viewed. }\end{array}$ & 72.43 & 326.368 & .766 & .965 \\
\hline $\begin{array}{l}\text { 7. The objects in the store displayenvironment I just } \\
\text { viewed gave me the feeling that I could do things with } \\
\text { them. }\end{array}$ & 72.87 & 318.338 & .782 & .965 \\
\hline $\begin{array}{l}\text { 8.To what extent was what you saw in the virtual world } \\
\text { was similar to reality? }\end{array}$ & 72.64 & 328.966 & .806 & .964 \\
\hline 9.To what extent did the experience seem real to you? & 72.92 & 322.676 & .872 & .963 \\
\hline $\begin{array}{l}\text { 10.To what extent did your interactions with the virtual } \\
\text { world seem natural to you, like in the real world? }\end{array}$ & 73.17 & 322.798 & .812 & .964 \\
\hline 11. How real did the virtual objects seem to you? & 72.78 & 330.584 & .770 & .965 \\
\hline $\begin{array}{l}\text { 12.To what extent did what you experience in the } \\
\text { virtual world congruent to other experiences in the real } \\
\text { world? }\end{array}$ & 72.94 & 331.346 & .801 & .965 \\
\hline
\end{tabular}




\section{Vita}

Ehsan Naderi is an Assistant Professor of Product Design at the University of Minnesota. Before joining the University of Minnesota, he served as a faculty of Industrial Design at Azad University of Mashhad (IAUM) for over six years. He has also taught at the University of Missouri Department of Architectural Studies, where he received his $\mathrm{PhD}$ and a master's degree in Design with Digital Media, beyond his bachelor's and master's degree in Industrial Design. Along with his academic experience, Ehsan has professional work experiences as a design consultant, product designer, user experience designer/researcher, and interior designer. Some of his works have been recognized by international design awards in the U.S. and Europe. 